\title{
Discovery of Key Dioxygenases that Diverged the Paraherquonin and Acetoxydehydroaustin Pathways in Penicillium brasilianum
}

\author{
Yudai Matsuda, ${ }^{\dagger+}$ Taiki Iwabuchi, ${ }^{\dagger+}$ Takayuki Fujimoto, ${ }^{\dagger}$ Takayoshi Awakawa, ${ }^{\dagger}$ Yu Nakashima, ${ }^{\dagger}$ \\ Takahiro Mori, ${ }^{\dagger}$ Huiping Zhang, ${ }^{\S}$ Fumiaki Hayashi, ${ }^{\S}$ Ikuro Abe ${ }^{*}, \dagger$ \\ ${ }^{\dagger}$ Graduate School of Pharmaceutical Sciences, The University of Tokyo, 7-3-1 Hongo, Bunkyo-ku, Tokyo \\ 113-0033, Japan. \\ ${ }^{\S}$ RIKEN Center for Life Science Technologies, 1-7-22 Suehiro-cho, Tsurumi-ku, Yokohama, Kanagawa, \\ 230-0045, Japan \\ ${ }^{\dagger}$ Y.M. and T.I. contributed equally to this work. \\ *To whom correspondence may be addressed. Email: abei@mol.f.u-tokyo.ac.jp.
}

\section{Table of Contents}

Supplementary Material and Methods

S2-S3

Supplementary Tables S1-S9

S4-S1 1

Supplementary Figures S1- S49

S12-S37 


\section{Supplementary Materials and Methods}

\section{General}

Solvents and chemicals were purchased from Wako Chemicals Ltd. (Tokyo, Japan) or Kanto Chemical Co., Inc. (Tokyo, Japan), unless noted otherwise. Oligonucleotide primers and the synthetic ausE' gene were purchased from Eurofins Genetics (Tokyo, Japan), and the primers are listed in Table S1. PCR was performed using a TaKaRa PCR Thermal Cycler Dice ${ }^{\circledR}$ Gradient (TaKaRa), with iProof DNA polymerase (BIO-RAD) or KOD Plus Ver. 2 DNA polymerase (TOYOBO). Sequence analyses were performed by Eurofins Genetics (Tokyo). Analytical and preparative HPLC were performed on a Shimadzu Prominence system, using a TSK-gel ODS-80T $\mathrm{T}_{\mathrm{S}}$ column (4.6 i.d. x $150 \mathrm{~mm}$, Tosoh Co. Ltd.) and an ODS-80T $\mathrm{T}_{\mathrm{M}}$ column (7.8 i.d. x 300 mm, Tosoh Co. Ltd.), respectively. Silica gel column chromatography was performed using Wakogel C-200. NMR spectra were obtained at $500 \mathrm{MHz}\left({ }^{1} \mathrm{H}\right)$ and $125 \mathrm{MHz}\left({ }^{13} \mathrm{C}\right)$ with a JEOL ECX-500 or ECA-500 spectrometer or at $900 \mathrm{MHz}\left({ }^{1} \mathrm{H}\right) / 225 \mathrm{MHz}\left({ }^{13} \mathrm{C}\right)$ with a Bruker Avance III HD $900 \mathrm{MHz}$ NMR spectrometer at RIKEN Yokohama, and chemical shifts were recorded with reference to solvent signals $\left({ }^{1} \mathrm{H}\right.$ NMR: $\mathrm{CDCl}_{3}$ $7.26 \mathrm{ppm} ;{ }^{13} \mathrm{C}$ NMR: $\left.\mathrm{CDCl}_{3} 77.0 \mathrm{ppm}\right)$. Samples for LC-MS/MS analysis were injected into an Agilent 1100 series HPLC-Esquire 4000 mass spectrometer (Bruker Daltonics), using electrospray ionization with a COSMOSIL 2.5C $\mathrm{C}_{18}$-MS-II column (2.0 i.d. x $100 \mathrm{~mm}$; Nacalai Tesque, Inc.). HR-ESI-MS analyses were performed with JMS-T100LP AccuTOF LC-plus mass spectrometer (JEOL), and HR-EI-MS analyses were performed with a JMS-SX102 mass spectrometer (JEOL).

\section{Isolation and Purification of Each Metabolite}

\section{Purification conditions for protoaustinoid B (4):}

The extract from A. oryzae NSAR1 with prhI was subjected to silica-gel column chromatography and eluted stepwise using a chloroform:methanol gradient (100:0 to 90:10). Fractions that contained 4 were further purified by reverse-phase preparative HPLC $(65 \%$ aqueous acetonitrile, $3.0 \mathrm{~mL} / \mathrm{min})$ to yield $13.0 \mathrm{mg}$ of a white solid.

\section{Purification conditions for preaustinoid A (5):}

The extract from $A$. oryzae NSAR1 with $p r h I$ and $p r h J$ was subjected to silica-gel column chromatography and eluted stepwise using a chloroform:methanol gradient (100:0 to 90:10). Fractions that contained 5 were further purified by reverse-phase preparative HPLC (70\% aqueous acetonitrile, $3.0 \mathrm{~mL} / \mathrm{min})$ to yield $13.1 \mathrm{mg}$ of a white solid.

\section{Purification conditions for preaustinoid A1 (6):}

The extract from $A$. oryzae NSAR1 with prhI, prhJ, and prhK was subjected to silica-gel column 
chromatography and eluted stepwise using a chloroform:methanol gradient (100:0 to 90:10). Fractions that contained 6 were further purified by reverse-phase preparative HPLC (60\% aqueous acetonitrile, $3.0 \mathrm{~mL} / \mathrm{min}$ ) to yield $12.2 \mathrm{mg}$ of a yellowish white solid.

\section{Purification conditions for berkeleyone B (7):}

The extract from A. oryzae NSAR1 with $p r h I, p r h J, p r h K$, and prhA (strain \#1) was subjected to silica-gel column chromatography and eluted stepwise using a chloroform:methanol gradient (100:0 to 90:10). Fractions that contained 7 were further purified by reverse-phase preparative HPLC (55\% aqueous acetonitrile, 3.0 $\mathrm{mL} / \mathrm{min}$ ) to yield $5.84 \mathrm{mg}$ of a white solid.

\section{Purification conditions for berkeleydione (2):}

The extract from A. oryzae NSAR1 with prhI, prhJ, prhK, and prhA (strain \#2) was subjected to silica-gel column chromatography and eluted stepwise using a chloroform:methanol gradient (100:0 to 90:10). Fractions that contained 2 were further purified by reverse-phase preparative HPLC (60\% aqueous acetonitrile, 3.0 $\mathrm{mL} / \mathrm{min}$ ) to yield $3.06 \mathrm{mg}$ of a white solid.

\section{Purification conditions for berkeleytrione (8):}

The extract from $A$. oryzae NSAR1 with prhI, prhJ, and prhA was subjected to silica-gel column chromatography and eluted stepwise using a chloroform:methanol gradient (100:0 to 90:10). Fractions that contained 8 were further purified by reverse-phase preparative HPLC (60\% aqueous acetonitrile, $3.0 \mathrm{~mL} / \mathrm{min})$ to yield $3.59 \mathrm{mg}$ of a white solid.

\section{Purification conditions for paraheroid A (10)}

The purified PrhA $(10 \mu \mathrm{M})$ was added to $12 \mathrm{~mL}$ of reaction buffer $(50 \mathrm{mM}$ PIPES buffer $\mathrm{pH} 7.5,0.2 \mathrm{mM}$ $\mathrm{FeSO}_{4}, 5 \mathrm{mM} \alpha$-ketoglutarate, $4 \mathrm{mM}$ ascorbate) and incubated with $1 \mathrm{mM}$ preaustinoid $\mathrm{A} 1(6)$ at $30{ }^{\circ} \mathrm{C}$ for 8 hrs. The extract that contained $\mathbf{1 0}$ was purified by reverse-phase preparative HPLC (55\% aqueous acetonitrile, $3.0 \mathrm{~mL} / \mathrm{min}$ ) to yield $0.2 \mathrm{mg}$ of amorphous solid. 
Table S1. Primers used in this study

\begin{tabular}{l|l}
\hline Primer & Sequence (5' to 3') \\
\hline Kpnl-prhl-F & CATACTAGGTACCATGTACAATATCCAAGACC \\
Kpnl-prhl-R & TGTACCGGTACCCTAGATAGTCGACCAAGCGTTG \\
EcoRl-prhJ-F & TTTAAACGAATTCATGGCTATCGGTCCGAAACCAG \\
EcoRI-prhJ-R & GTATTCGAATTCCTAGTCGTAAACAACTTCCAGTC \\
EcoRI-prhK-F & TCAGTAGAATTCATGACCATCTCGACGACCGCTC \\
EcoRI-prhK-R & GCACAGAGAATTCTTACGCAAAGAATGTCATCTCG \\
EcoRI-prhA-F & CGAACCGAATTCATGGCACCAATGATCCCTCCC \\
EcoRI-prhA-R & TGTGTGAATTCTCAAACATGAACACTGGGAGCTTC \\
Spel-pAdeA-F & GAGGAACTAGTTCATGGTGTTTTGATCATTTTAA \\
Spel-pAdeA-R & GACCATACTAGTTTCCGTTCCTTTGCTTTCTGC \\
InF-pAdeA-F & CAGGTCGACTCTAGACGACTCCAATCTTCAAGAGC \\
InF-pAdeA-R & AGTAGATCCTCTAGAGTAAGATACATGAGCTTCGG \\
InF-linker-F1 & GCTCGCGAGCGCGTTCCACTGCATCATCAGTCTAG \\
InF-linker-R1 & AACGCGCTCGCGAGCAAGTACCATACAGTACCGCG \\
Ndel-prhA-F & GGAGATATACATATGGCACCAATGATCCCTCCC \\
HindIII-prhA-R & CGCAAGCTTAACATGAACACTGGGAGCTTCCA \\
InF-ausE'-F & AAGGAGATATACATATGGCCCCGATGAATCCTCCA \\
InF-ausE'-R & GTGCGGCCGCAAGCTTAATGTGTACCGAAGGCGCT
\end{tabular}

Table S2. Plasmids constructed in this study and PCR / ligation conditions

\begin{tabular}{|c|c|c|c|c|c|c|}
\hline Plasmid & vector & Insert & Primer 1 & Primer 2 & PCR Template & Ligation method \\
\hline pUSA-prhl & pUSA digested with $K p n l$ & prhl & Kpnl-prhl-F & Kpnl-prhl-R & gDNA & DNA Ligation Kit Ver.2.1 \\
\hline pTAex3-prhJ & pTAex3 digested with EcoRI & prhJ & EcoRI-prhJ-F & EcoRI-prhJ-R & gDNA & DNA Ligation Kit Ver.2.1 \\
\hline pTAex3-prhK & pTAex3 digested with EcoRI & prhk & EcoRI-prhK-F & EcoRI-prhK-R & gDNA & DNA Ligation Kit Ver.2.1 \\
\hline pTAex3-prhA & pTAex3 digested with EcoRI & prhA & EcoRl-prhA-F & EcoRl-prhA-R & gDNA & DNA Ligation Kit Ver.2.1 \\
\hline pAdeA-prhJ & pAdeA digested with Spel & PатуB-prhJ-ТатуB & Spel-pAdeA-F & Spel-pAdeA-R & pTAex3-prhJ & DNA Ligation Kit Ver.2.1 \\
\hline \multirow{2}{*}{ pAdeA-prhJ+K } & \multirow{2}{*}{ pAdeA digested with $X b a l$} & РатуB-prhJ-ТатуB & InF-pAdeA-F & InF-linker-R1 & pTAex3-prhJ & \multirow{2}{*}{ In-Fusion ${ }^{\circledast} \mathrm{HD}$ Cloning Kit } \\
\hline & & PamyB-prhK-TamyB & InF-linker-F1 & InF-pAdeA-R & pTAex3-prhK & \\
\hline pUSA-prhl+A & pUSA-prhl digested with BamHI & РатуB-prhA-ТатуB & - & - & - & DNA Ligation Kit Ver.2.1 \\
\hline pET22b(+)-prhA & pET22b(+) digested with Ndel and HindIIII & prhA & Ndel-prhA-F & Hindlll-prhA-R & gDNA & T4 DNA Ligase \\
\hline pET22b(+)-ausE' & pET22b(+) digested with Ndel and HindIIII & ausE' & InF-ausE'-F & InF-ausE'-R & synthetic gene & In-Fusion $\circledast$ HD Cloning Kit \\
\hline
\end{tabular}




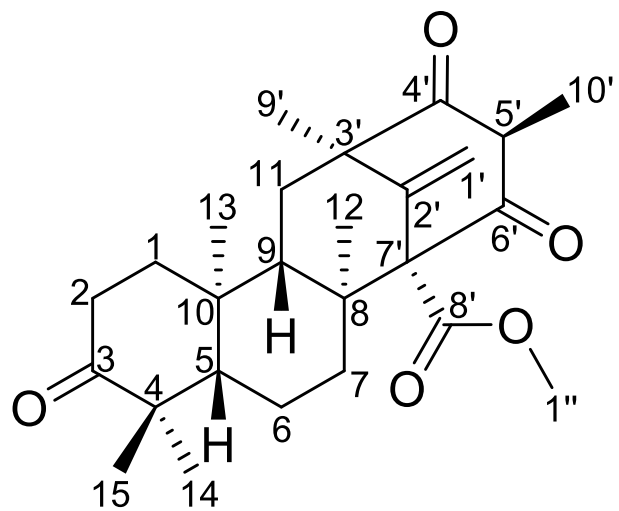

Table S3. NMR data for protoaustinoid B (4)

\begin{tabular}{|c|c|c|c|c|c|c|c|}
\hline \multirow[b]{2}{*}{ position } & \multirow{2}{*}{$\begin{array}{c}{ }^{13} \mathrm{C} \\
\delta(\mathrm{ppm})\end{array}$} & \multicolumn{6}{|c|}{${ }^{1} \mathrm{H}$} \\
\hline & & $\delta(\mathrm{ppm})$ & intensity & multiplicity & HMBC correlation & COSY correlation & NOESY correlation \\
\hline \multirow[t]{2}{*}{1} & 39.0 & $1.76(\alpha)$ & $1 \mathrm{H}$ & $m$ & $2,3,5,10,13$ & $\mathrm{H}-1 \beta, \mathrm{H}-2$ & $\mathrm{H}-1 \beta, \mathrm{H}-2, \mathrm{H}-11 \beta, \mathrm{H}-13$ \\
\hline & & $1.15(\beta)$ & $1 \mathrm{H}$ & $\mathrm{m}$ & $2,3,5,9,10,13$ & $\mathrm{H}-1 \alpha, \mathrm{H}-2$ & $\mathrm{H}-1 \alpha, \mathrm{H}-2, \mathrm{H}-9$ \\
\hline 2 & 33.5 & 2.37 & $2 \mathrm{H}$ & $\mathrm{m}$ & 1,3 & $\mathrm{H}-1 \alpha, \mathrm{H}-1 \beta$ & $\mathrm{H}-1 \alpha, \mathrm{H}-1 \beta, \mathrm{H}-13, \mathrm{H}-14$ \\
\hline 3 & 217.2 & & & & & & \\
\hline 4 & 47.0 & & & & & & \\
\hline 5 & 53.6 & 1.27 & $1 \mathrm{H}$ & $\mathrm{m}$ & $4,10,13,14,15$ & $\mathrm{H}-6$ & $\mathrm{H}-9, \mathrm{H}-15$ \\
\hline 6 & 19.6 & 1.50 & $2 \mathrm{H}$ & $\mathrm{m}$ & $4,7,10$ & $\mathrm{H}-5, \mathrm{H}-7$ & $\mathrm{H}-7, \mathrm{H}-12, \mathrm{H}-13, \mathrm{H}-14, \mathrm{H}-15$ \\
\hline 7 & 32.3 & 2.19 & $2 \mathrm{H}$ & $\mathrm{m}$ & $5,6,8,12$ & $\mathrm{H}-6$ & $\mathrm{H}-6, \mathrm{H}-9, \mathrm{H}-12$ \\
\hline 8 & 46.8 & & & & & & \\
\hline 9 & 51.2 & 0.65 & $1 \mathrm{H}$ & $\mathrm{dd}(J=13.6,2.8 \mathrm{~Hz})$ & $8,10,13$ & $\mathrm{H}-11 \alpha, \mathrm{H}-11 \beta$ & $\mathrm{H}-1 \beta, \mathrm{H}-5, \mathrm{H}-7, \mathrm{H}-11 \beta$ \\
\hline 10 & 37.1 & & & & & & \\
\hline \multirow[t]{2}{*}{11} & 37.9 & $1.59(\alpha)$ & $1 \mathrm{H}$ & $\mathrm{m}$ & $9,10,3^{\prime}, 4^{\prime}, 9^{\prime}$ & $\mathrm{H}-9, \mathrm{H}-11 \beta$ & $\mathrm{H}-11 \beta, \mathrm{H}-12, \mathrm{H}-13, \mathrm{H}^{-9}$ \\
\hline & & $1.92(\beta)$ & $1 \mathrm{H}$ & $\mathrm{dd}(J=13.0,3.0 \mathrm{~Hz})$ & $8,2^{\prime}, 3^{\prime}$ & $\mathrm{H}-9, \mathrm{H}-11 \alpha$ & $\mathrm{H}-1 \alpha, \mathrm{H}-9, \mathrm{H}-11 \alpha, \mathrm{H}-9^{\prime}$ \\
\hline 12 & 17.2 & 1.25 & $3 \mathrm{H}$ & $\mathrm{s}$ & $7,8,9,7$ & & $\mathrm{H}-6, \mathrm{H}-7, \mathrm{H}-11 \alpha, \mathrm{H}-13, \mathrm{H}-1{ }^{\prime} \mathrm{a}, \mathrm{H}-1{ }^{\prime \prime}$ \\
\hline 13 & 16.1 & 0.84 & $3 \mathrm{H}$ & s & $1,5,9$ & & $\mathrm{H}-1 \alpha, \mathrm{H}-2, \mathrm{H}-6, \mathrm{H}-11 \alpha, \mathrm{H}-12$ \\
\hline 14 & 20.9 & 0.99 & $3 \mathrm{H}$ & $\mathrm{s}$ & $3,4,5,15$ & & $\mathrm{H}-2, \mathrm{H}-6$ \\
\hline 15 & 27.0 & 1.04 & $3 \mathrm{H}$ & $\mathrm{s}$ & $3,4,5,14$ & & $\mathrm{H}-5, \mathrm{H}-6$ \\
\hline \multirow[t]{2}{*}{$1^{\prime}$} & 112.3 & $4.85(a)$ & $1 \mathrm{H}$ & brs & $2^{\prime}, 3^{\prime}, 7^{\prime}$ & $\mathrm{H}-1$ 'b & $\mathrm{H}-12, \mathrm{H}-1$ 'b, H-1" \\
\hline & & $5.32(b)$ & $1 \mathrm{H}$ & brs & $2^{\prime}, 3^{\prime}, 7^{\prime}$ & $\mathrm{H}-1$ 'a & $H-1 ' a, H-9^{\prime}$ \\
\hline $2^{\prime}$ & 146.7 & & & & & & \\
\hline $3^{\prime}$ & 52.2 & & & & & & \\
\hline $4^{\prime}$ & 209.1 & & & & & & \\
\hline $5^{\prime}$ & 62.6 & 3.93 & $1 \mathrm{H}$ & $\mathrm{q}(J=6.2 \mathrm{~Hz})$ & $4^{\prime}, 6^{\prime}, 10^{\prime}$ & $\mathrm{H}-10^{\prime}$ & $\mathrm{H}-10^{\prime}$ \\
\hline $6^{\prime}$ & 203.9 & & & & & & \\
\hline $7^{\prime}$ & 72.9 & & & & & & \\
\hline $8^{\prime}$ & 169.0 & & & & & & \\
\hline $9^{\prime}$ & 21.3 & 1.39 & $3 \mathrm{H}$ & $\mathrm{s}$ & $11,2^{\prime}, 3^{\prime}, 4^{\prime}$ & & $\mathrm{H}-11 \alpha, \mathrm{H}-11 \beta, \mathrm{H}-1$ 'b \\
\hline $10^{\prime}$ & 6.4 & 1.20 & $3 \mathrm{H}$ & $\mathrm{d}(J=6.2 \mathrm{~Hz})$ & $4^{\prime}, 5^{\prime}, 6^{\prime}$ & $H-5^{\prime}$ & $H-5^{\prime}$ \\
\hline $1 "$ & 52.0 & 3.68 & $3 \mathrm{H}$ & $\mathrm{s}$ & $8^{\prime}$ & & $\mathrm{H}-1$ 'a, $\mathrm{H}-12$ \\
\hline
\end{tabular}

${ }^{1} \mathrm{H}$ NMR: $500 \mathrm{MHz},{ }^{13} \mathrm{C}$ NMR: $125 \mathrm{MHz}$ (in $\mathrm{CDCl}_{3}$ )

Note: Stereochemistry of $\mathrm{C}^{-5}$ ' was deduced from that of protoaustinoid A (3), which is the biosynthetic precursor of 4 (see ref. 5 in the main text). Additionally, the chemical shifts for C-5' and C-10' were almost identical with those for $\mathbf{3}$ (62.6 and $6.6 \mathrm{ppm}$, respectively). 


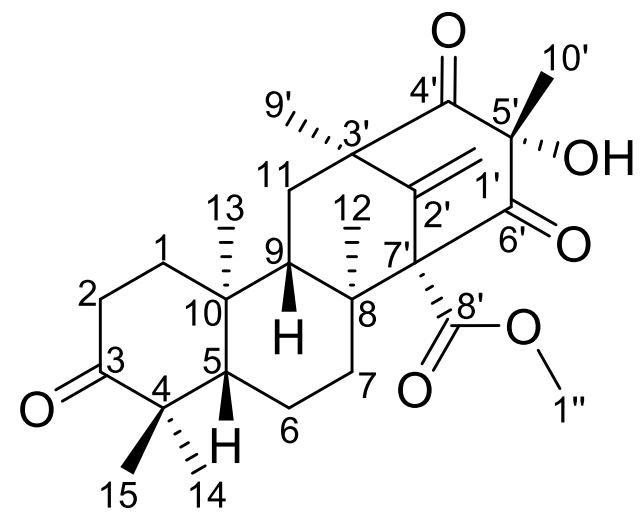

Table S4. NMR data for preaustinoid A (5)

\begin{tabular}{|c|c|c|c|c|c|c|c|}
\hline \multirow[b]{2}{*}{ position } & \multirow{2}{*}{$\begin{array}{c}{ }^{13} \mathrm{C} \\
\delta(\mathrm{ppm})\end{array}$} & \multicolumn{6}{|c|}{${ }^{1} \mathrm{H}$} \\
\hline & & $\delta(\mathrm{ppm})$ & intensity & multiplicity & HMBC correlation & COSY correlation & NOESY correlation \\
\hline \multirow[t]{2}{*}{1} & 39.0 & $1.78(\alpha)$ & $1 \mathrm{H}$ & $\mathrm{m}$ & $2,3,5,10$ & $\mathrm{H}-1 \beta, \mathrm{H}-2$ & $\mathrm{H}-1 \beta, \mathrm{H}-2, \mathrm{H}-11 \beta, \mathrm{H}-13, \mathrm{H}-14$ \\
\hline & & $1.11(\beta)$ & $1 \mathrm{H}$ & $\mathrm{dt}(J=13.5,8.4 \mathrm{~Hz})$ & 5,13 & $\mathrm{H}-1 \alpha, \mathrm{H}-2$ & $\mathrm{H}-1 \alpha, \mathrm{H}-2, \mathrm{H}-9$ \\
\hline 2 & 33.5 & 2.38 & $2 \mathrm{H}$ & $\mathrm{m}$ & 1,3 & $\mathrm{H}-1 \alpha, \mathrm{H}-1 \beta$ & $\mathrm{H}-1 \alpha, \mathrm{H}-1 \beta, \mathrm{H}-13, \mathrm{H}-15$ \\
\hline 3 & 216.9 & & & & & & \\
\hline 4 & 47.0 & & & & & & \\
\hline 5 & 53.8 & 1.22 & $1 \mathrm{H}$ & $\mathrm{m}$ & $4,7,10,13,14,15$ & $\mathrm{H}-6$ & $\mathrm{H}-6, \mathrm{H}-7 \beta, \mathrm{H}-9$ \\
\hline 6 & 19.7 & 1.53 & $2 \mathrm{H}$ & $\mathrm{m}$ & & $\mathrm{H}-5, \mathrm{H}-7 \alpha, \mathrm{H}-7 \beta$ & $\mathrm{H}-5, \mathrm{H}-7 \alpha, \mathrm{H}-7 \beta, \mathrm{H}-13, \mathrm{H}-14, \mathrm{H}-15$ \\
\hline \multirow[t]{2}{*}{7} & 32.2 & $2.26(\alpha)$ & $1 \mathrm{H}$ & $\mathrm{dt}(J=13.5,3.4 \mathrm{~Hz})$ & & $\mathrm{H}-6, \mathrm{H}-7 \beta$ & $\mathrm{H}-6, \mathrm{H}-7 \beta, \mathrm{H}-12$ \\
\hline & & $2.02(\beta)$ & $1 \mathrm{H}$ & $\mathrm{m}$ & 12 & $\mathrm{H}-6, \mathrm{H}-7 \alpha$ & $\mathrm{H}-5, \mathrm{H}-6, \mathrm{H}-7 \alpha, \mathrm{H}-9$ \\
\hline 8 & 47.7 & & & & & & \\
\hline 9 & 51.9 & 0.60 & $1 \mathrm{H}$ & $\mathrm{dd}(J=13.5,2.8 \mathrm{~Hz})$ & 11 & $\mathrm{H}-11 \beta$ & $\mathrm{H}-1 \beta, \mathrm{H}-5, \mathrm{H}-7 \beta, \mathrm{H}-11 \beta$ \\
\hline 10 & 37.2 & & & & & & \\
\hline \multirow[t]{2}{*}{11} & 39.2 & $1.63(\alpha)$ & $1 \mathrm{H}$ & $\mathrm{t}(\mathrm{J}=12.9 \mathrm{~Hz})$ & $4^{\prime}$ & $\mathrm{H}-11 \beta$ & $\mathrm{H}-11 \beta, \mathrm{H}-12, \mathrm{H}-13$ \\
\hline & & $1.93(\beta)$ & $1 \mathrm{H}$ & $\mathrm{dd}(J=12.9,2.8 \mathrm{~Hz})$ & $8,2^{\prime}$ & $\mathrm{H}-9, \mathrm{H}-11 \alpha$ & $\mathrm{H}-1 \alpha, \mathrm{H}-9, \mathrm{H}-11 \alpha, \mathrm{H}-9^{\prime}$ \\
\hline 12 & 16.8 & 1.25 & $3 \mathrm{H}$ & $\mathrm{s}$ & $7,8,9,7^{\prime}$ & & $\mathrm{H}-7 \alpha, \mathrm{H}-11 \alpha, \mathrm{H}-13, \mathrm{H}-1$ 'a \\
\hline 13 & 16.0 & 0.85 & $3 \mathrm{H}$ & s & $1,5,9$ & & $\mathrm{H}-1 \alpha, \mathrm{H}-2, \mathrm{H}-6, \mathrm{H}-11 \alpha, \mathrm{H}-12$ \\
\hline 14 & 20.9 & 1.00 & $3 \mathrm{H}$ & s & $3,4,5,15$ & & $\mathrm{H}-1 \alpha, \mathrm{H}-6$ \\
\hline 15 & 27.0 & 1.05 & $3 \mathrm{H}$ & $\mathrm{s}$ & $3,4,5,14$ & & H-2, H-6 \\
\hline \multirow[t]{2}{*}{$1^{\prime}$} & 112.6 & 4.88 (a) & $1 \mathrm{H}$ & brs & 3', 7' & $\mathrm{H}-1$ 'b & $\mathrm{H}-12, \mathrm{H}-1$ 'b, H-1" \\
\hline & & $5.40(b)$ & $1 \mathrm{H}$ & brs & $3^{\prime}, 7^{\prime}$ & $\mathrm{H}-1$ 'a & H-1'a, H-9' \\
\hline $2^{\prime}$ & 145.5 & & & & & & \\
\hline $3^{\prime}$ & 51.0 & & & & & & \\
\hline $4^{\prime}$ & 207.7 & & & & & & \\
\hline $5^{\prime}$ & 80.1 & & & & & & \\
\hline $6^{\prime}$ & 203.9 & & & & & & \\
\hline $7^{\prime}$ & 72.5 & & & & & & \\
\hline $8^{\prime}$ & 168.5 & & & & & & \\
\hline $9^{\prime}$ & 22.1 & 1.48 & $3 \mathrm{H}$ & s & $11,2^{\prime}, 3^{\prime}, 4^{\prime}$ & & $\mathrm{H}-11 \beta, \mathrm{H}-1$ 'b \\
\hline $10^{\prime}$ & 15.1 & 1.38 & $3 \mathrm{H}$ & s & $4^{\prime}, 5^{\prime}, 6^{\prime}$ & & \\
\hline $1 "$ & 52.5 & 3.73 & $3 \mathrm{H}$ & $\mathrm{s}$ & $8^{\prime}$ & & H-1'a \\
\hline $\mathrm{OH}$ & & 3.26 & $1 \mathrm{H}$ & brs & & & \\
\hline
\end{tabular}

${ }^{1} \mathrm{H}$ NMR: $500 \mathrm{MHz},{ }^{13} \mathrm{C}$ NMR: $125 \mathrm{MHz}$ (in $\mathrm{CDCl}_{3}$ ) 


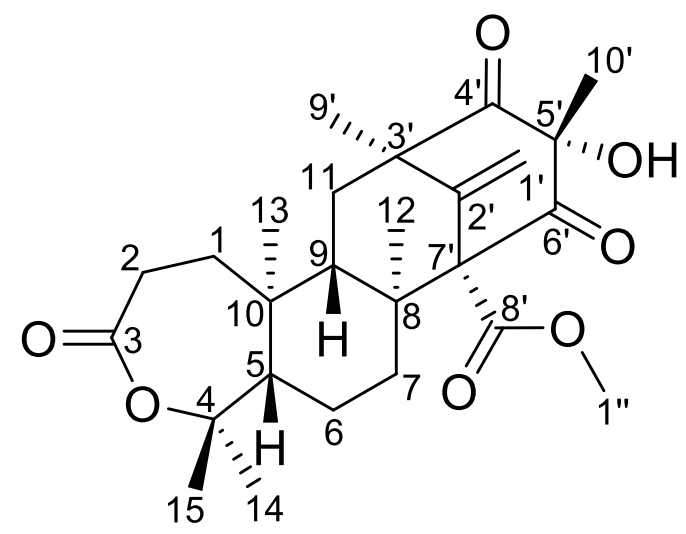

Table S5. NMR data for preaustinoid A1 (6)

\begin{tabular}{|c|c|c|c|c|c|c|c|}
\hline \multirow[b]{2}{*}{ position } & \multirow{2}{*}{$\begin{array}{c}{ }^{13} \mathrm{C} \\
\delta(\mathrm{ppm})\end{array}$} & \multicolumn{6}{|c|}{${ }^{1} \mathrm{H}$} \\
\hline & & $\delta(\mathrm{ppm})$ & intensity & multiplicity & HMBC correlation & COSY correlation & NOESY correlation \\
\hline \multirow[t]{2}{*}{1} & 39.7 & $1.69(\alpha)$ & $1 \mathrm{H}$ & $\mathrm{m}$ & & $\mathrm{H}-1 \beta, \mathrm{H}-2 \alpha, \mathrm{H}-2 \beta$ & $\mathrm{H}-1 \beta, \mathrm{H}-2 \beta$ \\
\hline & & $1.12(\beta)$ & $1 \mathrm{H}$ & $\mathrm{dt}(J=14.6,5.1 \mathrm{~Hz})$ & $2,3,9,10,13$ & $\mathrm{H}-1 \alpha, \mathrm{H}-2 \alpha, \mathrm{H}-2 \beta$ & $\mathrm{H}-1 \alpha, \mathrm{H}-9, \mathrm{H}-2 \alpha, \mathrm{H}-2 \beta, \mathrm{H}-11 \beta$ \\
\hline \multirow[t]{2}{*}{2} & 32.0 & $2.41(\alpha)$ & $1 \mathrm{H}$ & $\mathrm{dt}(J=14.6,5.1 \mathrm{~Hz})$ & 1,3 & $H-1 \alpha, H-1 \beta, H-2 \beta$ & $\mathrm{H}-1 \beta, \mathrm{H}-2 \beta, \mathrm{H}-13, \mathrm{H}-14$ \\
\hline & & $2.49(\beta)$ & $1 \mathrm{H}$ & $\operatorname{td}(J=14.6,5.1 \mathrm{~Hz})$ & 1,3 & $H-1 \alpha, H-1 \beta, H-2 \alpha$ & $\mathrm{H}-1 \alpha, \mathrm{H}-1 \beta, \mathrm{H}-2 \alpha, \mathrm{H}-15$ \\
\hline 3 & 174.1 & & & & & & \\
\hline 4 & 85.4 & & & & & & \\
\hline 5 & 51.7 & 1.63 & $1 \mathrm{H}$ & $\mathrm{m}$ & $4,6,10,13,14,15$ & $\mathrm{H}-6 \alpha, \mathrm{H}-6 \beta$ & $\mathrm{H}-9, \mathrm{H}-15$ \\
\hline \multirow[t]{2}{*}{6} & 23.4 & $1.69(\alpha)$ & $1 \mathrm{H}$ & $\mathrm{m}$ & $5,7,8$ & $\mathrm{H}-5, \mathrm{H}-6 \beta, \mathrm{H}-7$ & $H-6 \beta$ \\
\hline & & $1.47(\beta)$ & $1 \mathrm{H}$ & $\mathrm{m}$ & 8 & $\mathrm{H}-5, \mathrm{H}-6 \mathrm{a}, \mathrm{H}-7$ & $\mathrm{H}-6 \alpha, \mathrm{H}-7 \alpha, \mathrm{H}-7 \beta$ \\
\hline \multirow[t]{2}{*}{7} & 31.8 & $2.23(\alpha)$ & $1 \mathrm{H}$ & $\mathrm{dt}(J=13.5,3.4 \mathrm{~Hz})$ & 5,8 & $\mathrm{H}-6 \alpha, \mathrm{H}-6 \beta, \mathrm{H}-7 \beta$ & $\mathrm{H}-6 \beta, \mathrm{H}-7 \beta, \mathrm{H}-12$ \\
\hline & & $1.89(\beta)$ & $1 \mathrm{H}$ & $\operatorname{td}(J=13.5,2.0 \mathrm{~Hz})$ & $6,8,12$ & $\mathrm{H}-6 \alpha, \mathrm{H}-6 \beta, \mathrm{H}-7 \alpha$ & $\mathrm{H}-6 \beta, \mathrm{H}-7 \alpha$ \\
\hline 8 & 47.7 & & & & & & \\
\hline 9 & 53.0 & 0.55 & $1 \mathrm{H}$ & $\mathrm{dd}(J=13.5,2.2 \mathrm{~Hz})$ & $1,8,10,11,12,13,7^{\prime}$ & $\mathrm{H}-11 \alpha, \mathrm{H}-11 \beta$ & $\mathrm{H}-1 \beta, \mathrm{H}-5, \mathrm{H}-11 \beta$ \\
\hline 10 & 39.6 & & & & & & \\
\hline \multirow[t]{2}{*}{11} & 39.5 & $1.64(\alpha)$ & $1 \mathrm{H}$ & $\mathrm{dd}(J=13.5,12.9 \mathrm{~Hz})$ & $8,9,3^{\prime}, 4^{\prime}, 9^{\prime}$ & $\mathrm{H}-9, \mathrm{H}-11 \beta$ & $\mathrm{H}-11 \beta, \mathrm{H}-12, \mathrm{H}-13, \mathrm{H}-9^{\prime}$ \\
\hline & & $1.93(\beta)$ & $1 \mathrm{H}$ & $\mathrm{dd}(J=12.9,2.2 \mathrm{~Hz})$ & $8,2^{\prime}, 4^{\prime}$ & $\mathrm{H}-9, \mathrm{H}-11 \alpha$ & $\mathrm{H}-1 \beta, \mathrm{H}-9, \mathrm{H}-11 \alpha, \mathrm{H}-9^{\prime}$ \\
\hline 12 & 16.3 & 1.28 & $3 \mathrm{H}$ & $\mathrm{s}$ & $7,8,9,7^{\prime}$ & & $\mathrm{H}-7 \alpha, \mathrm{H}-11 \alpha, \mathrm{H}-13, \mathrm{H}-1$ 'a \\
\hline 13 & 18.5 & 1.01 & $3 \mathrm{H}$ & $\mathrm{s}$ & $1,9,10$ & & $\mathrm{H}-2 \alpha, \mathrm{H}-11 \alpha, \mathrm{H}-12, \mathrm{H}-14$ \\
\hline 14 & 27.0 & 1.36 & $3 \mathrm{H}$ & s & $4,5,15$ & & $\mathrm{H}-2 \alpha, \mathrm{H}-13$ \\
\hline 15 & 30.6 & 1.44 & $3 \mathrm{H}$ & $\mathrm{s}$ & $4,5,14$ & & $\mathrm{H}-2 \beta, \mathrm{H}-5$ \\
\hline \multirow[t]{2}{*}{$1^{\prime}$} & 112.8 & 4.89 (a) & $1 \mathrm{H}$ & brs & $2^{\prime}, 3^{\prime}, 7^{\prime}$ & $\mathrm{H}-1$ 'b & $\mathrm{H}-12, \mathrm{H}-1$ 'b, H-1", $\mathrm{OH}$ \\
\hline & & $5.42(\mathrm{~b})$ & $1 \mathrm{H}$ & brs & $2^{\prime}, 3^{\prime}, 7^{\prime}$ & $\mathrm{H}-1$ 'a & H-1'a, H-9' \\
\hline $2^{\prime}$ & 145.5 & & & & & & \\
\hline $3^{\prime}$ & 51.1 & & & & & & \\
\hline $4^{\prime}$ & 207.8 & & & & & & \\
\hline $5^{\prime}$ & 80.3 & & & & & & \\
\hline $6^{\prime}$ & 203.7 & & & & & & \\
\hline $7^{\prime}$ & 72.5 & & & & & & \\
\hline $8^{\prime}$ & 168.3 & & & & & & \\
\hline $9^{\prime}$ & 22.0 & 1.49 & $3 \mathrm{H}$ & s & $11,2^{\prime}, 3^{\prime}, 4^{\prime}$ & & $\mathrm{H}-11 \alpha, \mathrm{H}-11 \beta, \mathrm{H}-1$ 'b, OH \\
\hline $10^{\prime}$ & 15.0 & 1.36 & $3 \mathrm{H}$ & $\mathrm{s}$ & $4^{\prime}, 5^{\prime}, 6^{\prime}$ & & $\mathrm{OH}$ \\
\hline $1 "$ & 52.6 & 3.73 & $3 \mathrm{H}$ & s & $8^{\prime}$ & & $H-1$ 'a \\
\hline $\mathrm{OH}$ & & 3.25 & $1 \mathrm{H}$ & s & $5^{\prime}, 6^{\prime}, 10^{\prime}$ & & $\mathrm{H}-1$ 'a, H-9', H-10' \\
\hline
\end{tabular}

${ }^{1} \mathrm{H}$ NMR: $500 \mathrm{MHz},{ }^{13} \mathrm{C}$ NMR: $125 \mathrm{MHz}$ (in $\mathrm{CDCl}_{3}$ ) 


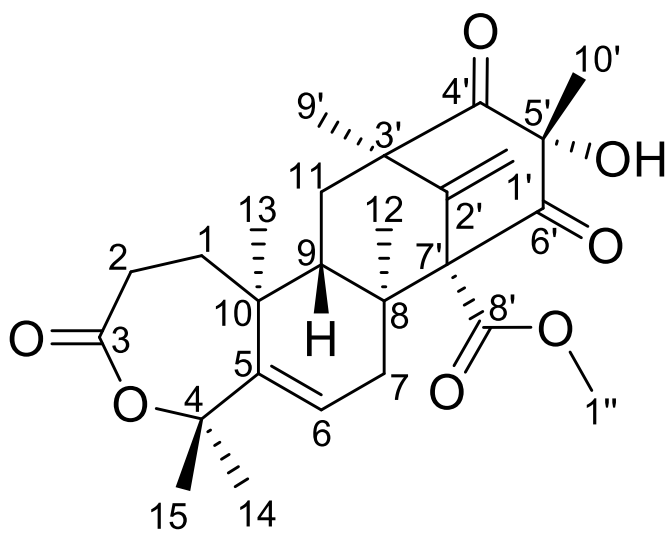

Table S6. NMR data for berkeleyone B (7)

\begin{tabular}{|c|c|c|c|c|c|c|c|}
\hline \multirow[b]{2}{*}{ position } & \multirow{2}{*}{$\begin{array}{c}{ }^{13} \mathrm{C} \\
\delta(\mathrm{ppm})\end{array}$} & \multicolumn{6}{|c|}{${ }^{1} \mathrm{H}$} \\
\hline & & $\delta(\mathrm{ppm})$ & intensity & multiplicity & HMBC correlation & COSY correlation & NOESY correlation \\
\hline \multirow[t]{2}{*}{1} & 33.8 & $2.28(\alpha)$ & $1 \mathrm{H}$ & $\mathrm{m}$ & & $\mathrm{H}-1 \beta, \mathrm{H}-2 \alpha, \mathrm{H}-2 \beta$ & $\mathrm{H}-1 \beta, \mathrm{H}-12, \mathrm{H}-13$ \\
\hline & & $1.44(\beta)$ & $1 \mathrm{H}$ & $\mathrm{m}$ & & $\mathrm{H}-1 \alpha, \mathrm{H}-2 \alpha, \mathrm{H}-2 \beta$ & $\mathrm{H}-1 \alpha, \mathrm{H}-9, \mathrm{H}-11 \beta$ \\
\hline \multirow[t]{2}{*}{2} & 29.6 & $2.00(\alpha)$ & $1 \mathrm{H}$ & $\mathrm{m}$ & & $\mathrm{H}-1 \alpha, \mathrm{H}-1 \beta, \mathrm{H}-2 \beta$ & $\mathrm{H}-2 \beta$ \\
\hline & & $1.86(\beta)$ & $1 \mathrm{H}$ & $\mathrm{m}$ & & $\mathrm{H}-1 \alpha, \mathrm{H}-1 \beta, \mathrm{H}-2 \beta$ & $\mathrm{H}-9, \mathrm{H}-2 \alpha$ \\
\hline 3 & 178.2 & & & & & & \\
\hline 4 & 75.9 & & & & & & \\
\hline 5 & 144.5 & & & & & & \\
\hline 6 & 124.0 & 5.73 & $1 \mathrm{H}$ & $\mathrm{dd}(J=7.3,2.0 \mathrm{~Hz})$ & $4,8,10$ & $\mathrm{H}-7 \alpha, \mathrm{H}-7 \beta$ & $\mathrm{H}-15, \mathrm{H}-7 \alpha, \mathrm{H}-7 \beta$ \\
\hline \multirow[t]{2}{*}{7} & 31.3 & $2.46(\alpha)$ & $1 \mathrm{H}$ & $\operatorname{dd}(J=18.0,7.3 \mathrm{~Hz})$ & 6,9 & $\mathrm{H}-6, \mathrm{H}-7 \beta$ & $\mathrm{H}-6, \mathrm{H}-7 \beta, \mathrm{H}-12$ \\
\hline & & $2.65(\beta)$ & $1 \mathrm{H}$ & brd & & $\mathrm{H}-6, \mathrm{H}-7 \alpha$ & $\mathrm{H}-6, \mathrm{H}-7 \alpha, \mathrm{H}-9$ \\
\hline 8 & 45.9 & & & & & & \\
\hline 9 & 43.8 & 0.88 & $1 \mathrm{H}$ & $\mathrm{dd}(J=13.5,3.9 \mathrm{~Hz})$ & & $\mathrm{H}-11 \alpha, \mathrm{H}-11 \beta$ & $\mathrm{H}-1 \beta, \mathrm{H}-2 \beta, \mathrm{H}-7 \beta, \mathrm{H}-11 \beta$ \\
\hline 10 & 43.1 & & & & & & \\
\hline \multirow[t]{2}{*}{11} & 41.4 & $1.72(\alpha)$ & $1 \mathrm{H}$ & $\mathrm{t}(J=13.5 \mathrm{~Hz})$ & & $\mathrm{H}-9, \mathrm{H}-11 \beta$ & $\mathrm{H}-11 \beta, \mathrm{H}-12, \mathrm{H}-13$ \\
\hline & & $2.03(\beta)$ & $1 \mathrm{H}$ & $\mathrm{m}$ & & $H-9, H-11 \alpha$ & $\mathrm{H}-1 \beta, \mathrm{H}-9, \mathrm{H}-11 \alpha, \mathrm{H}-13$ \\
\hline 12 & 15.6 & 1.21 & $3 \mathrm{H}$ & $\mathrm{s}$ & $7,9,7^{\prime}$ & & $\mathrm{H}-1 \alpha, \mathrm{H}-7 \alpha, \mathrm{H}-11 \alpha, \mathrm{H}-1$ 'a, H-1" \\
\hline 13 & 21.5 & 1.21 & $3 \mathrm{H}$ & s & $1,5,10$ & & $\mathrm{H}-1 \alpha, \mathrm{H}-11 \alpha, \mathrm{H}-11 \beta, \mathrm{H}-14$ \\
\hline 14 & 35.6 & 1.39 & $3 \mathrm{H}$ & s & $4,5,15$ & & $\mathrm{H}-13$ \\
\hline 15 & 33.8 & 1.43 & $3 \mathrm{H}$ & $\mathrm{s}$ & $4,5,14$ & & $\mathrm{H}-6$ \\
\hline \multirow[t]{2}{*}{$1^{\prime}$} & 112.3 & $4.89(a)$ & $1 \mathrm{H}$ & brs & $3^{\prime}, 7^{\prime}$ & $\mathrm{H}-1$ 'b & $\mathrm{H}-12, \mathrm{H}-1$ 'b, H-1" \\
\hline & & $5.41(b)$ & $1 \mathrm{H}$ & brs & & $\mathrm{H}-1$ 'a & H-1'a, H-9' \\
\hline $2^{\prime}$ & 145.5 & & & & & & \\
\hline $3^{\prime}$ & 51.3 & & & & & & \\
\hline $4^{\prime}$ & 207.5 & & & & & & \\
\hline $5^{\prime}$ & 80.0 & & & & & & \\
\hline $6^{\prime}$ & 204.0 & & & & & & \\
\hline $7^{\prime}$ & 71.9 & & & & & & \\
\hline $8^{\prime}$ & 168.6 & & & & & & \\
\hline $9^{\prime}$ & 22.4 & 1.52 & $3 \mathrm{H}$ & s & $11,2^{\prime}, 3^{\prime}, 4^{\prime}$ & & $\mathrm{H}-1$ 'b \\
\hline $10^{\prime}$ & 15.0 & 1.34 & $3 \mathrm{H}$ & s & $4^{\prime}, 5^{\prime}, 6^{\prime}$ & & \\
\hline 1" & 52.5 & 3.73 & $3 \mathrm{H}$ & s & $8^{\prime}$ & & $\mathrm{H}-12, \mathrm{H}-1$ 'a \\
\hline $\mathrm{OH}$ & & 3.49 & $1 \mathrm{H}$ & $\mathrm{s}$ & & & \\
\hline
\end{tabular}

${ }^{1} \mathrm{H}$ NMR: $500 \mathrm{MHz},{ }^{13} \mathrm{C}$ NMR: $125 \mathrm{MHz}$ (in $\mathrm{CDCl}_{3}$ ) 


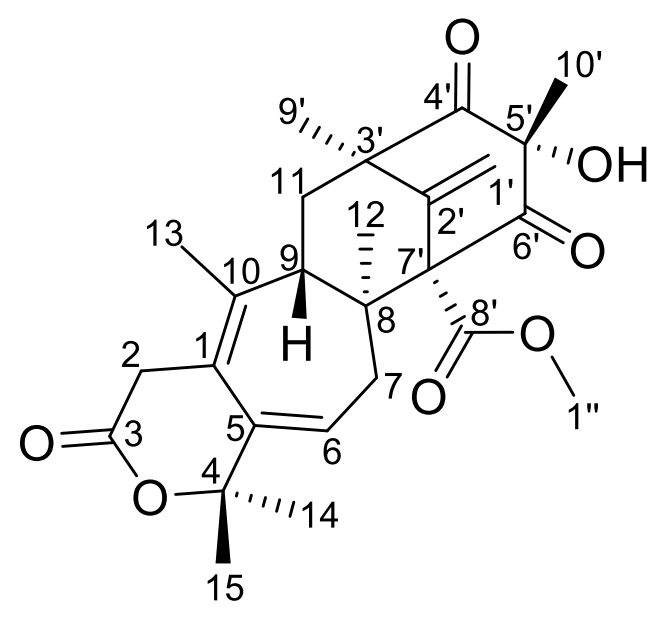

Table S7. NMR data for berkeleydione (2)

\begin{tabular}{|c|c|c|c|c|c|c|c|}
\hline \multirow[b]{2}{*}{ position } & \multirow{2}{*}{$\begin{array}{c}{ }^{13} \mathrm{C} \\
\delta(\mathrm{ppm})\end{array}$} & \multicolumn{6}{|c|}{${ }^{1} \mathrm{H}$} \\
\hline & & $\delta(\mathrm{ppm})$ & intensity & multiplicity & HMBC correlation & COSY correlation & NOESY correlation \\
\hline 1 & 126.2 & & & & & & \\
\hline \multirow[t]{2}{*}{2} & 34.2 & $3.24(\alpha)$ & $1 \mathrm{H}$ & $\operatorname{brd}(J=20.4 \mathrm{~Hz})$ & $1,3,10$ & $\mathrm{H}-2 \beta, \mathrm{H}-13$ & $\mathrm{H}-2 \beta, \mathrm{H}-13$ \\
\hline & & $3.35(\beta)$ & $1 \mathrm{H}$ & $\operatorname{brd}(J=21.0 \mathrm{~Hz})$ & $1,3,5,10$ & $\mathrm{H}-2 \alpha, \mathrm{H}-13$ & $\mathrm{H}-2 \alpha, \mathrm{H}-13, \mathrm{H}-15$ \\
\hline 3 & 169.8 & & & & & & \\
\hline 4 & 82.3 & & & & & & \\
\hline 5 & 139.9 & & & & & & \\
\hline 6 & 129.6 & 5.93 & $1 \mathrm{H}$ & $\mathrm{dd}(J=8.5,5.7 \mathrm{~Hz})$ & $1,4,7$ & $\mathrm{H}-7 \alpha, \mathrm{H}-7 \beta$ & $\mathrm{H}-7 \alpha, \mathrm{H}-7 \beta, \mathrm{H}-14$ \\
\hline \multirow[t]{2}{*}{7} & 36.4 & $1.90(\alpha)$ & $1 \mathrm{H}$ & $\mathrm{m}$ & $5,6,8,9,7^{\prime}$ & $\mathrm{H}-6, \mathrm{H}-7 \beta$ & $\mathrm{H}-6, \mathrm{H}-7 \beta$ \\
\hline & & $3.06(\beta)$ & $1 \mathrm{H}$ & $\mathrm{dd}(J=14.2,8.5 \mathrm{~Hz})$ & $5,6,8,9,7^{\prime}$ & $\mathrm{H}-6, \mathrm{H}-7 \alpha$ & $\mathrm{H}-6, \mathrm{H}-7 \alpha, \mathrm{H}-9$ \\
\hline 8 & 67.0 & & & & & & \\
\hline 9 & 44.5 & 1.90 & $1 \mathrm{H}$ & $\mathrm{m}$ & $1,8,10,11,12,13$ & $\mathrm{H}-11 \alpha, \mathrm{H}-11 \beta$ & $\mathrm{H}-7 \beta, \mathrm{H}-11 \beta$ \\
\hline 10 & 135.2 & & & & & & \\
\hline \multirow[t]{2}{*}{11} & 41.8 & $1.90(\alpha)$ & $1 \mathrm{H}$ & $\mathrm{m}$ & $9,3^{\prime}, 4^{\prime}$ & $\mathrm{H}-9, \mathrm{H}-11 \beta$ & $\mathrm{H}-11 \beta$ \\
\hline & & $1.97(\beta)$ & $1 \mathrm{H}$ & $\mathrm{dd}(J=11.3,2.3 \mathrm{~Hz})$ & $8,9,2^{\prime}, 3^{\prime}$ & $\mathrm{H}-9, \mathrm{H}-11 \alpha$ & $\mathrm{H}-9, \mathrm{H}-11 \alpha$ \\
\hline 12 & 19.9 & 1.28 & $3 \mathrm{H}$ & $\mathrm{s}$ & $7,8,9,7^{\prime}$ & & $\mathrm{H}-13, \mathrm{H}-14, \mathrm{H}-1$ 'a \\
\hline 13 & 15.5 & 1.67 & $3 \mathrm{H}$ & brs & $1,9,10$ & $\mathrm{H}-2 \alpha, \mathrm{H}-2 \beta$ & $\mathrm{H}-2 \alpha, \mathrm{H}-2 \beta, \mathrm{H}-12$ \\
\hline 14 & 26.8 & 1.52 & $3 \mathrm{H}$ & brs & $4,5,15$ & $\mathrm{H}-15$ & $\mathrm{H}-6, \mathrm{H}-12$ \\
\hline 15 & 29.5 & 1.28 & $3 \mathrm{H}$ & brs & $4,5,14$ & $\mathrm{H}-14$ & $\mathrm{H}-2 \beta$ \\
\hline \multirow[t]{2}{*}{$1^{\prime}$} & 113.1 & $4.90(a)$ & $1 \mathrm{H}$ & brs & $2^{\prime}, 3^{\prime}, 7^{\prime}$ & $\mathrm{H}-1^{\prime} \mathrm{b}$ & $\mathrm{H}-12, \mathrm{H}-1$ 'b, H-1" \\
\hline & & $5.42(b)$ & $1 \mathrm{H}$ & brs & $3^{\prime}, 7^{\prime}$ & $\mathrm{H}-1$ 'a & H-1'a, H-9' \\
\hline $2^{\prime}$ & 145.4 & & & & & & \\
\hline $3^{\prime}$ & 51.0 & & & & & & \\
\hline $4^{\prime}$ & 207.5 & & & & & & \\
\hline $5^{\prime}$ & 79.5 & & & & & & \\
\hline $6^{\prime}$ & 204.1 & & & & & & \\
\hline $7^{\prime}$ & 71.3 & & & & & & \\
\hline $8^{\prime}$ & 169.0 & & & & & & \\
\hline $9^{\prime}$ & 22.1 & 1.49 & $3 \mathrm{H}$ & s & $11,2^{\prime}, 3^{\prime}, 4^{\prime}$ & & $\mathrm{H}-1$ 'b \\
\hline $10^{\prime}$ & 14.9 & 1.31 & $3 \mathrm{H}$ & $\mathrm{s}$ & $4^{\prime}, 5^{\prime}, 6^{\prime}$ & & \\
\hline 1" & 52.6 & 3.77 & $3 \mathrm{H}$ & s & $8^{\prime}$ & & $\mathrm{H}-1$ 'a \\
\hline
\end{tabular}

${ }^{1} \mathrm{H}$ NMR: $500 \mathrm{MHz},{ }^{13} \mathrm{C}$ NMR: $125 \mathrm{MHz}$ (in $\mathrm{CDCl}_{3}$ ) 


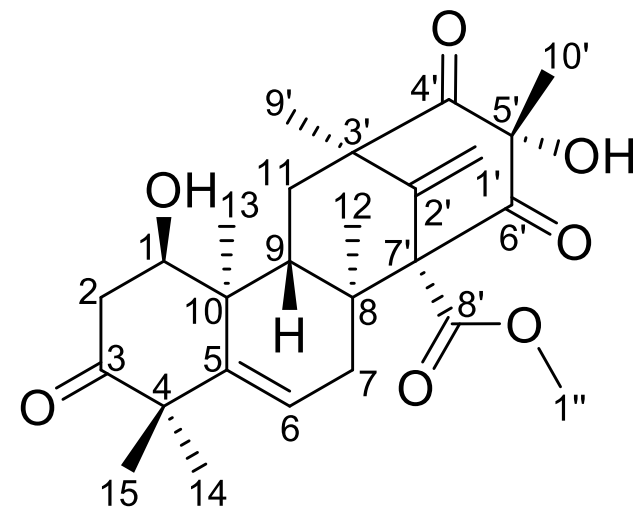

Table S8. NMR data for berkeleytrione (8)

\begin{tabular}{|c|c|c|c|c|c|c|c|}
\hline \multirow[b]{2}{*}{ position } & \multirow{2}{*}{$\begin{array}{c}{ }^{13} \mathrm{C} \\
\delta(\mathrm{ppm})\end{array}$} & \multicolumn{6}{|c|}{${ }^{1} \mathrm{H}$} \\
\hline & & $\delta(\mathrm{ppm})$ & intensity & multiplicity & HMBC correlation & COSY correlation & NOESY correlation \\
\hline 1 & 69.7 & 3.70 & $1 \mathrm{H}$ & $\mathrm{m}$ & 5 & $\mathrm{H}-2 \alpha, \mathrm{H}-2 \beta$ & $\mathrm{H}-2 \alpha, \mathrm{H}-2 \beta, \mathrm{H}-9, \mathrm{H}-11 \beta, \mathrm{H}-13$ \\
\hline \multirow[t]{2}{*}{2} & 43.6 & $2.68(\alpha)$ & $1 \mathrm{H}$ & $\mathrm{dd}(J=19.3,5.7 \mathrm{~Hz})$ & $1,3,10$ & $\mathrm{H}-1, \mathrm{H}-2 \beta$ & $\mathrm{H}-1, \mathrm{H}-2 \beta, \mathrm{H}-13$ \\
\hline & & $2.50(\beta)$ & $1 \mathrm{H}$ & $\operatorname{brd}(J=19.3 \mathrm{~Hz})$ & $1,3,10$ & $\mathrm{H}-1, \mathrm{H}-2 \alpha$ & $\mathrm{H}-1, \mathrm{H}-2 \alpha, \mathrm{H}-15$ \\
\hline 3 & 214.5 & & & & & & \\
\hline 4 & 48.3 & & & & & & \\
\hline 5 & 140.6 & & & & & & \\
\hline 6 & 124.9 & 5.87 & $1 \mathrm{H}$ & $\mathrm{dd}(J=5.7,2.3 \mathrm{~Hz})$ & $4,8,10$ & $\mathrm{H}-7 \alpha, \mathrm{H}-7 \beta$ & $\mathrm{H}-7 \alpha, \mathrm{H}-7 \beta, \mathrm{H}-14, \mathrm{H}-15$ \\
\hline \multirow[t]{2}{*}{7} & 31.3 & $2.57(\alpha)$ & $1 \mathrm{H}$ & $\mathrm{dd}(J=18.7,6.2 \mathrm{~Hz})$ & $5,6,8,9,12$ & $\mathrm{H}-6, \mathrm{H}-7 \beta$ & $\mathrm{H}-6, \mathrm{H}-7 \beta, \mathrm{H}-12$ \\
\hline & & $2.98(\beta)$ & $1 \mathrm{H}$ & $\operatorname{brd}(J=18.7 \mathrm{~Hz})$ & $5,6,8,9,12$ & $\mathrm{H}-6, \mathrm{H}-7 \alpha$ & $\mathrm{H}-6, \mathrm{H}-7 \alpha, \mathrm{H}-9$ \\
\hline 8 & 45.4 & & & & & & \\
\hline 9 & 37.9 & 1.80 & $1 \mathrm{H}$ & $\operatorname{dd}(J=13.6,2.8 \mathrm{~Hz})$ & $8,10,11,12$ & & $\mathrm{H}-1, \mathrm{H}-7 \beta, \mathrm{H}-11 \beta, \mathrm{H}-10^{\prime}$ \\
\hline 10 & 43.0 & & & & & & \\
\hline \multirow{2}{*}{11} & 40.4 & $1.73(\alpha)$ & $1 \mathrm{H}$ & $\mathrm{dd}(J=13.6,12.2 \mathrm{~Hz})$ & $8,9,2^{\prime}, 3^{\prime}, 4^{\prime}$ & $\mathrm{H}-11 \beta$ & $\mathrm{H}-11 \beta, \mathrm{H}-12, \mathrm{H}-13$ \\
\hline & & $1.98(\beta)$ & $1 \mathrm{H}$ & $\mathrm{dd}(J=12.2,2.8 \mathrm{~Hz})$ & $8,9,2^{\prime}, 3^{\prime}, 4^{\prime}$ & $\mathrm{H}-11 \alpha$ & $\mathrm{H}-1, \mathrm{H}-9, \mathrm{H}-11 \alpha, \mathrm{H}-13, \mathrm{H}-9^{\prime}$ \\
\hline 12 & 16.9 & 1.27 & $3 \mathrm{H}$ & $\mathrm{s}$ & $7,8,9,7^{\prime}$ & & H-7a, H-11a, H-13, H-1'a \\
\hline 13 & 17.5 & 0.80 & $3 \mathrm{H}$ & s & $1,5,9,10$ & & $\mathrm{H}-1, \mathrm{H}-2 \beta, \mathrm{H}-11 \alpha, \mathrm{H}-11 \beta, \mathrm{H}-12$ \\
\hline 14 & 29.3 & 1.27 & $3 \mathrm{H}$ & s & $3,4,5,15$ & & $\mathrm{H}-6$ \\
\hline 15 & 29.0 & 1.25 & $3 \mathrm{H}$ & $\mathrm{s}$ & $3,4,5,14$ & & $\mathrm{H}-6, \mathrm{H}-2 \beta$ \\
\hline \multirow[t]{2}{*}{$1^{\prime}$} & 112.7 & $4.92(a)$ & $1 \mathrm{H}$ & brs & $3^{\prime}, 7^{\prime}$ & $\mathrm{H}-1$ 'b & $\mathrm{H}-12, \mathrm{H}-1^{\prime} \mathrm{b}, \mathrm{H}-1^{\prime \prime}, 5^{\prime}-\mathrm{OH}$ \\
\hline & & $5.42(b)$ & $1 \mathrm{H}$ & brs & $3^{\prime}, 7^{\prime}$ & $\mathrm{H}-1$ 'a & $\mathrm{H}-1$ 'a, H-9' \\
\hline $2^{\prime}$ & 144.9 & & & & & & \\
\hline $3^{\prime}$ & 51.1 & & & & & & \\
\hline $4^{\prime}$ & 207.5 & & & & & & \\
\hline $5^{\prime}$ & 79.7 & & & & & & \\
\hline $6^{\prime}$ & 204.2 & & & & & & \\
\hline $7^{\prime}$ & 71.9 & & & & & & \\
\hline $8^{\prime}$ & 168.6 & & & & & & \\
\hline $9^{\prime}$ & 22.3 & 1.52 & $3 \mathrm{H}$ & $\mathrm{s}$ & $11,2^{\prime}, 4^{\prime}$ & & $\mathrm{H}-11 \beta, \mathrm{H}-1$ 'b \\
\hline $10^{\prime}$ & 15.3 & 1.37 & $3 \mathrm{H}$ & s & $4^{\prime}, 5^{\prime}, 6^{\prime}$ & & $\mathrm{H}-9$ \\
\hline $1 "$ & 52.6 & 3.74 & $3 \mathrm{H}$ & s & $8^{\prime}$ & & $\mathrm{H}-1$ 'a \\
\hline
\end{tabular}

${ }^{1} \mathrm{H}$ NMR: $500 \mathrm{MHz},{ }^{13} \mathrm{C}$ NMR: $125 \mathrm{MHz}$ (in $\mathrm{CDCl}_{3}$ ) 


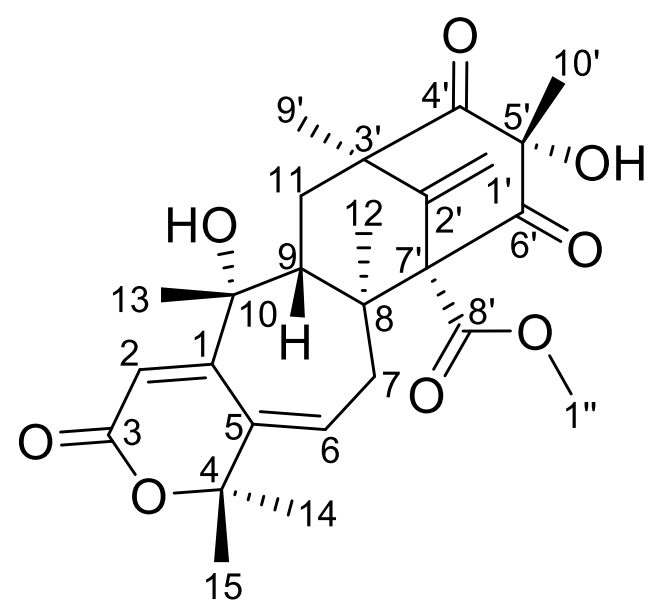

Table S9. NMR data for paraheroid A (10)

\begin{tabular}{|c|c|c|c|c|c|c|c|}
\hline \multirow[b]{2}{*}{ position } & \multirow{2}{*}{$\begin{array}{c}{ }^{13} \mathrm{C} \\
\delta(\mathrm{ppm})\end{array}$} & \multicolumn{6}{|c|}{${ }^{1} \mathrm{H}$} \\
\hline & & $\delta(\mathrm{ppm})$ & intensity & multiplicity & HMBC correlation & COSY correlation & NOESY correlation \\
\hline 1 & 158.9 & & & & & & \\
\hline 2 & 116.0 & 6.00 & $1 \mathrm{H}$ & brs & $3,5,10$ & & $\mathrm{H}-13$ \\
\hline 3 & 164.1 & & & & & & \\
\hline 4 & 83.2 & & & & & & \\
\hline 5 & 135.8 & & & & & & \\
\hline 6 & 131.2 & 6.21 & $1 \mathrm{H}$ & $\operatorname{ddd}(J=9.0,3.5,1.4 \mathrm{~Hz})$ & $1,4,8$ & $\mathrm{H}-7 \alpha, \mathrm{H}-7 \beta$ & $\mathrm{H}-7 \alpha, \mathrm{H}-14, \mathrm{H}-15$ \\
\hline \multirow[t]{2}{*}{7} & 35.4 & $3.00(\alpha)$ & $1 \mathrm{H}$ & $\mathrm{dd}(J=16.8,9.0 \mathrm{~Hz})$ & $5,6,8,9,7$ & $\mathrm{H}-6, \mathrm{H}-7 \beta$ & $\mathrm{H}-6, \mathrm{H}-7 \beta, \mathrm{H}-12$ \\
\hline & & $2.82(\beta)$ & $1 \mathrm{H}$ & $\mathrm{dd}(J=16.5,3.0 \mathrm{~Hz})$ & $5,6,8,12$ & $\mathrm{H}-6, \mathrm{H}-7 \alpha$ & $\mathrm{H}-7 \alpha, \mathrm{H}-9$ \\
\hline 8 & 48.9 & & & & & & \\
\hline 9 & 54.3 & 1.44 & $1 \mathrm{H}$ & $\mathrm{dd}(J=14.0,2.7 \mathrm{~Hz})$ & $8,10,11,12$ & $\mathrm{H}-11 \alpha, \mathrm{H}-11 \beta$ & $H-7 \beta, H-11 \beta$ \\
\hline 10 & 75.5 & & & & & & \\
\hline \multirow[t]{2}{*}{11} & 40.2 & $1.57(\alpha)$ & $1 \mathrm{H}$ & $\mathrm{m}$ & $9,3^{\prime}, 4^{\prime}, 9^{\prime}$ & $\mathrm{H}-9, \mathrm{H}-11 \beta$ & $\mathrm{H}-11 \beta$ \\
\hline & & $2.26(\beta)$ & $1 \mathrm{H}$ & $\mathrm{dd}(J=12.3,2.2 \mathrm{~Hz})$ & $8,2^{\prime}, 3^{\prime}$ & $\mathrm{H}-9, \mathrm{H}-11 \alpha$ & $\mathrm{H}-9, \mathrm{H}-11 \alpha, \mathrm{H}-13$ \\
\hline 12 & 16.2 & 1.20 & $3 \mathrm{H}$ & $\mathrm{s}$ & $7,8,9,7^{\prime}$ & & $\mathrm{H}-7 \alpha, \mathrm{H}-9^{\prime}$ \\
\hline 13 & 27.2 & 1.30 & $3 \mathrm{H}$ & s & $1,9,10$ & & $\mathrm{H}-2, \mathrm{H}-11 \beta$ \\
\hline 14 & 26.6 & 1.60 & $3 \mathrm{H}$ & s & $4,5,15$ & & $\mathrm{H}-6$ \\
\hline 15 & 27.0 & 1.49 & $3 \mathrm{H}$ & $\mathrm{s}$ & $4,5,14$ & & $\mathrm{H}-6$ \\
\hline \multirow[t]{2}{*}{$1^{\prime}$} & 113.6 & $4.92(a)$ & $1 \mathrm{H}$ & $\mathrm{d}(J=1.1 \mathrm{~Hz})$ & $3^{\prime}, 7^{\prime}$ & $\mathrm{H}-1$ 'b & $\mathrm{H}-1$ 'b, H-1" \\
\hline & & $5.45(b)$ & $1 \mathrm{H}$ & $\mathrm{d}(J=1.1 \mathrm{~Hz})$ & $3^{\prime}, 7^{\prime}$ & $\mathrm{H}-1$ 'a & $\mathrm{H}-1$ 'a, H-9' \\
\hline $2^{\prime}$ & 145.4 & & & & & & \\
\hline $3^{\prime}$ & 51.1 & & & & & & \\
\hline $4^{\prime}$ & 207.2 & & & & & & \\
\hline $5^{\prime}$ & 80.6 & & & & & & \\
\hline $6^{\prime}$ & 203.2 & & & & & & \\
\hline $7^{\prime}$ & 72.6 & & & & & & \\
\hline $8^{\prime}$ & 168.8 & & & & & & \\
\hline $9^{\prime}$ & 21.9 & 1.50 & $3 \mathrm{H}$ & s & $11,2^{\prime}, 3^{\prime}, 4^{\prime}$ & & $\mathrm{H}-1$ 'b \\
\hline $10^{\prime}$ & 15.1 & 1.39 & $3 \mathrm{H}$ & s & $4^{\prime}, 5^{\prime}, 6^{\prime}$ & & \\
\hline 1" & 52.8 & 3.77 & $3 \mathrm{H}$ & s & $8^{\prime}$ & & $\mathrm{H}-1$ 'a \\
\hline
\end{tabular}

${ }^{1} \mathrm{H}$ NMR: $900 \mathrm{MHz},{ }^{13} \mathrm{C}$ NMR: $225 \mathrm{MHz}$ (in $\mathrm{CDCl}_{3}$ ) 

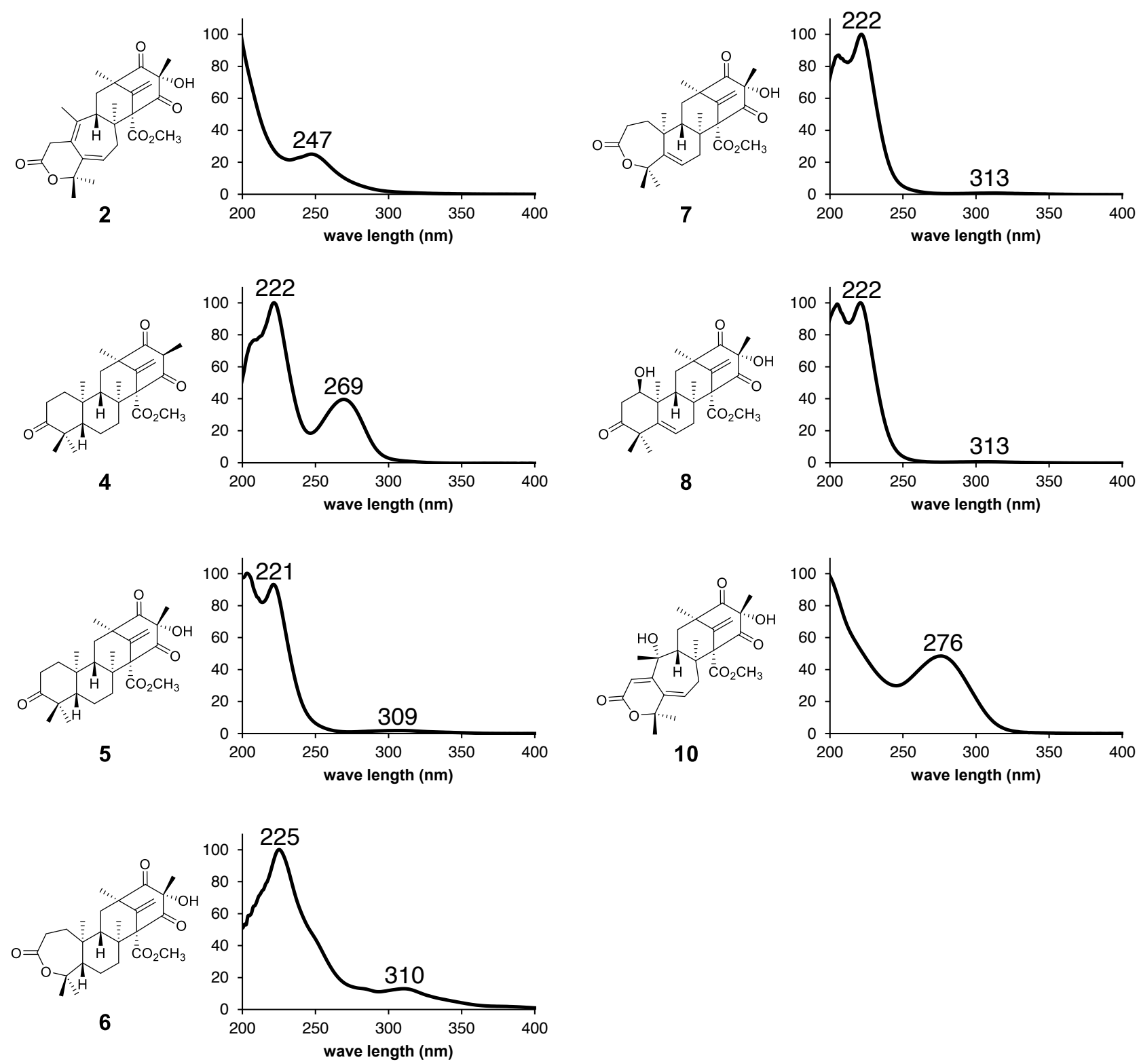

Figure S1. UV spectra of secondary metabolites isolated in this study. 
(A)
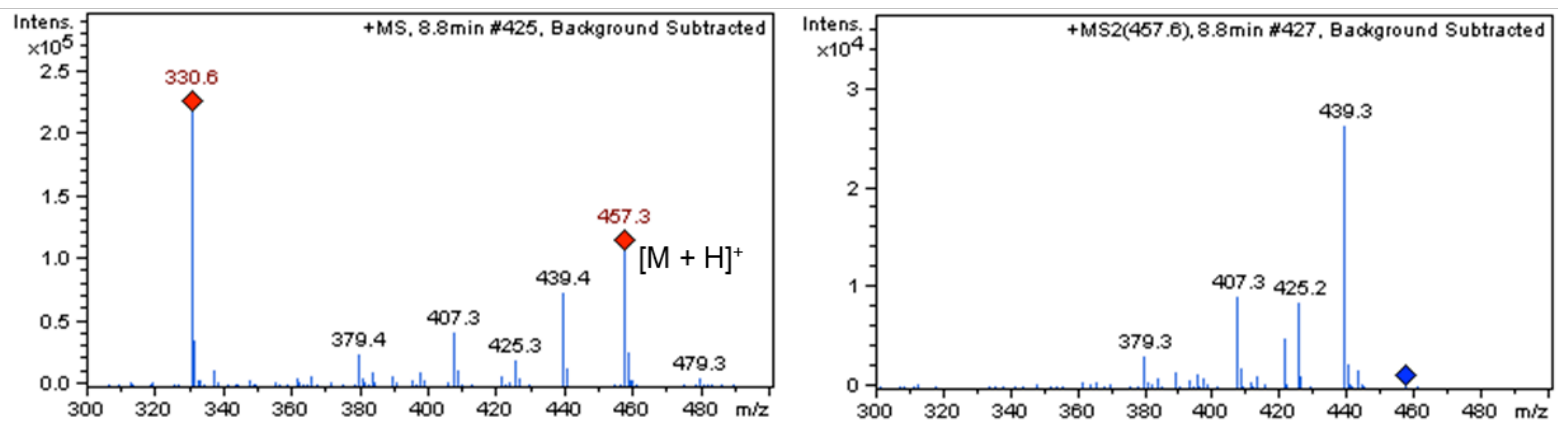

(B)
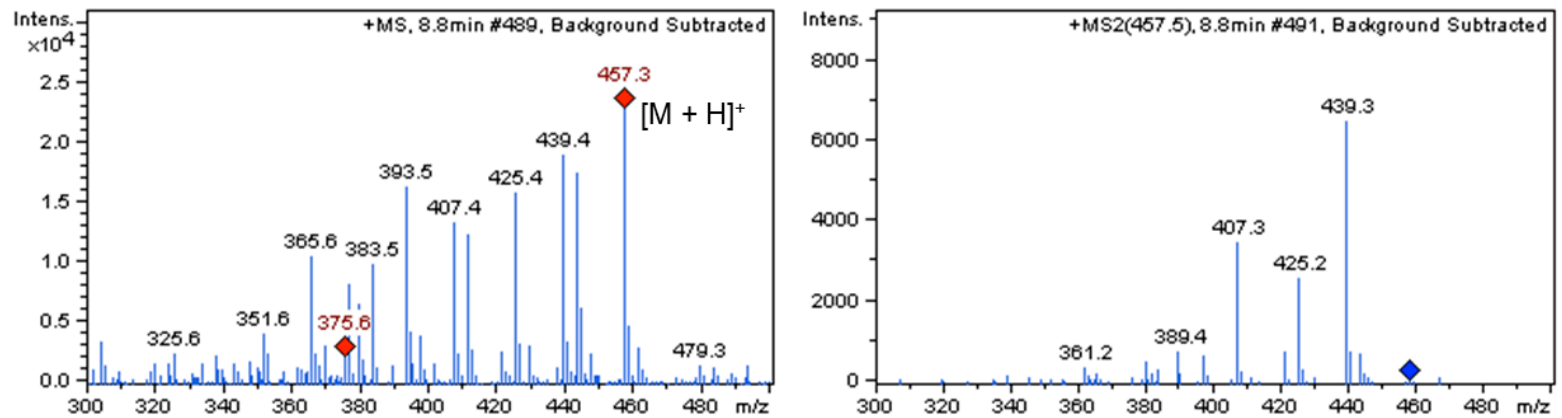

Figure S2. MS and $\mathrm{MS}^{2}$ spectra of (A) berkeleydione (2) and (B) enzymatic product from PrhA. Note that the marked fragments in the spectra are the ones used for $\mathrm{MS}^{2}$ analyses. 


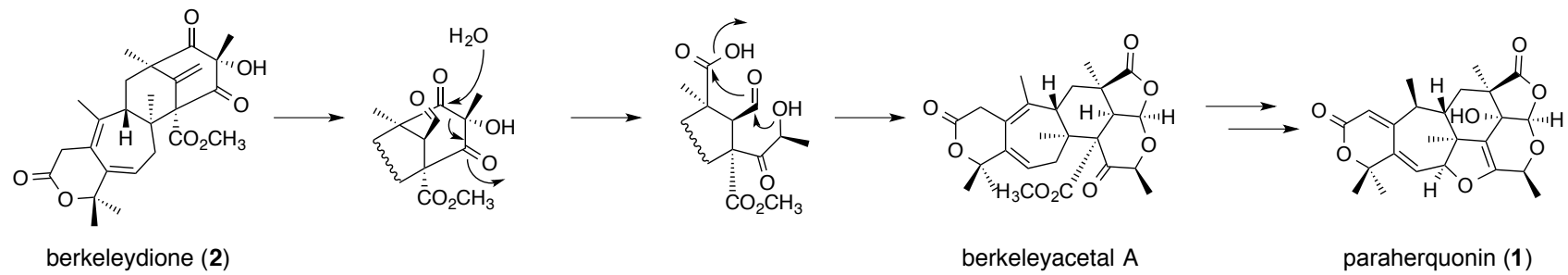

Figure S3. Predicted late-stage biosynthesis of paraherquonin (1).

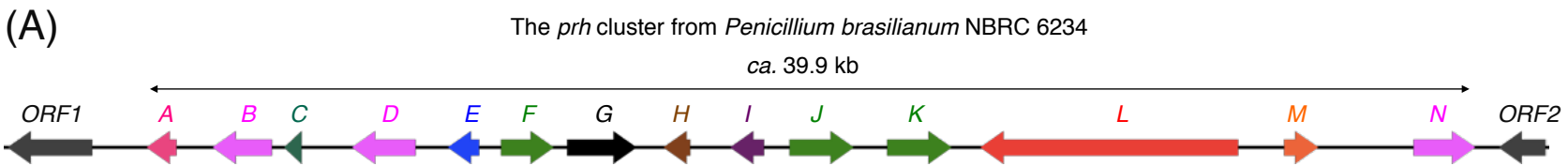

\begin{tabular}{|c|c|c|c|c|}
\hline Gene & Amino acids (base pairs) & Protein homologue, origin & Similarity/identity (\%) & Proposed function \\
\hline \multirow{2}{*}{ ORF1 } & \multirow{2}{*}{$720(2541)$} & PDE_04408, Penicillium oxalicum & $93 / 86$ & \multirow{2}{*}{ Transcriptional factor } \\
\hline & & ACN42_g2465, Penicillium freii & $87 / 78$ & \\
\hline prhA & $301(906)$ & AusE, Aspergillus nidulans & $87 / 78$ & PhyH-like dioxygenase \\
\hline prhB & 489 (1781) & TSTA_093880, Talaromyces stipitatus & $71 / 53$ & Cytochrome P450 \\
\hline prhC & $174(525)$ & AusJ, Aspergillus nidulans & $63 / 42$ & Isomerase \\
\hline $\operatorname{prhD}$ & $511(1913)$ & AdrA, Penicillium chrysogenum & $57 / 37$ & Cytochrome P450 \\
\hline prhE & $316(951)$ & AusN, Aspergillus nidulans & $73 / 62$ & Prenyltransferase \\
\hline prhF & $476(1591)$ & AusM, Aspergillus nidulans & $72 / 59$ & FAD-dependent monooxygenase \\
\hline prhG & $589(1917)$ & HK57_00369, Aspergillus ustus & $70 / 50$ & Major facilitator superfamily \\
\hline prhH & $245(807)$ & AusL, Aspergillus nidulans & $75 / 63$ & Terpene cyclase \\
\hline prhl & 257 (1018) & AdrF, Penicillium chrysogenum & $78 / 64$ & Short chain dehydrogenase \\
\hline prhJ & $641(1926)$ & AusB, Aspergillus nidulans & $73 / 63$ & FAD-dependent monooxygenase \\
\hline prhK & $646(1941)$ & AusC, Aspergillus nidulans & $84 / 74$ & FAD-dependent monooxygenase \\
\hline prhL & $2475(7744)$ & AusA, Aspergillus nidulans & $78 / 65$ & Polyketide synthase \\
\hline prhM & 279 (1035) & AusD, Aspergillus nidulans & $90 / 82$ & Methyltransferase \\
\hline $\operatorname{prhN}$ & $502(1847)$ & AdrA, Penicillium chrysogenum & $56 / 37$ & Cytochrome P450 \\
\hline ORF2 & $444(1411)$ & PDIP_02930, Penicillium digitatum & $85 / 75$ & Glycosyltransferase \\
\hline & & Pc12g01550, Penicillium rubens & $84 / 74$ & \\
\hline
\end{tabular}

Figure S4. (A) Schematic representation of the prh cluster. The direction of the arrow indicates the direction from the start to the stop codon. (B) Annotation of each protein of the prh cluster. The deduced function of each open reading frame (ORF) and the amino acid sequence similarity/identity, as compared with the homologues are shown. 
(A)
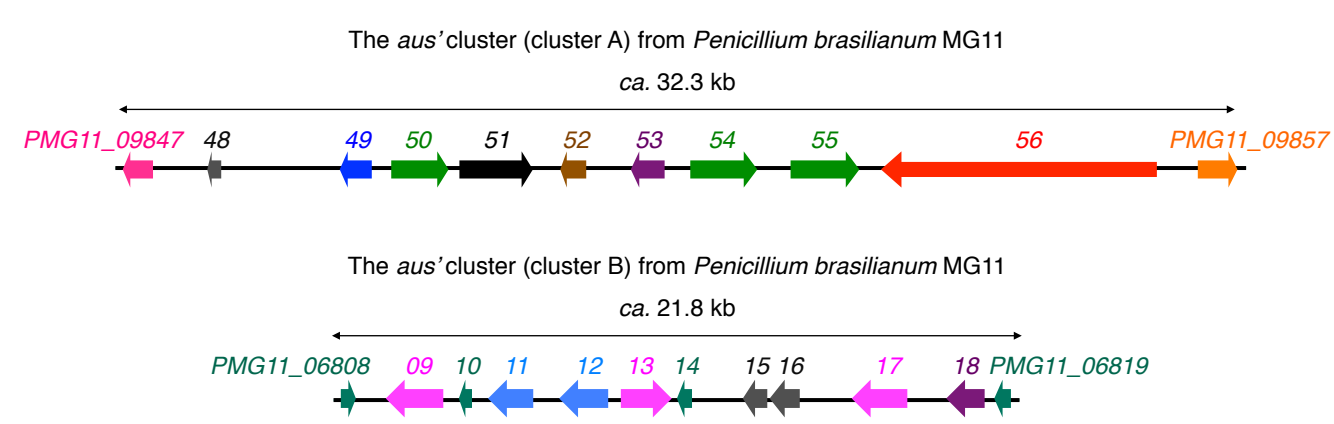

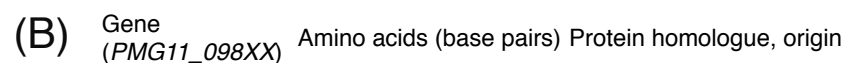

Similarity/identity (\%) Proposed function

\begin{tabular}{lllll}
\hline 47 & $301(906)$ & PrhA, Penicillium brasilianum NBRC 6234 & $96 / 92$ & PhyH-like dioxygenase \\
48 & $66(269)$ & - & - & Pseudogene (partial cytochrome P450) \\
49 & $316(951)$ & PrhE, Penicillium brasilianum NBRC 6234 & $97 / 96$ & Prenyltransferase \\
50 & $476(1588)$ & PrhF, Penicillium brasilianum NBRC 6234 & $97 / 95$ & FAD-dependent monooxygenase \\
51 & $588(1903)$ & PrhG, Penicillium brasilianum NBRC 6234 & $93 / 89$ & Major facilitator superfamily \\
52 & $245(808)$ & PrhH, Penicillium brasilianum NBRC 6234 & $96 / 95$ & Terpene cyclase \\
53 & $259(1021)$ & Prhl, Penicillium brasilianum NBRC 6234 & $99 / 98$ & Short chain dehydrogenase \\
54 & $641(1926)$ & PrhJ, Penicillium brasilianum NBRC 6234 & $96 / 95$ & FAD-dependent monooxygenase \\
55 & $646(1941)$ & PrhK, Penicillium brasilianum NBRC 6234 & $98 / 96$ & FAD-dependent monooxygenase \\
56 & $2475(7747)$ & PrhL, Penicillium brasilianum NBRC 6234 & $97 / 95$ & Polyketide synthase \\
57 & $279(1035)$ & PrhM, Penicillium brasilianum NBRC 6234 & $100 / 99$ & Methyltransferase
\end{tabular}

$\begin{array}{ll}\text { Gene } & \text { Similarity/identity (\%) Proposed function }\end{array}$

\begin{tabular}{lllll}
\hline 08 & $151(456)$ & AusF, Aspergillus nidulans FGSC A4 & $96 / 89$ & Isomerase \\
09 & $1844(530)$ & AusG, Aspergillus nidulans FGSC A4 & $91 / 87$ & Cytochrome P450 \\
10 & $147(444)$ & AusH, Aspergillus nidulans FGSC A4 & $97 / 93$ & Isomerase \\
11 & $482(1496)$ & AdrJ, Penicillium chrysogenum & $48 / 29$ & O-acetyltransferase \\
12 & $516(1551)$ & AN9250.4, Aspergillus nidulans FGSC A4 & $89 / 83$ & O-acetyltransferase \\
13 & $496(1718)$ & AN9251.4, Aspergillus nidulans FGSC A4 & $93 / 89$ & Cytochrome P450 \\
14 & $144(435)$ & AN9252.4, Aspergillus nidulans FGSC A4 & $97 / 91$ & Isomerase \\
15 & $253(762)$ & - & - & Hypothetical protein \\
16 & $310(1000)$ & - & - & Hypothetical protein \\
17 & $500(1794)$ & Ausl, Aspergillus nidulans FGSC A4 & $95 / 92$ & Cytochrome P450 \\
18 & $398(1197)$ & AusK, Aspergillus nidulans FGSC A4 & $97 / 95$ & Ketoreductase \\
19 & $172(569)$ & AusJ, Aspergillus nidulans FGSC A4 & $95 / 93$ & Isomerase
\end{tabular}

Figure S5. (A) Schematic representation of the aus' cluster. The direction of the arrow indicates the direction from the start to the stop codon. (B) (C) Annotation of each protein in (B) cluster A and (C) cluster B of the aus' cluster. The deduced function of each open reading frame (ORF) and the amino acid sequence similarity/identity, as compared with the homologues are shown. 
The aus cluster (cluster B) from Aspergillus nidulans FGSC A4

The aus'cluster (cluster B) from Penicillium brasilianum MG11

A genomic region from

Penicillium brasilianum NBRC 6234

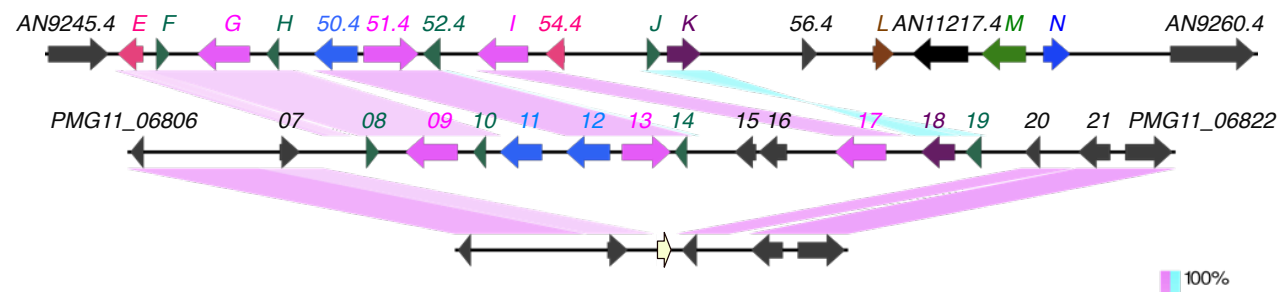

$100 \%$

Figure S6. Comparison of the aus' cluster (cluster B) and the corresponding genomic region in $P$. brasilianum NBRC6234 as well as of the aus cluster.

PrhA (Penicillium brasilianum NBRC 6234) AusE' (Penicillium brasilianum MG11) AusE (Aspergillus nidulans FGSC A4)
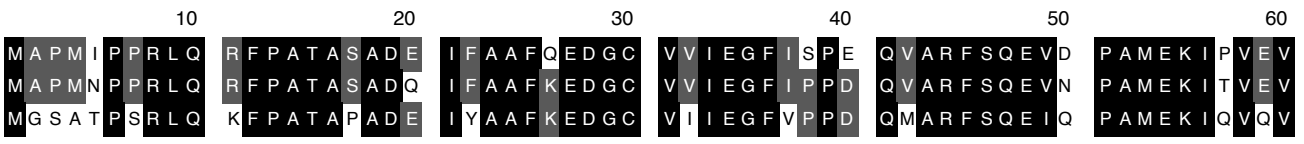

PrhA (Penicillium brasilianum NBRC 6234) AusE' (Penicillium brasilianum MG11)
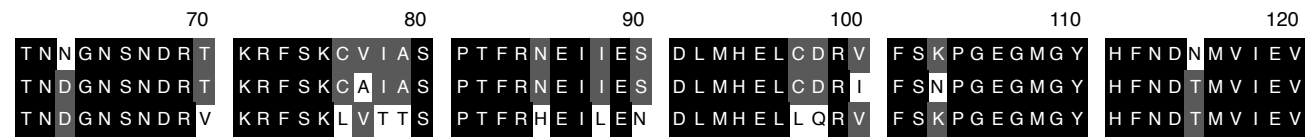

PrhA (Penicillium brasilianum NBRC 6234) AusE' (Penicillium brasilianum MG11) AusE (Aspergillus nidulans FGSC A4)
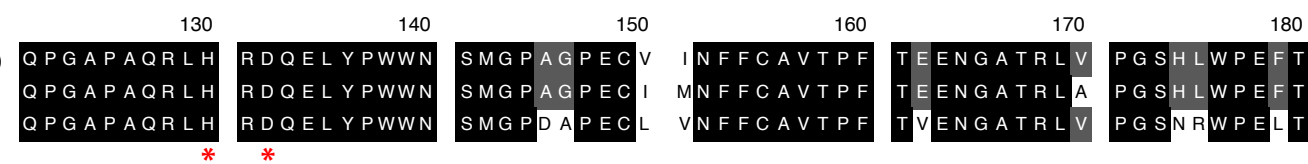

PrhA (Penicillium brasilianum NBRC 6234) AusE' (Penicillium brasilianum MG11)
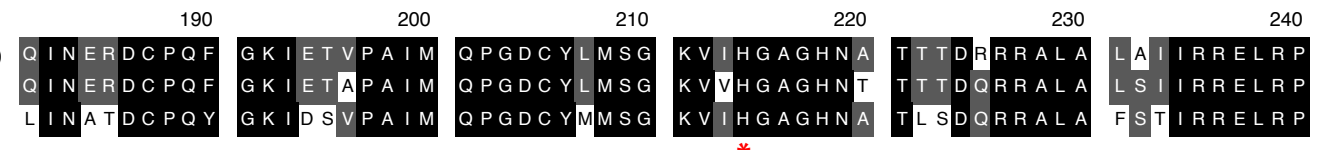

PrhA (Penicillium brasilianum NBRC 6234) AusE' (Penicillium brasilianum MG11)
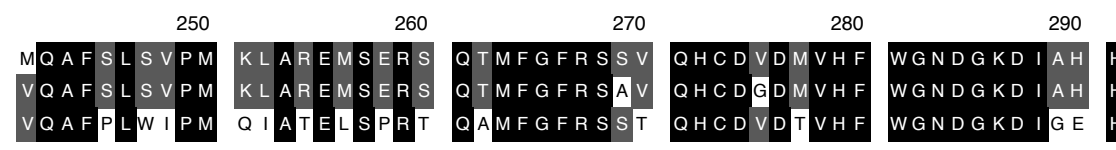

300
$H L G L E A P S \vee H$
$H L G L E A P S \vee H$
$H L G L$ I S S A - -

PrhA ( Penicillium brasilianum NBRC 6234) V

AusE' (Penicillium brasilianum MG11)

AusE (Aspergillus nidulans FGSC A4)

Figure S7. Sequence alignment between PrhA, AusE', and AusE. Red asterisks indicate the conserved 2-His-1-carboxylate iron-binding triad. 


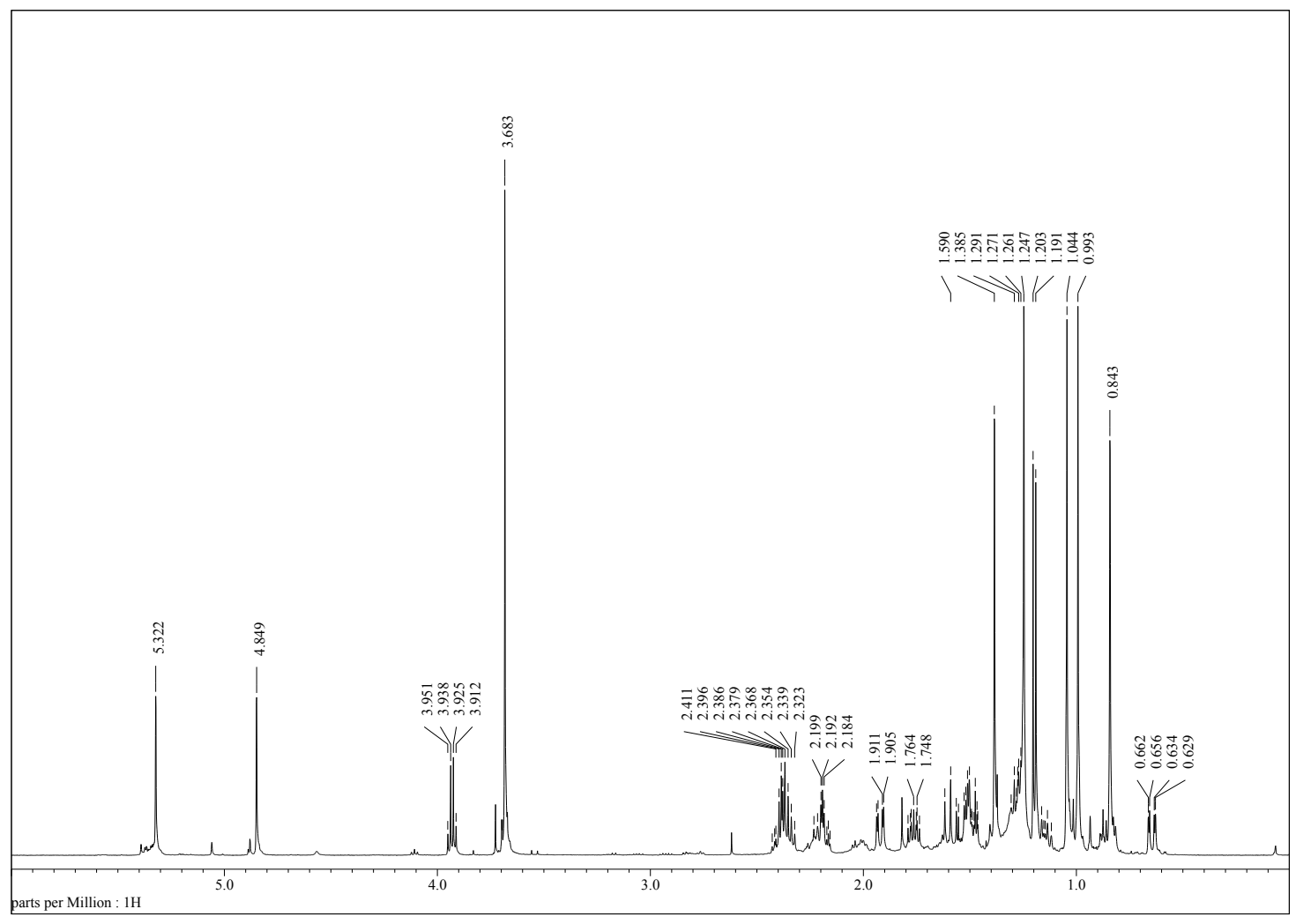

Figure S8. ${ }^{1} \mathrm{H}$ NMR spectrum of protoaustinoid B (4).

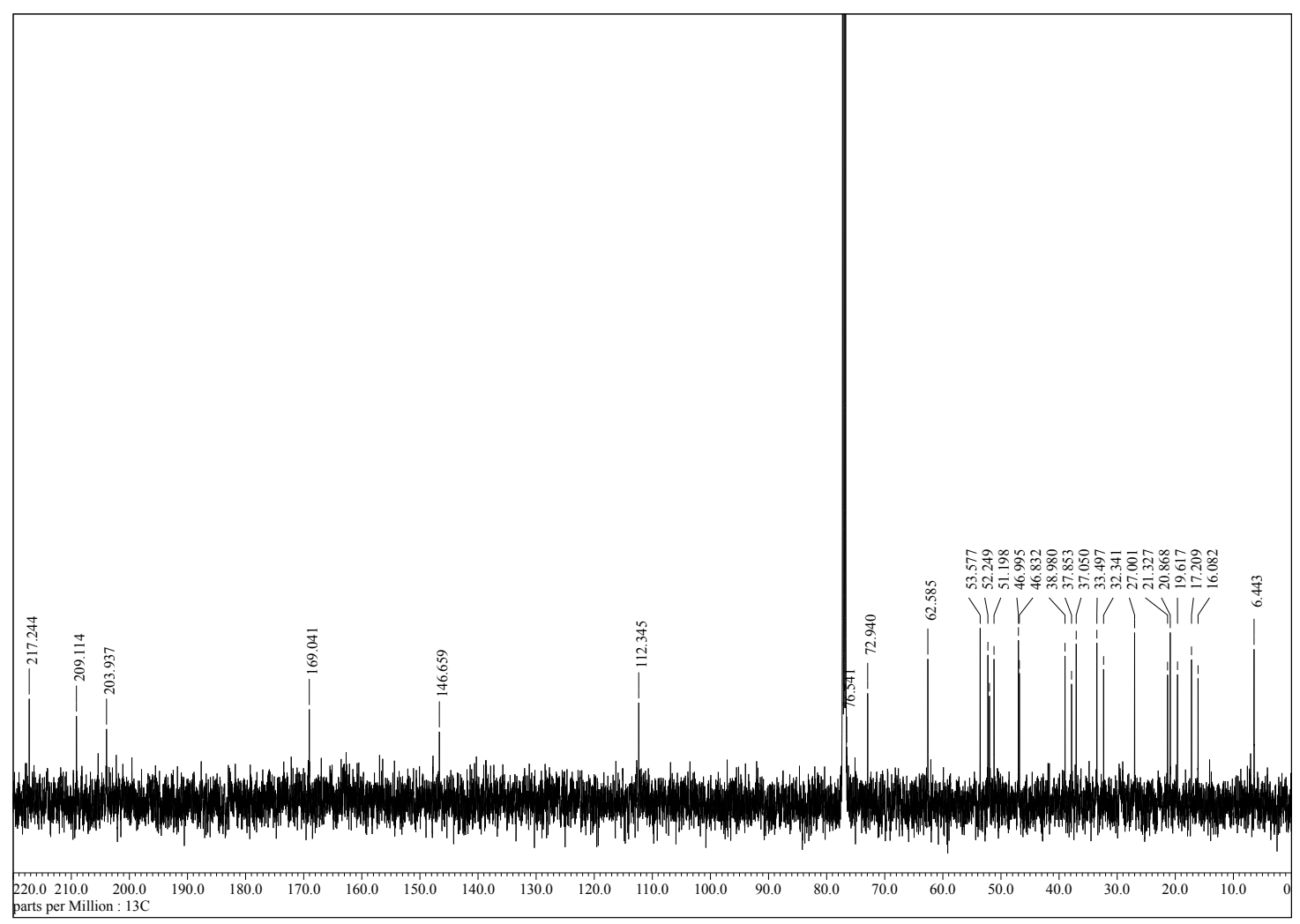

Figure S9. ${ }^{13} \mathrm{C}$ NMR spectrum of protoaustinoid B (4). 


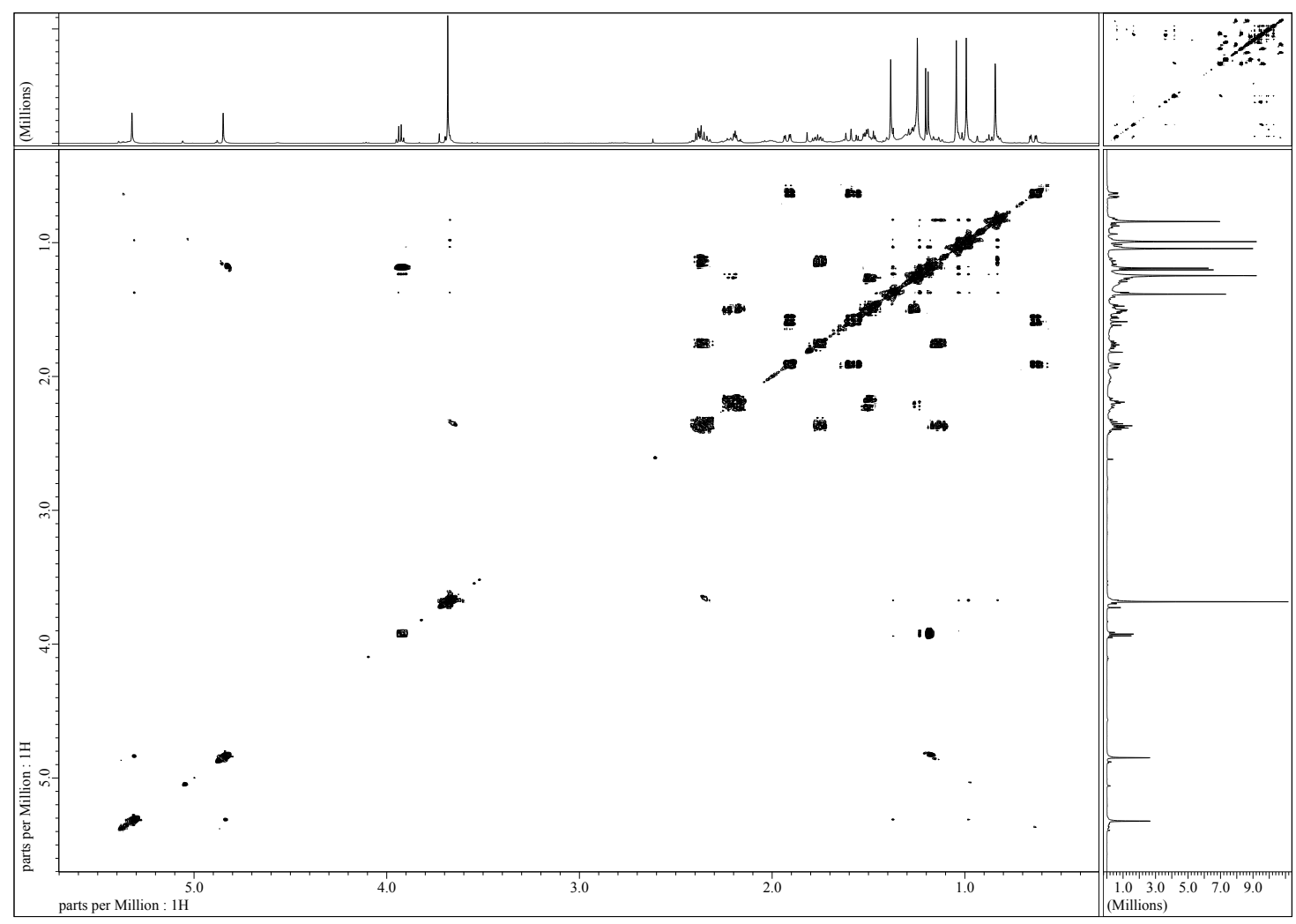

Figure S10. ${ }^{1} \mathrm{H}-{ }^{1} \mathrm{H}$ COSY spectrum of protoaustinoid B (4).

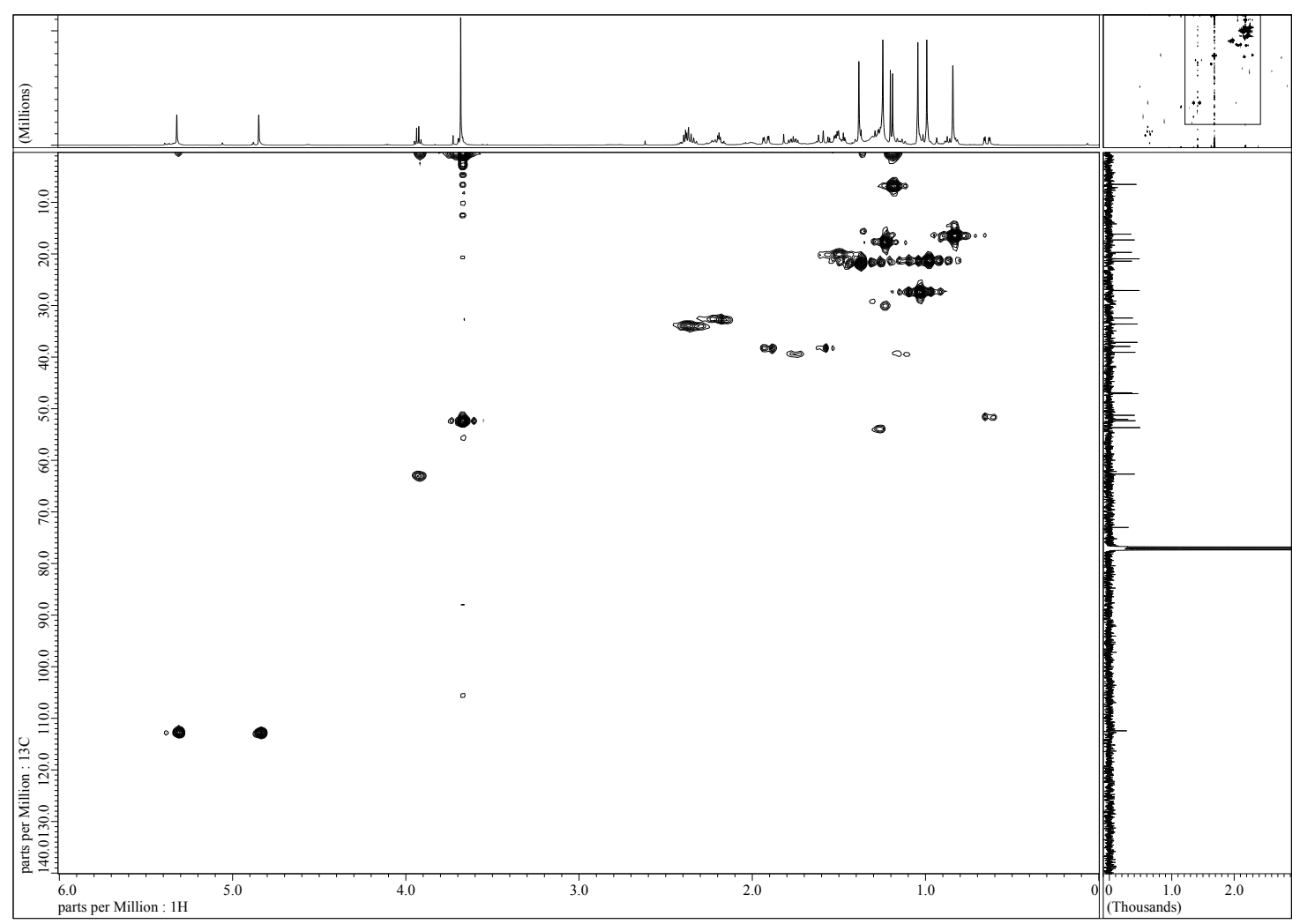

Figure S11. HMQC spectrum of protoaustinoid B (4). 


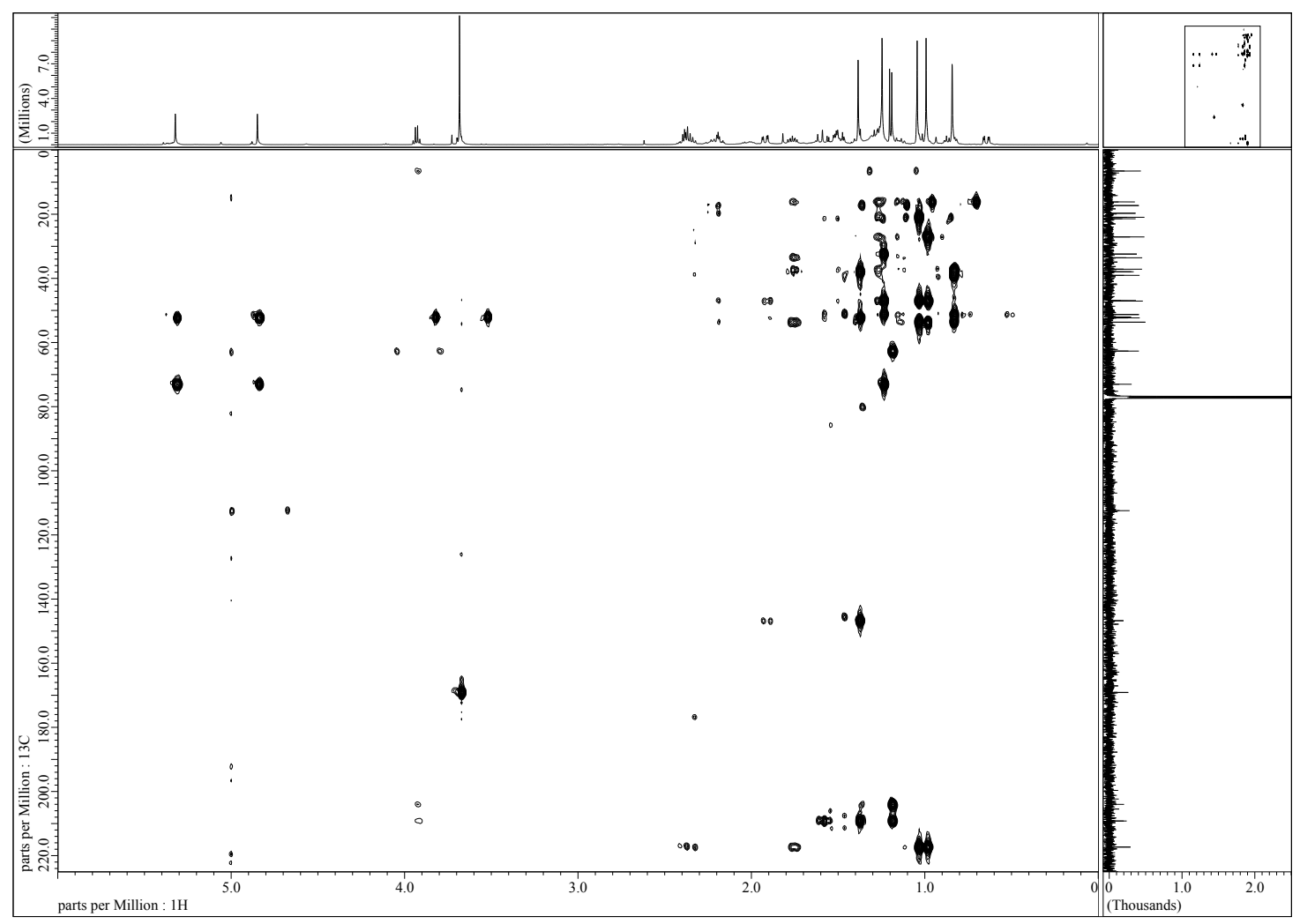

Figure S12. HMBC spectrum of protoaustinoid B (4).

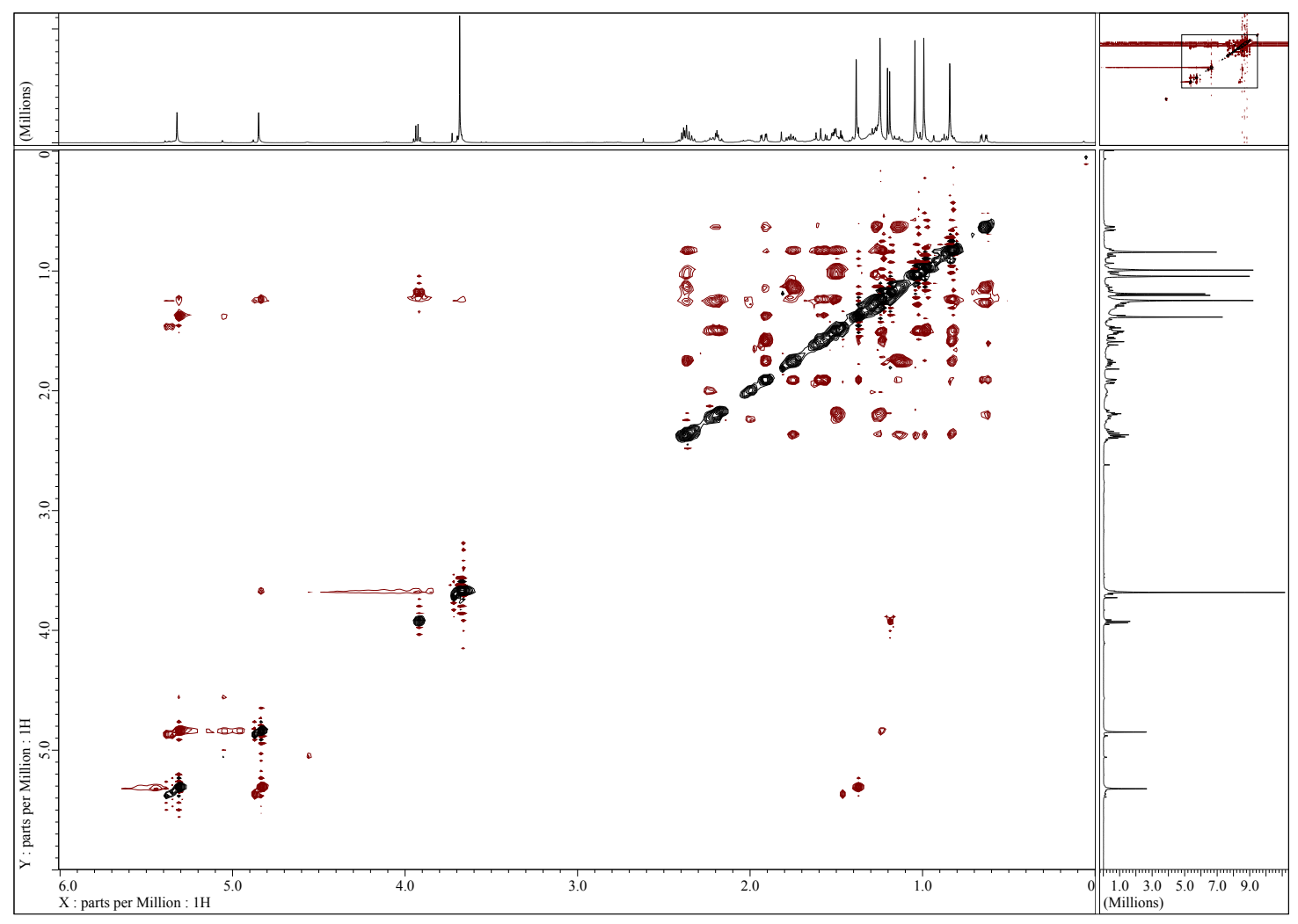

Figure S13. NOESY spectrum of protoaustinoid B (4). 


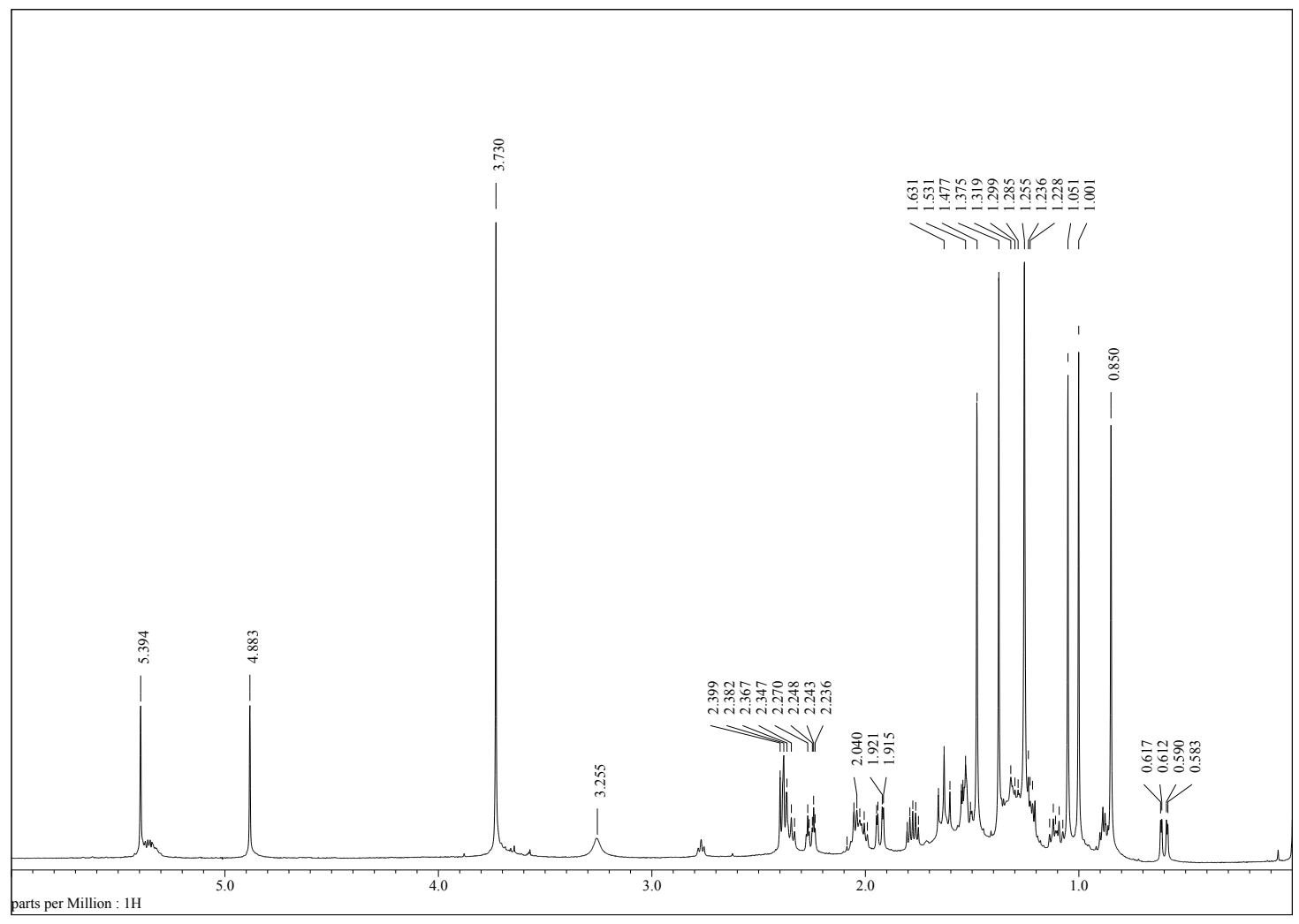

Figure S14. ${ }^{1} \mathrm{H}$ NMR spectrum of preaustinoid A (5).

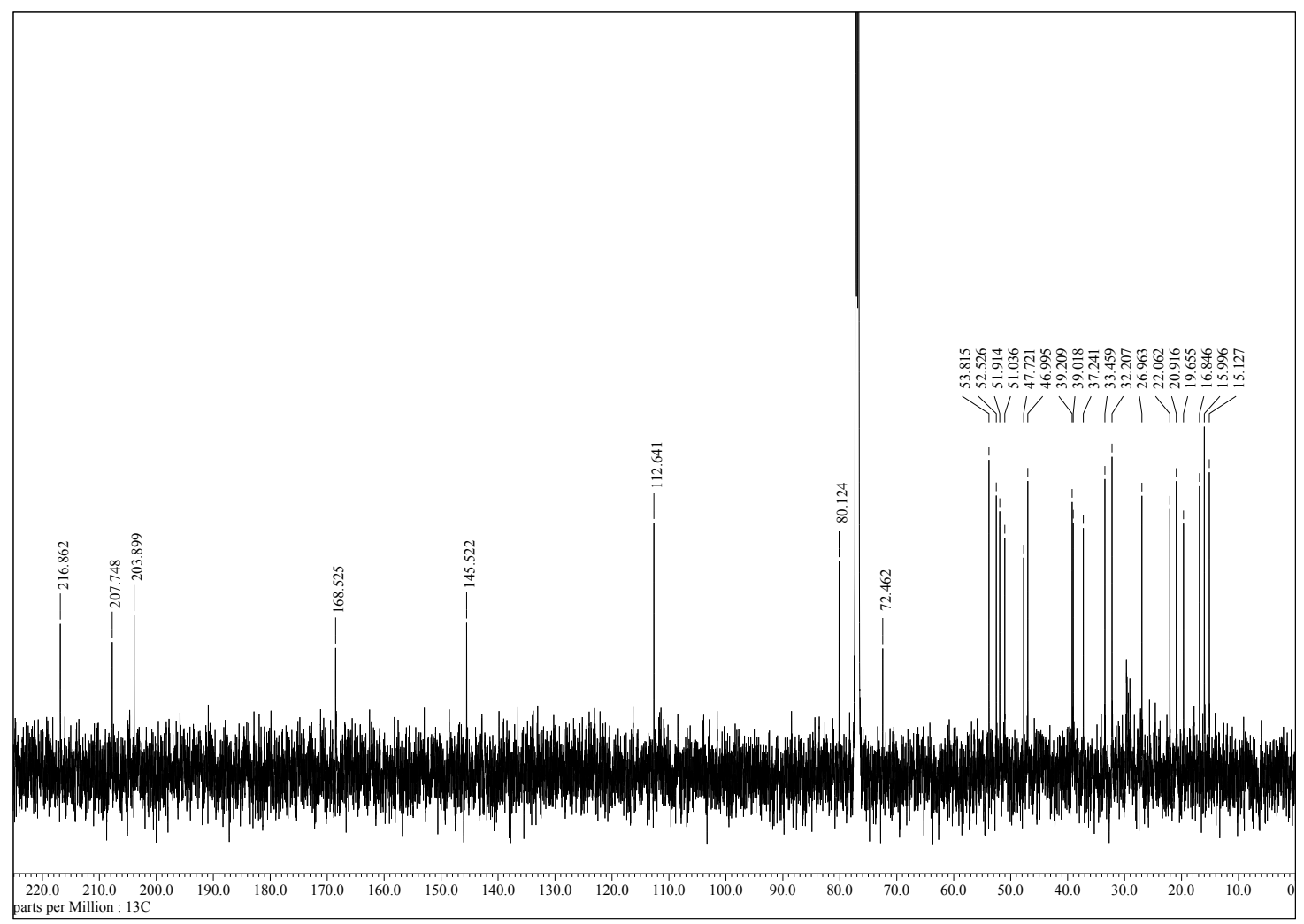

Figure S15. ${ }^{13} \mathrm{C}$ NMR spectrum of preaustinoid A (5). 


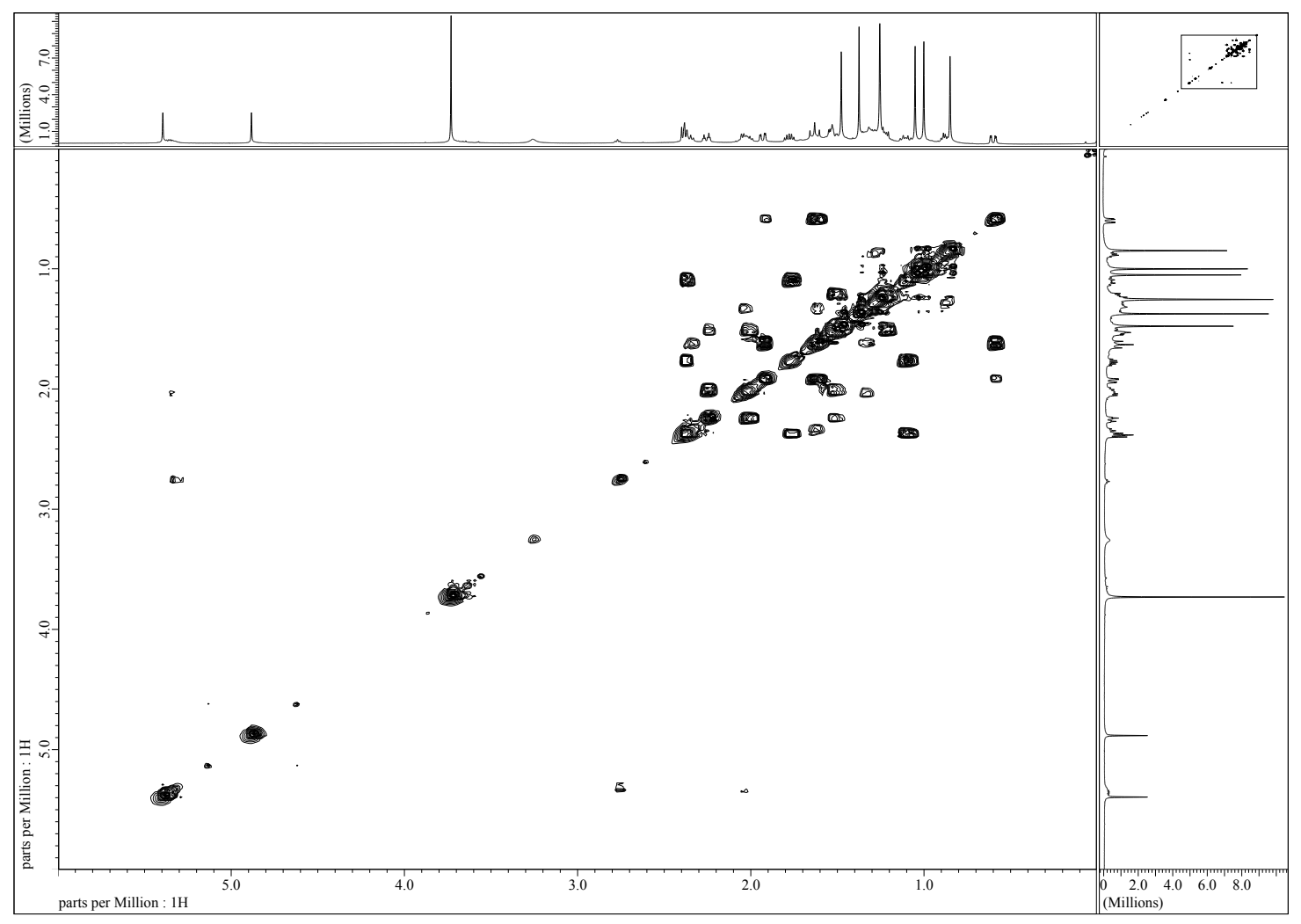

Figure S16. ${ }^{1} \mathrm{H}-{ }^{1} \mathrm{H}$ COSY spectrum of preaustinoid A (5).

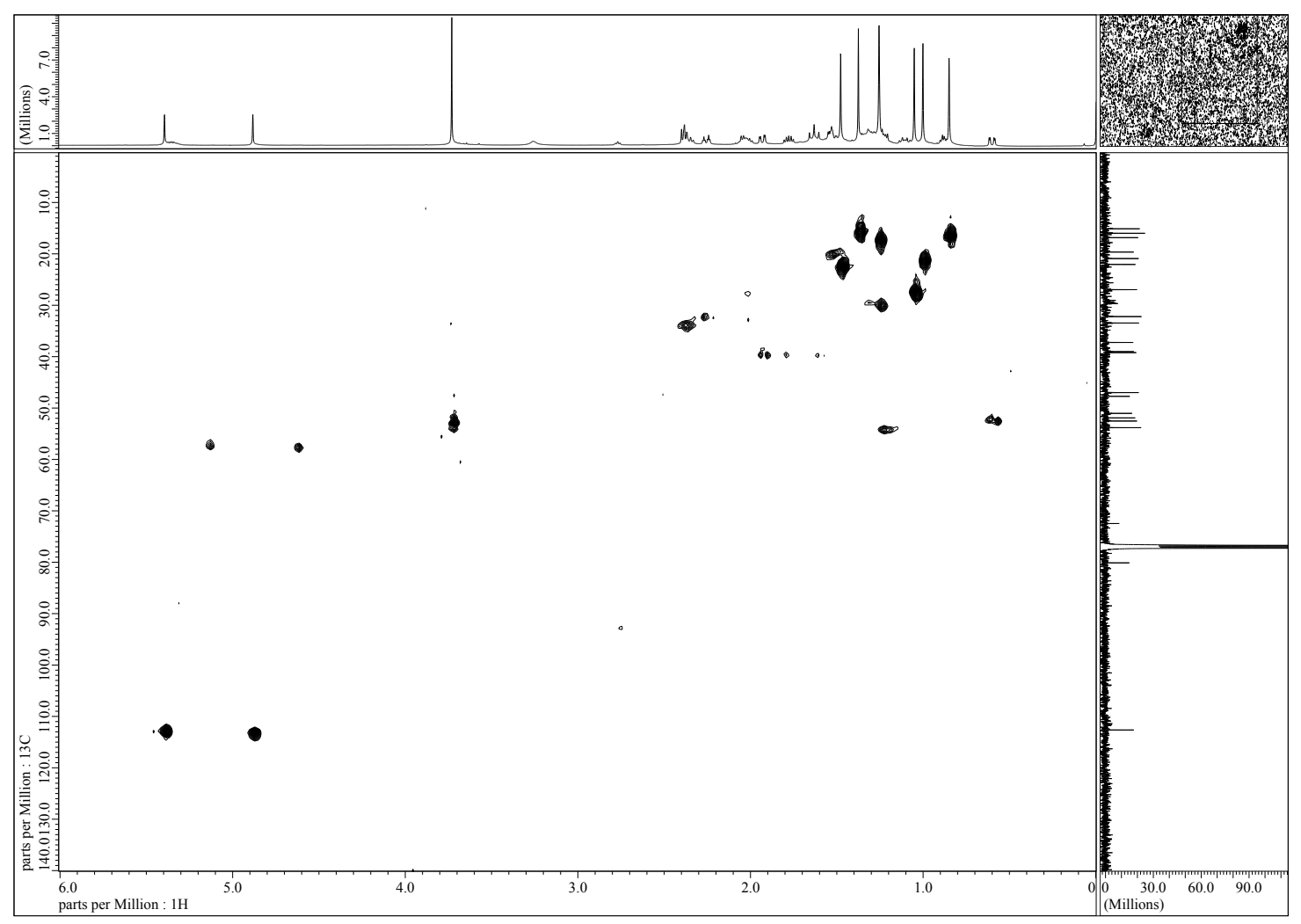

Figure S17. HMQC spectrum of preaustinoid A (5).

S21 


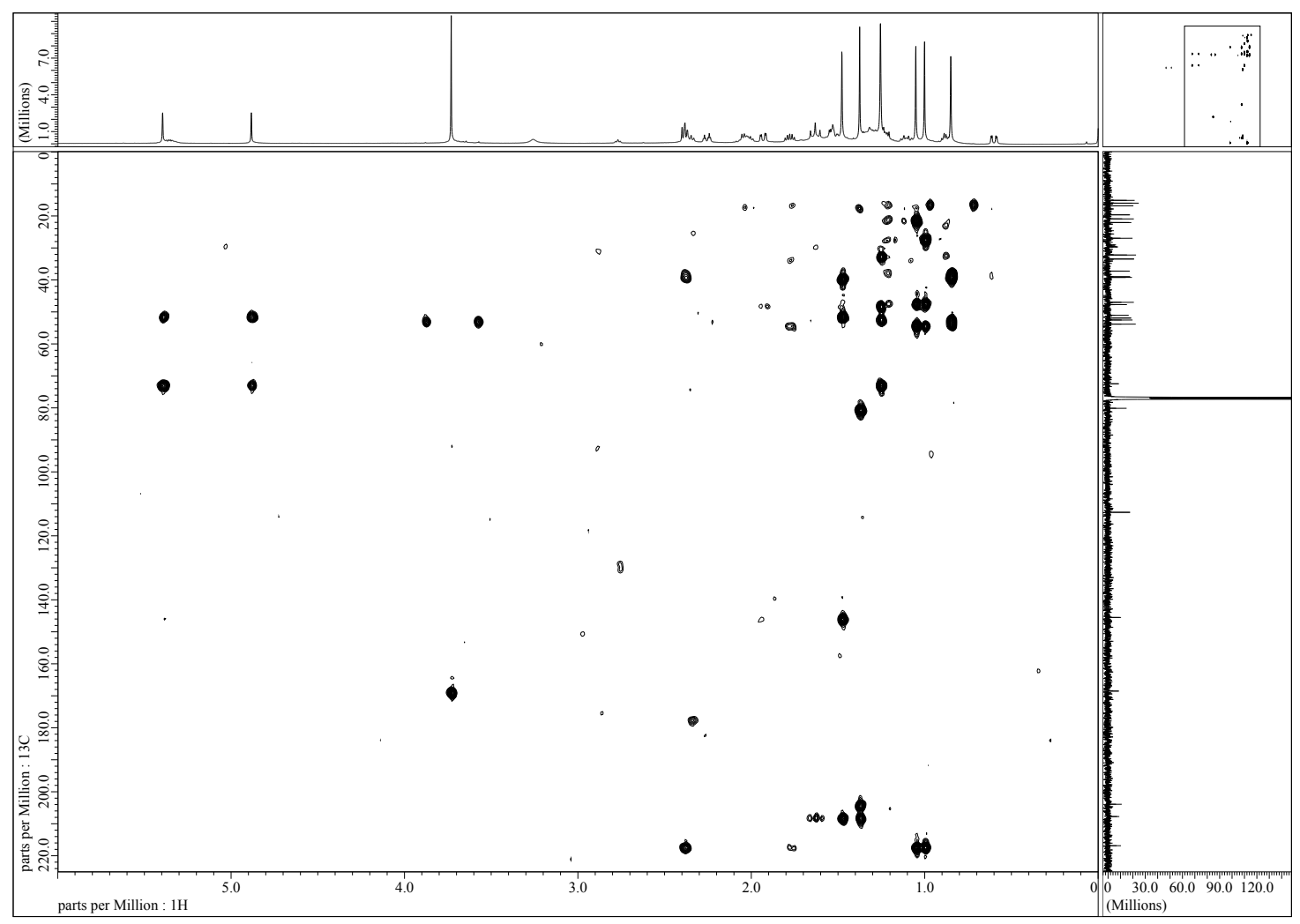

Figure S18. HMBC spectrum of preaustinoid A (5).

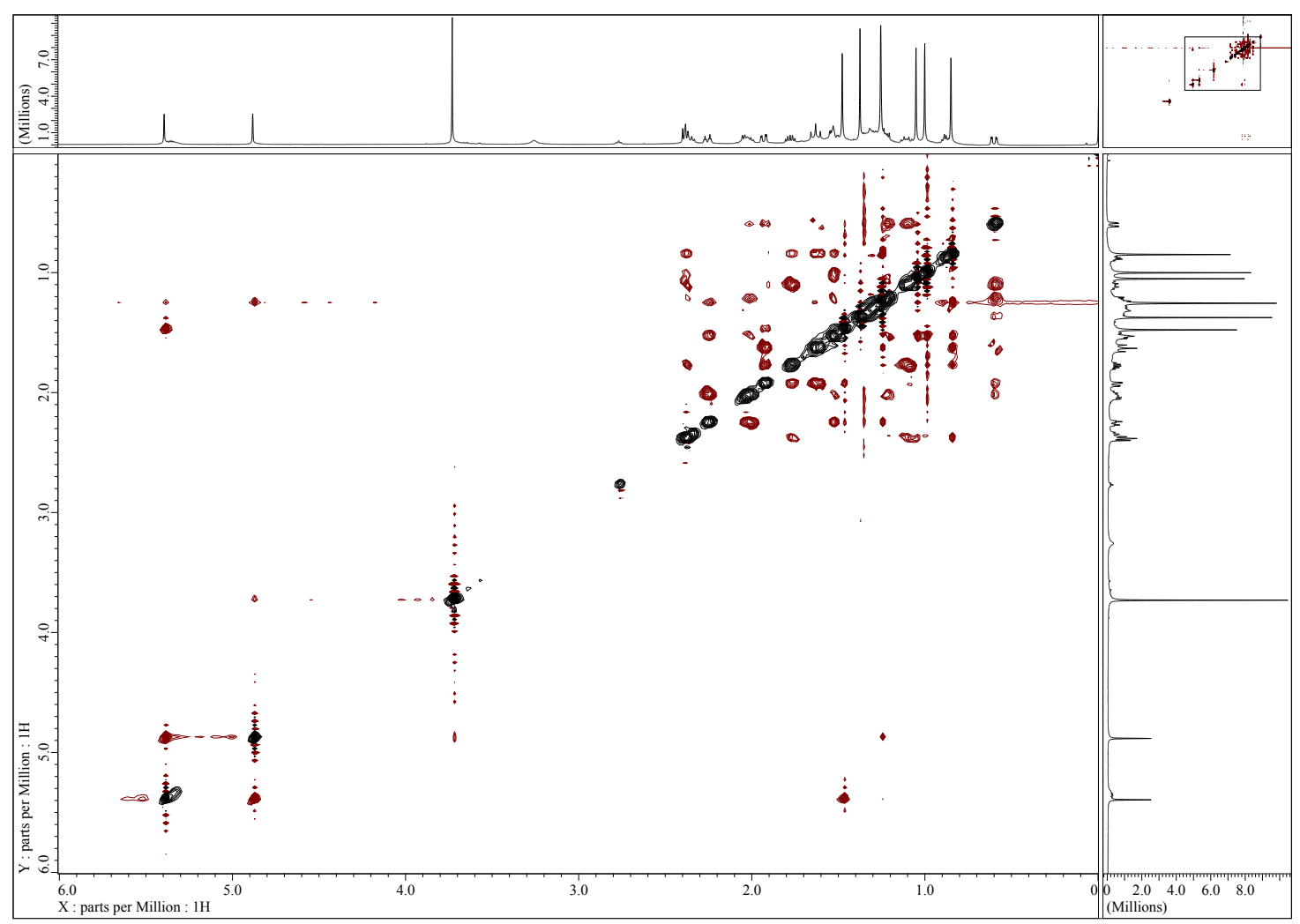

Figure S19. NOESY spectrum of preaustinoid A (5). 


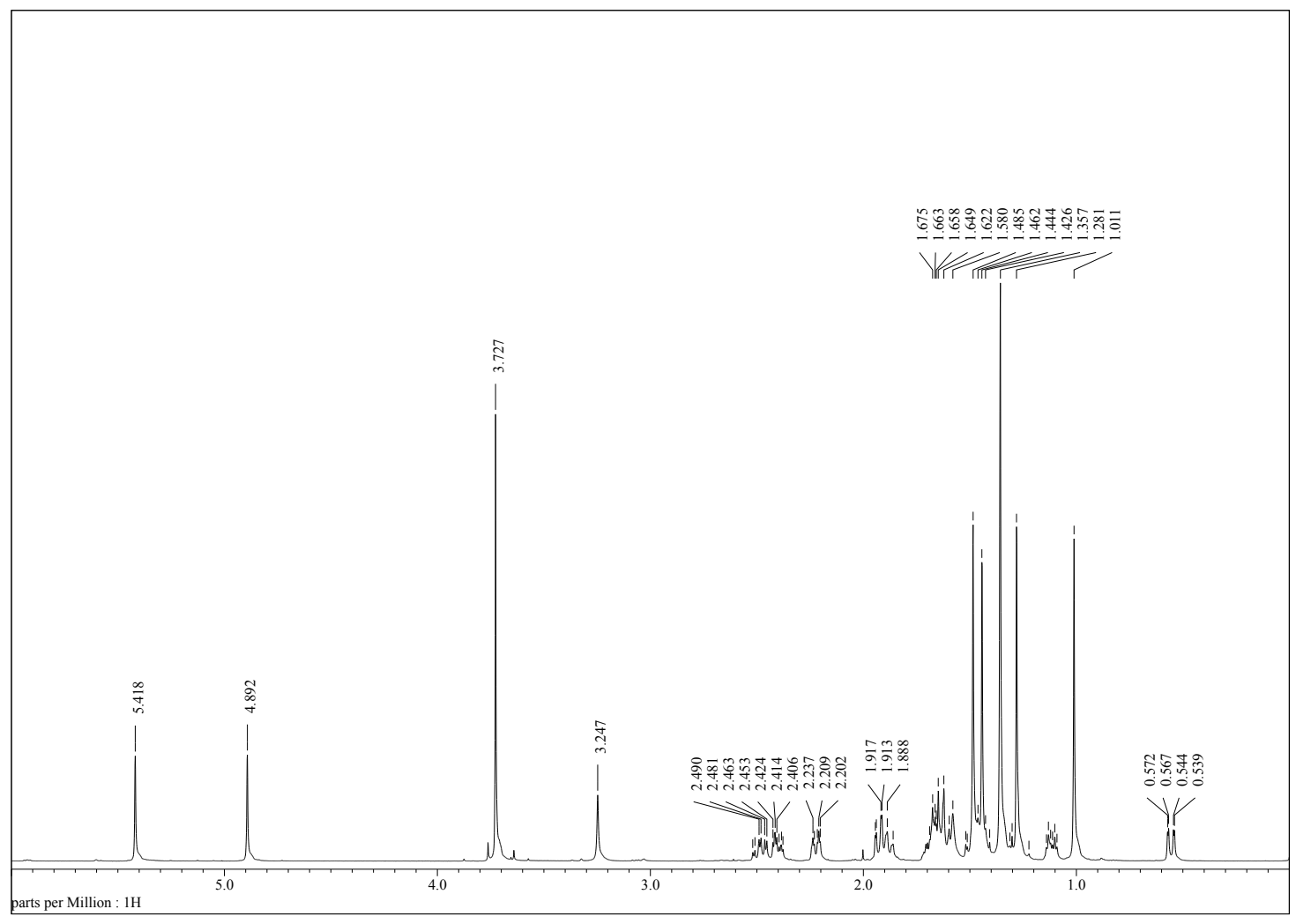

Figure S20. ${ }^{1} \mathrm{H}$ NMR spectrum of preaustinoid A1 (6).

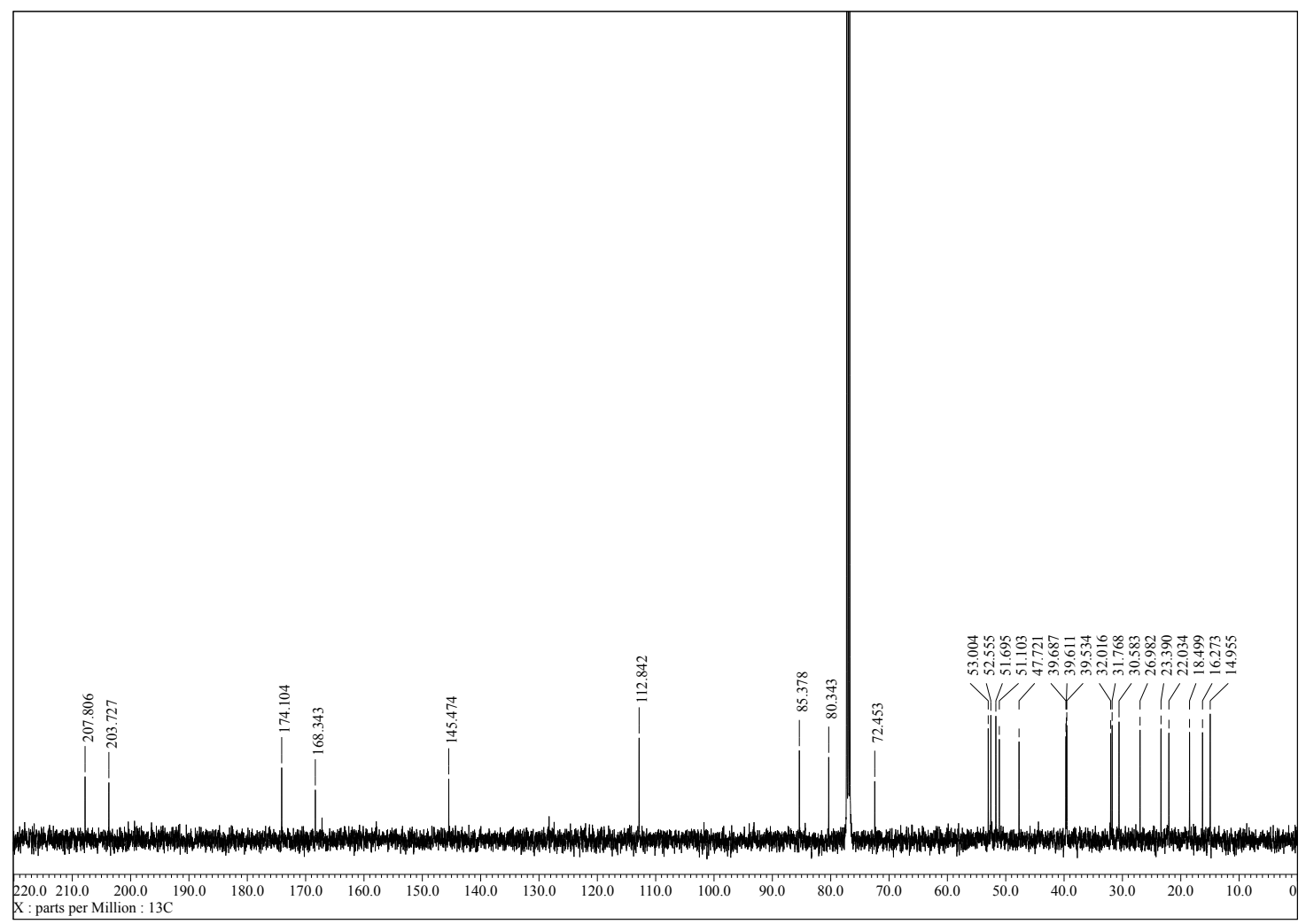

Figure S21. ${ }^{13} \mathrm{C}$ NMR spectrum of preaustinoid A1 (6). 


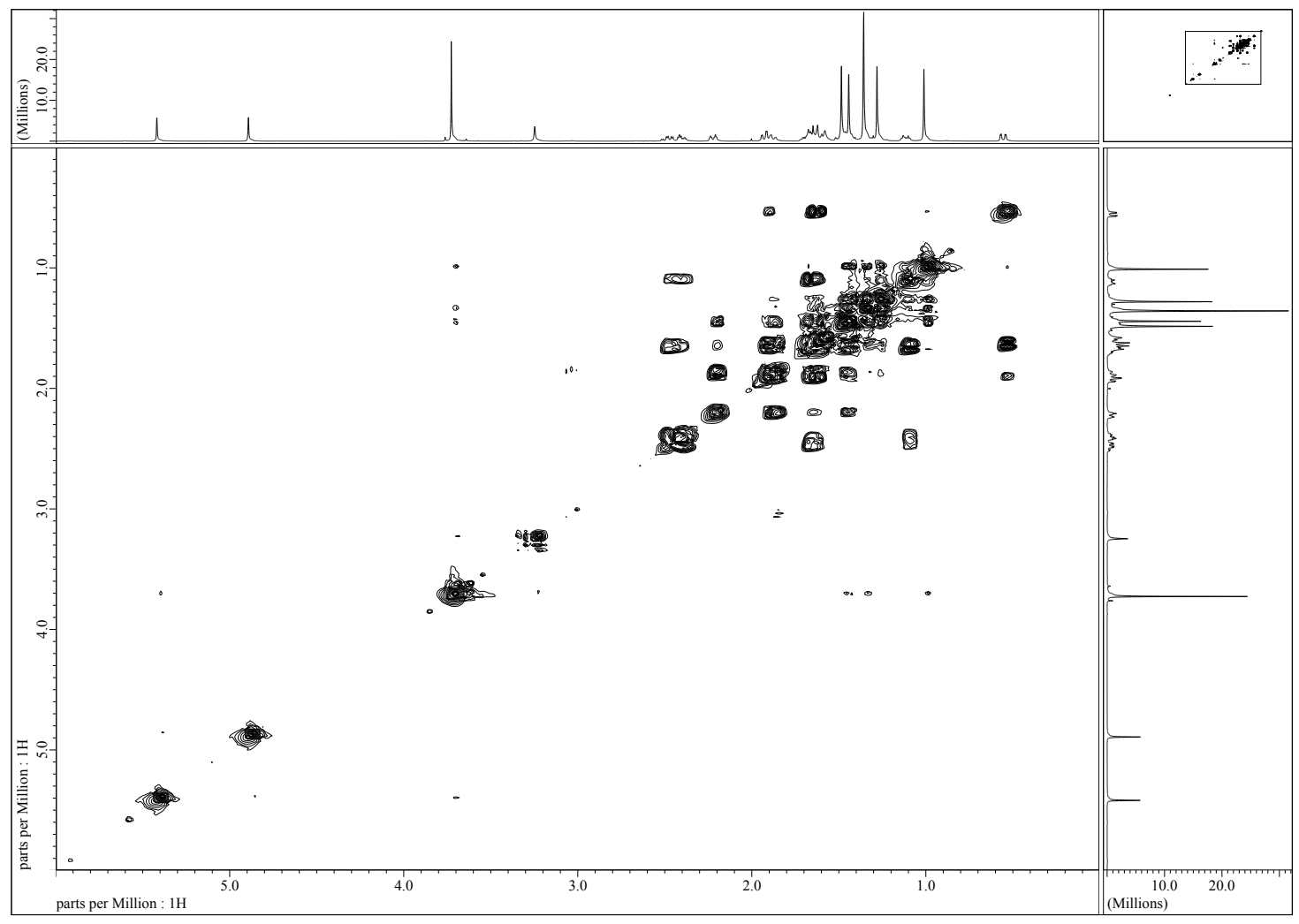

Figure S22. ${ }^{1} \mathrm{H}-{ }^{1} \mathrm{H}$ COSY spectrum of preaustinoid A1 (6).

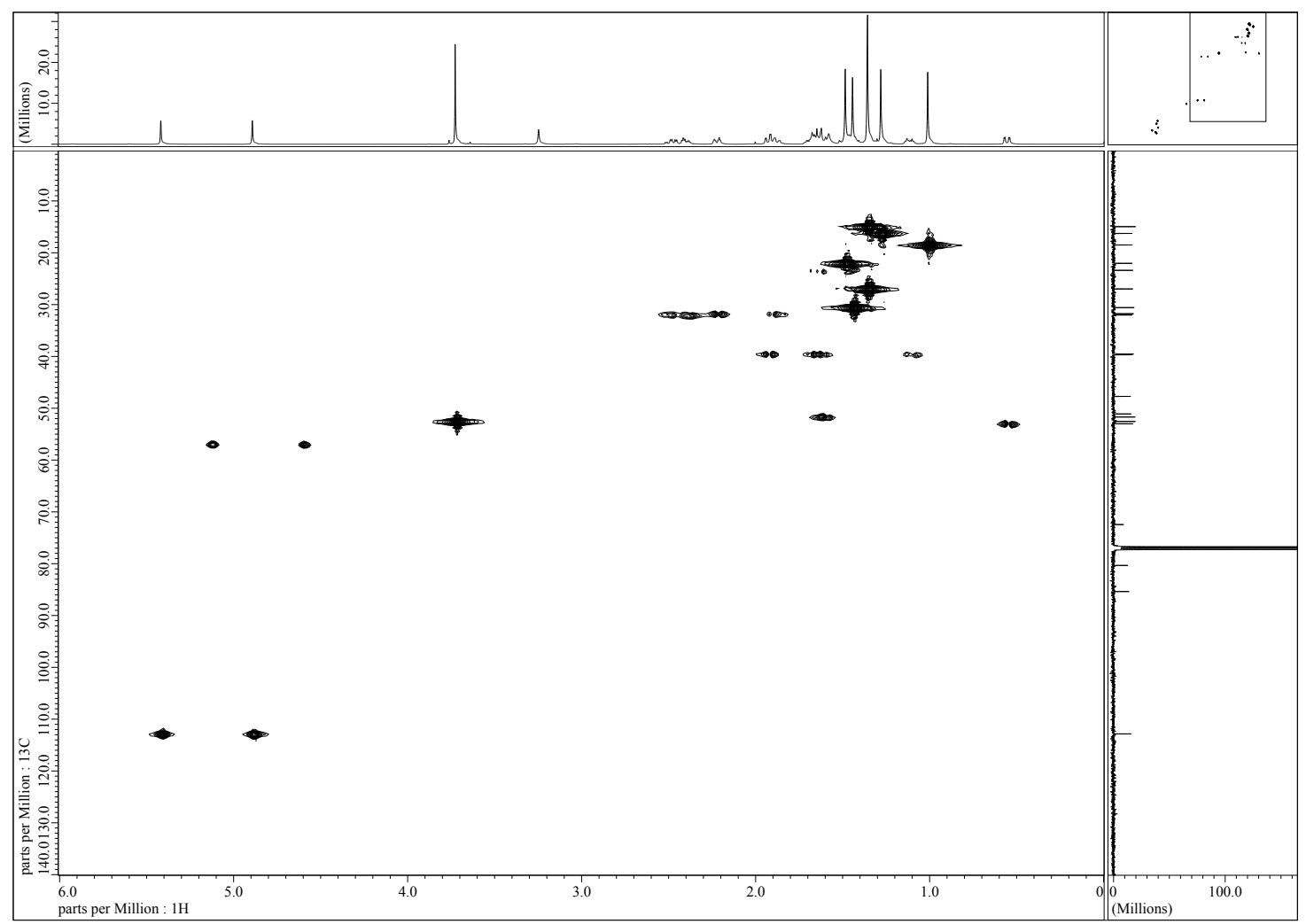

Figure S23. HMQC spectrum of preaustinoid A1 (6). 


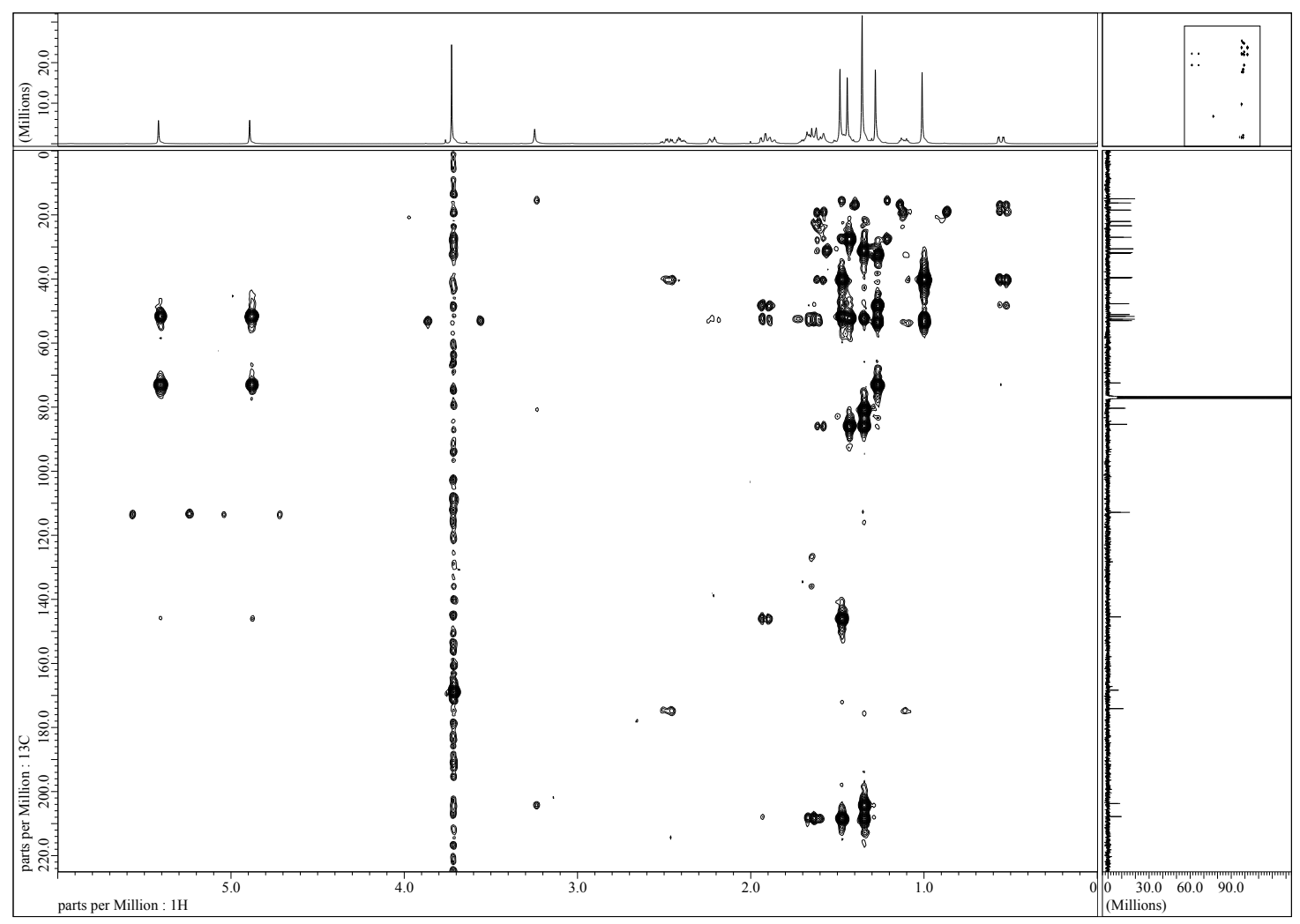

Figure S24. HMBC spectrum of preaustinoid A1 (6).

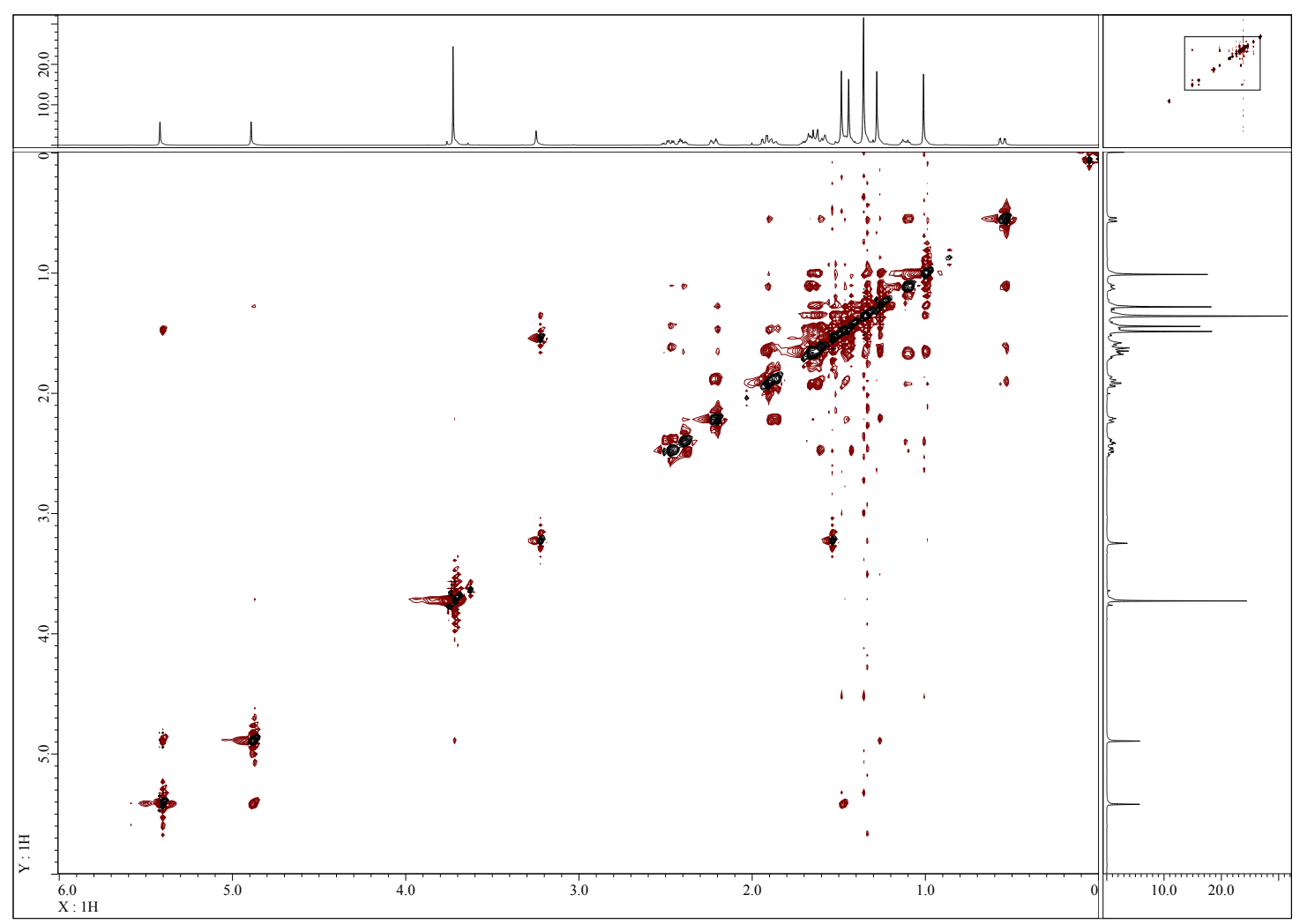

Figure S25. NOESY spectrum of preaustinoid A1 (6). 


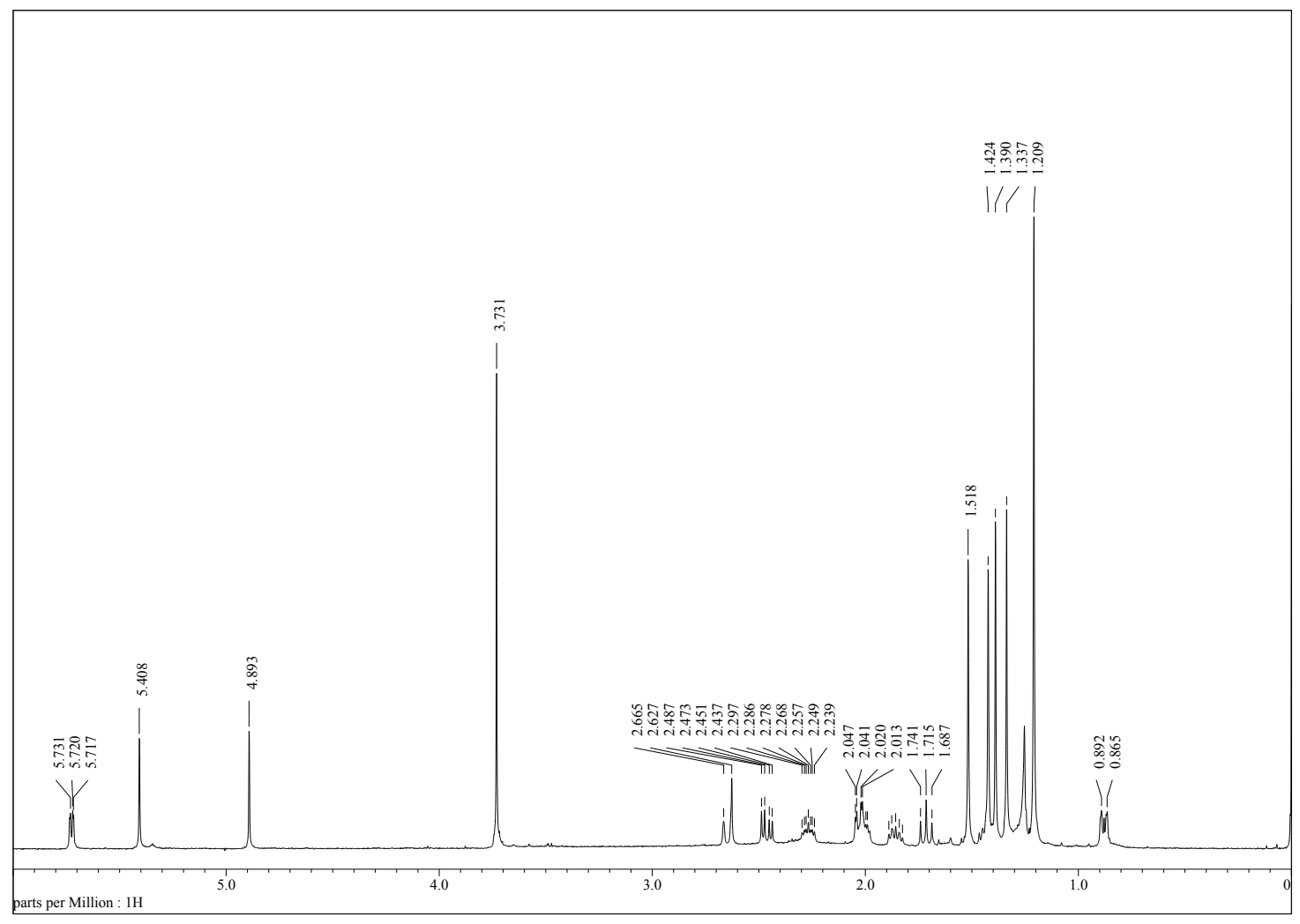

Figure S26. ${ }^{1} \mathrm{H}$ NMR spectrum of berkeleyone B (7).

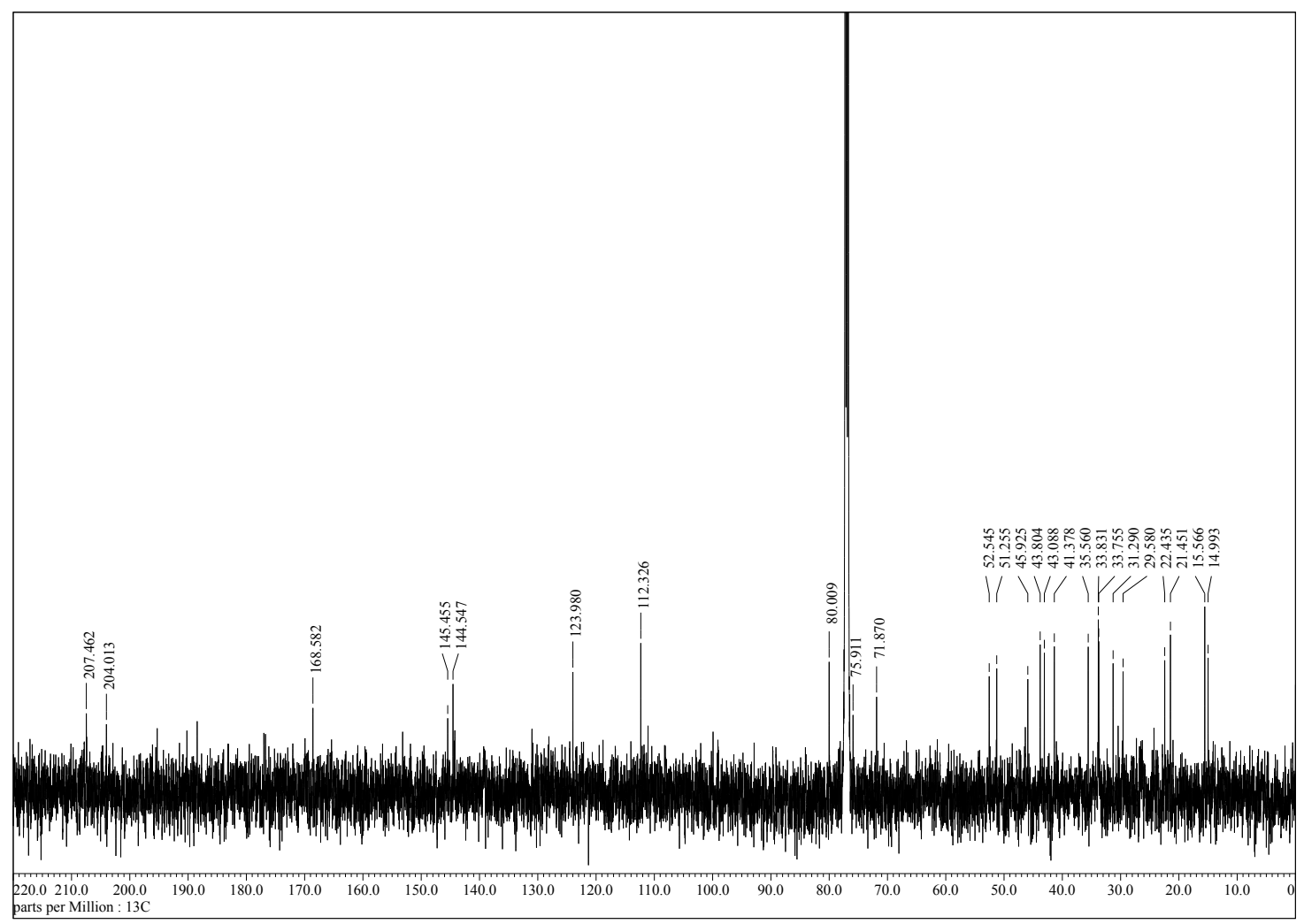

Figure S27. ${ }^{13} \mathrm{C}$ NMR spectrum of berkeleyone B (7). 


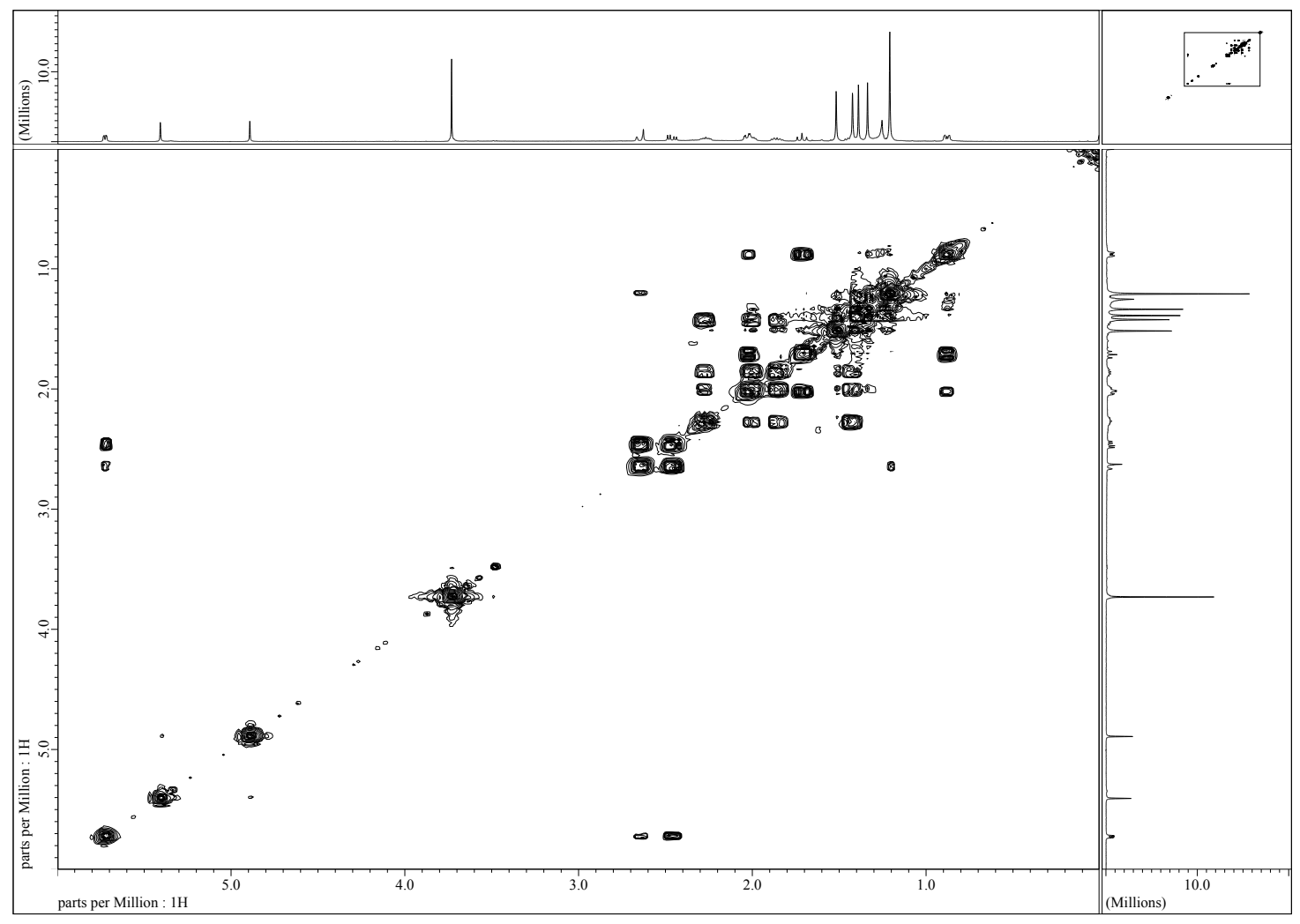

Figure S28. ${ }^{1} \mathrm{H}-{ }^{1} \mathrm{H}$ COSY spectrum of berkeleyone B (7).

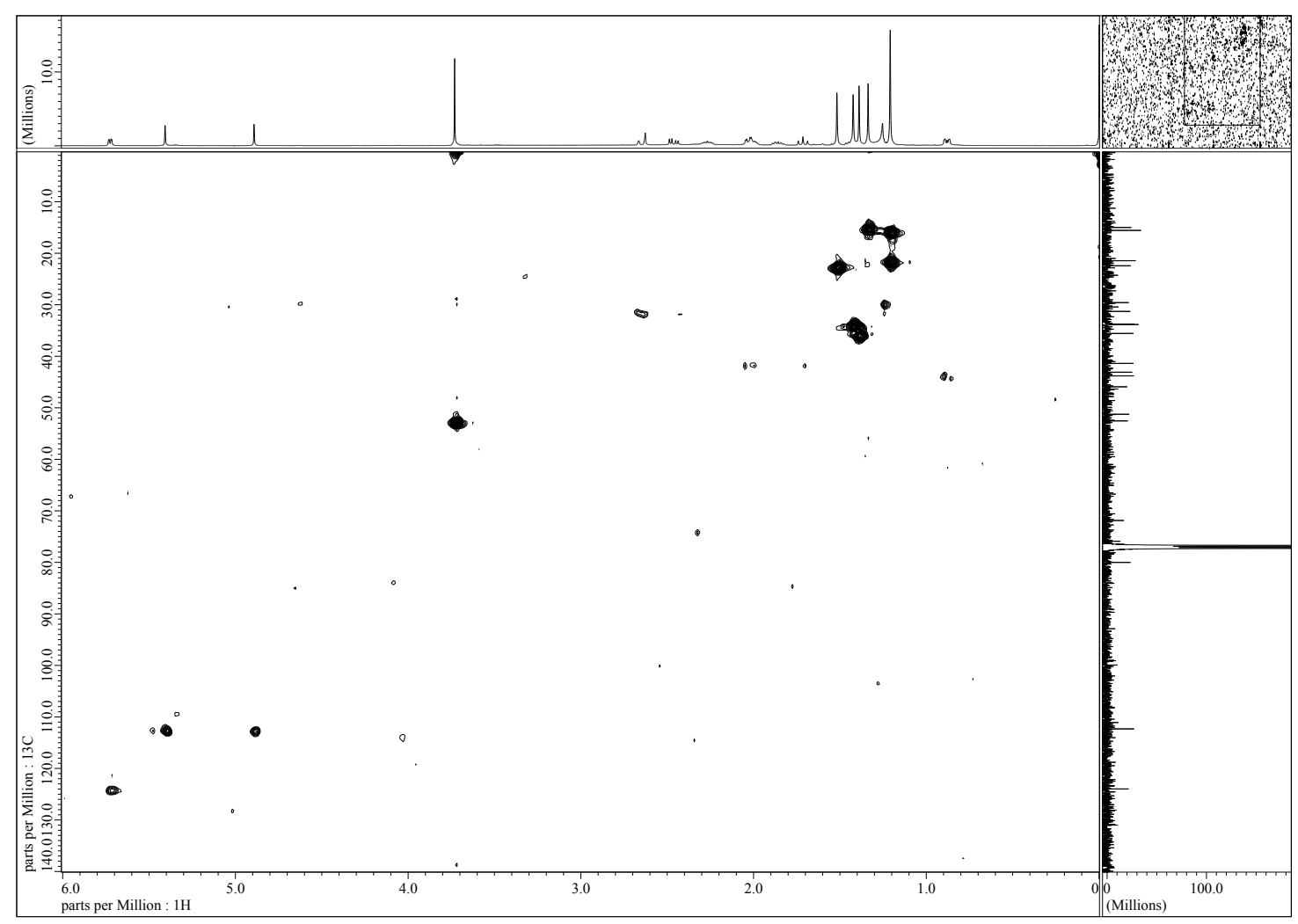

Figure S29. HMQC spectrum of berkeleyone B (7). 


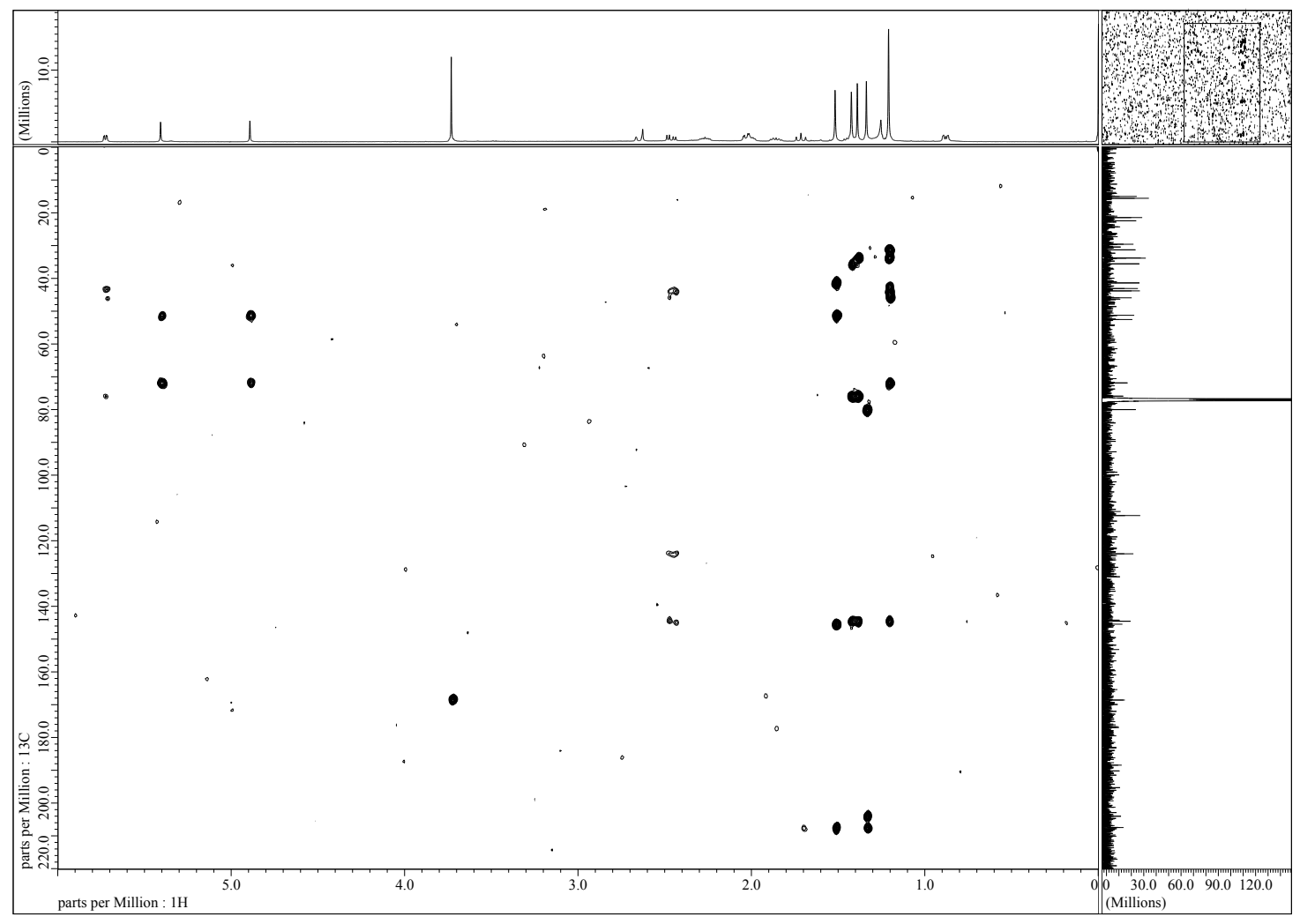

Figure S30. HMBC spectrum of berkeleyone B (7).

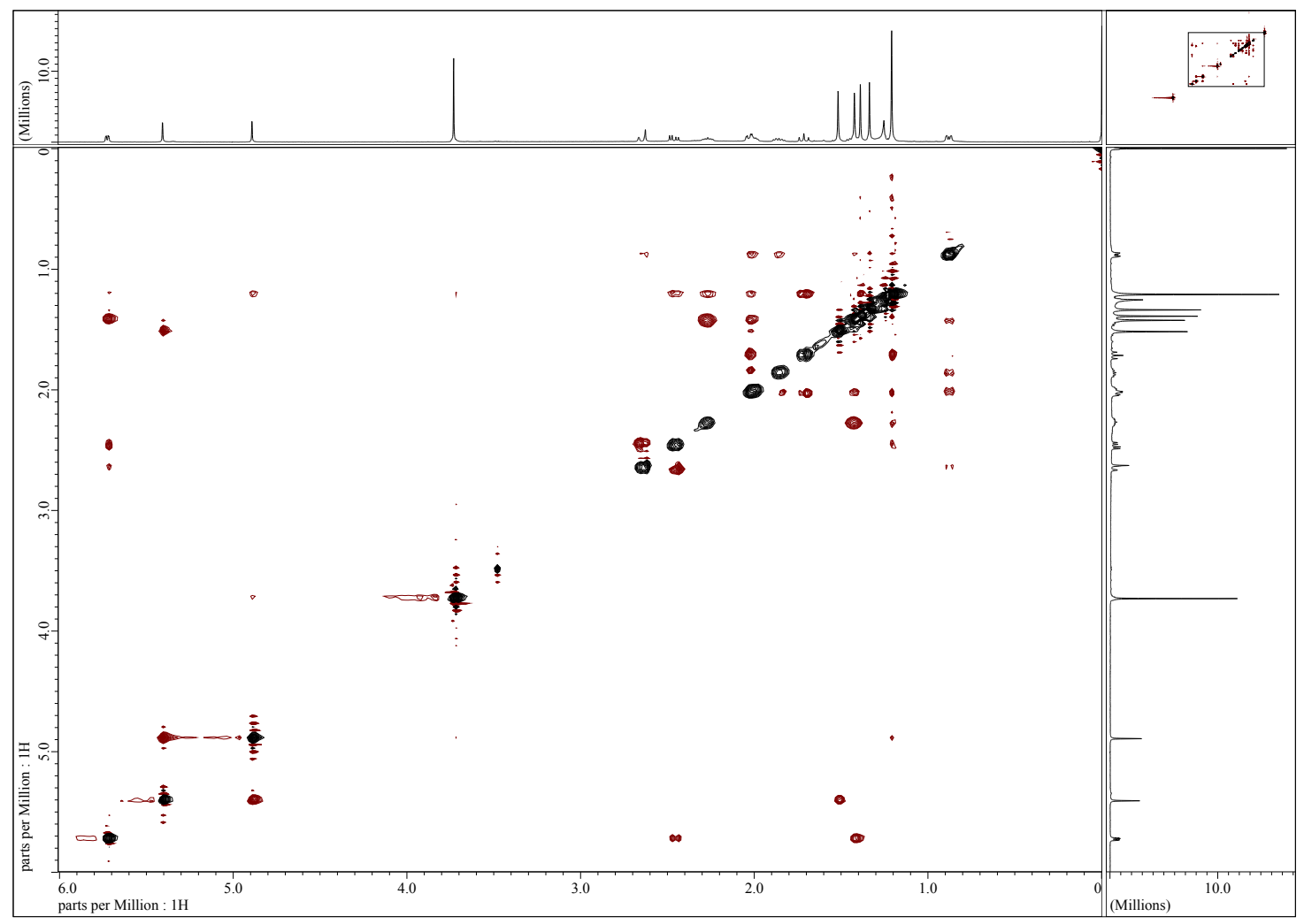

Figure S31. NOESY spectrum of berkeleyone B (7). 


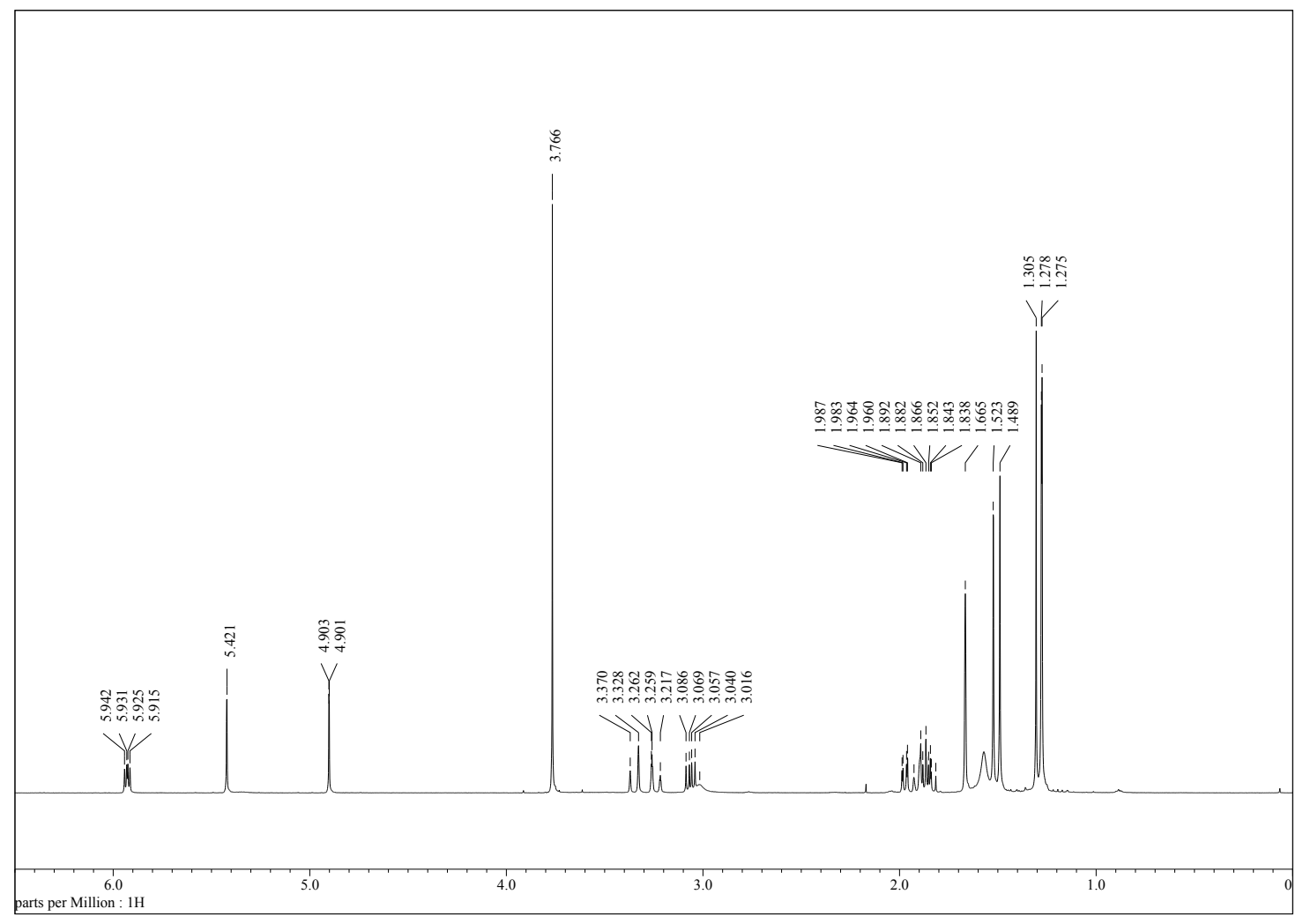

Figure S32. ${ }^{1} \mathrm{H}$ NMR spectrum of berkeleydione (2).

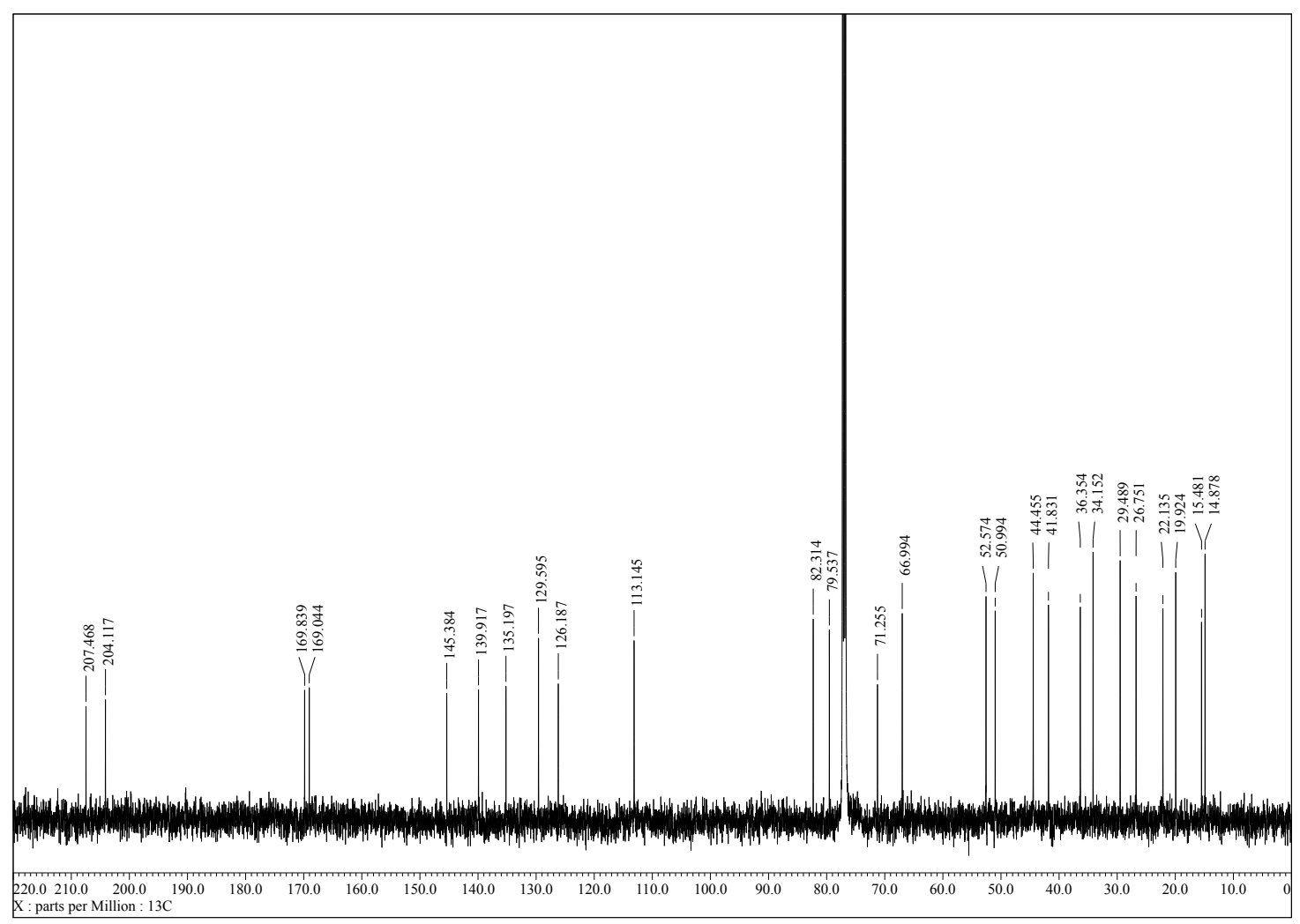

Figure S33. ${ }^{13} \mathrm{C}$ NMR spectrum of berkeleydione (2). 


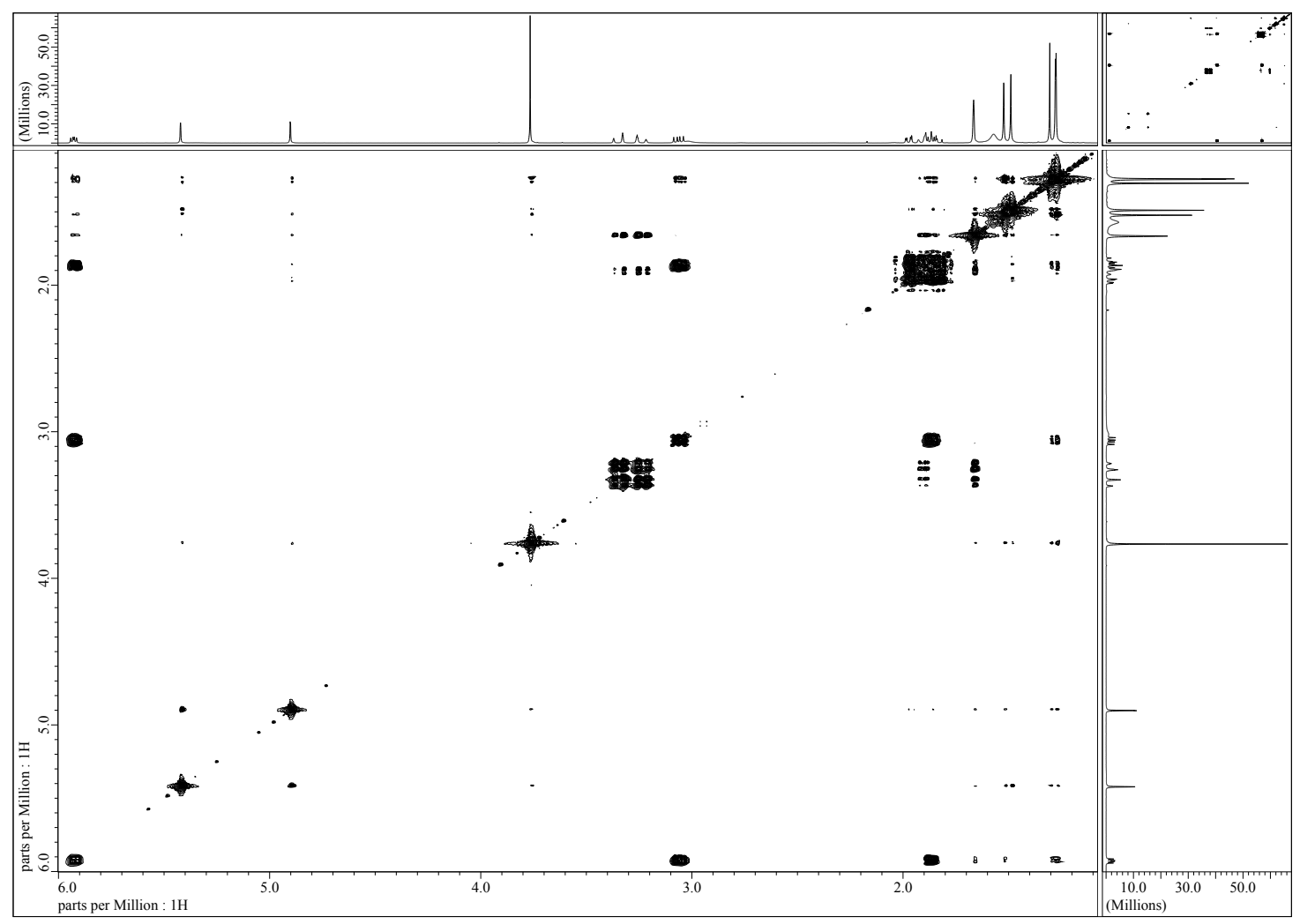

Figure S34. ${ }^{1} \mathrm{H}-{ }^{1} \mathrm{H}$ COSY spectrum of berkeleydione (2).

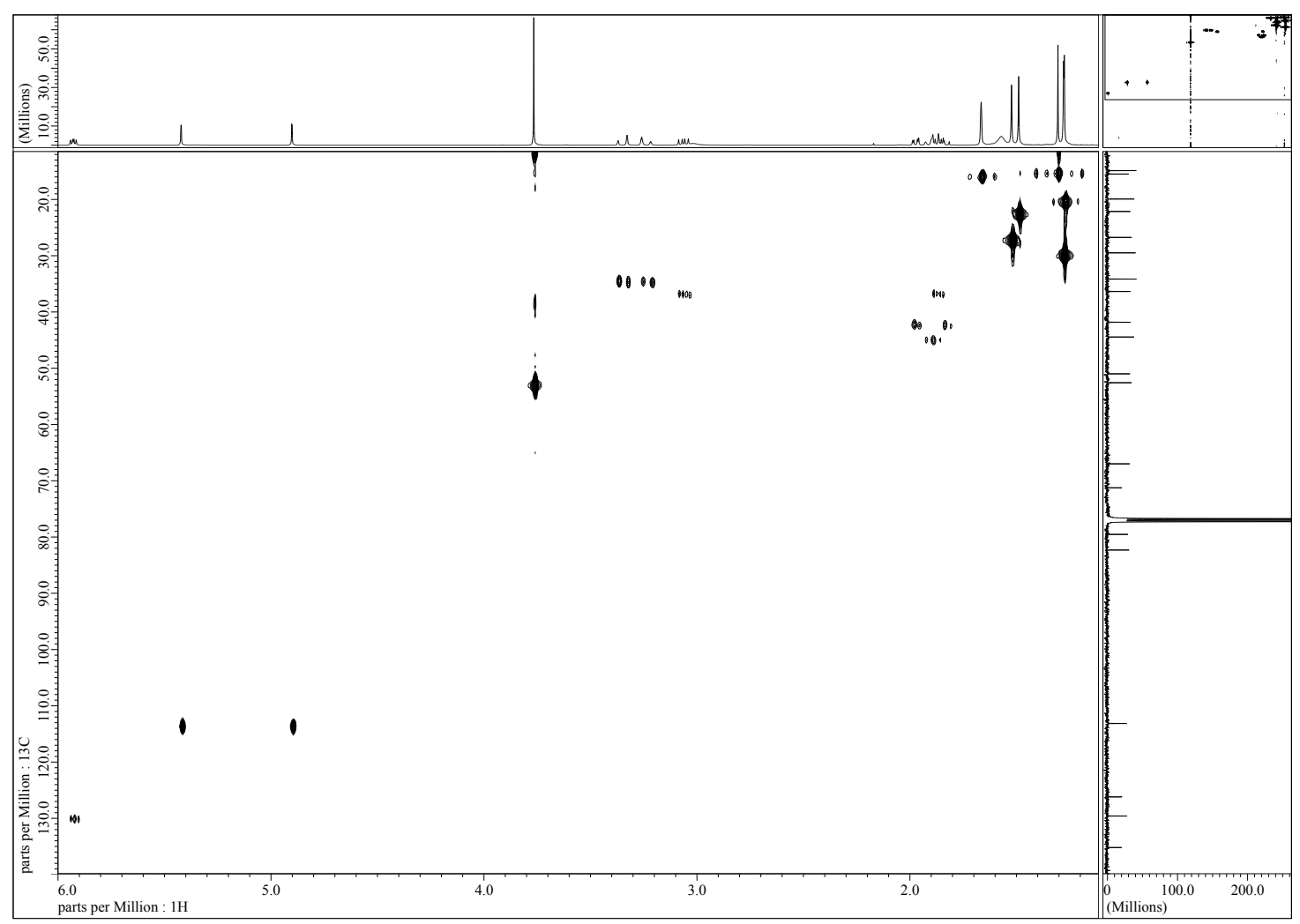

Figure S35. HMQC spectrum of berkeleydione (2). 


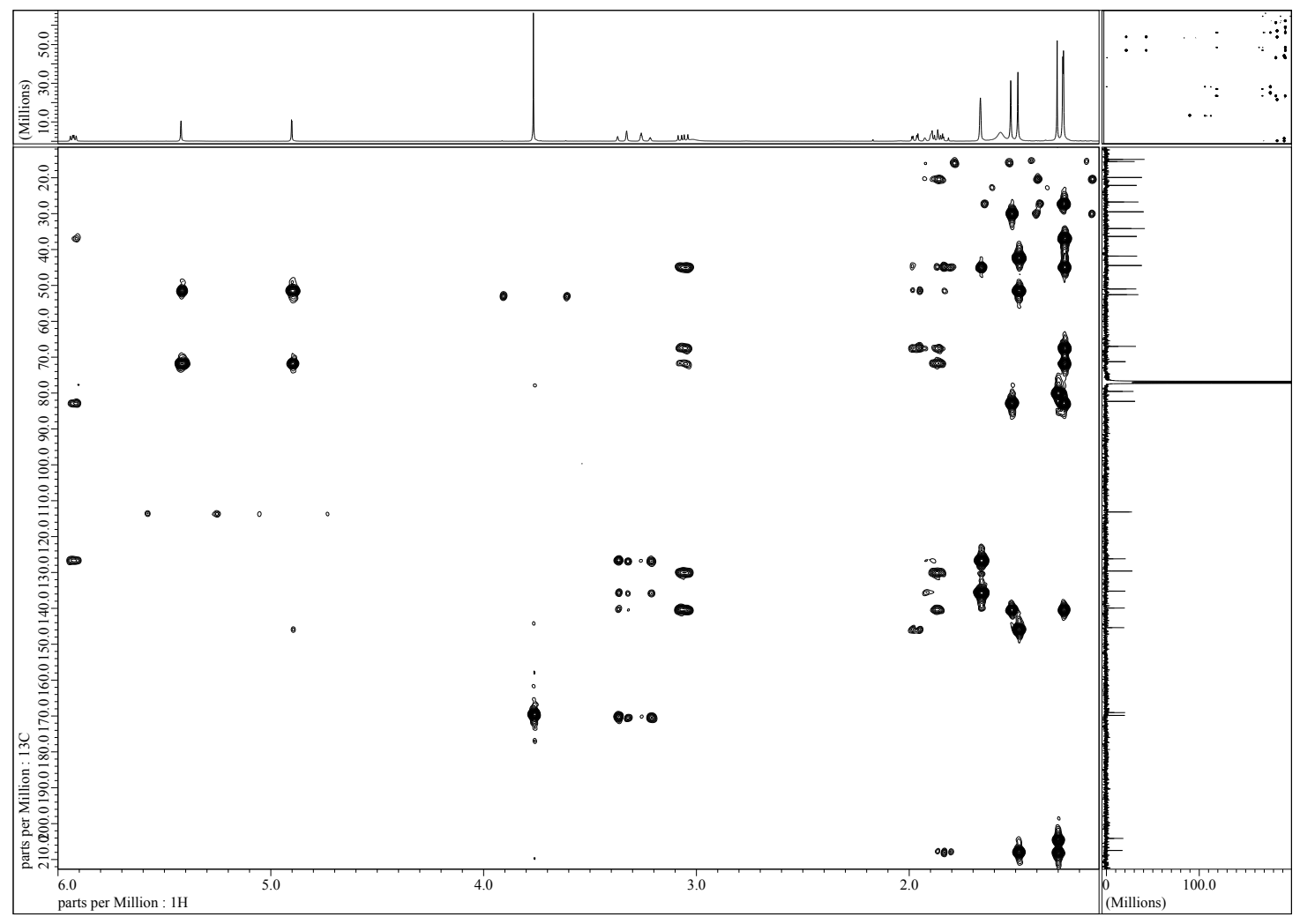

Figure S36. HMBC spectrum of berkeleydione (2).

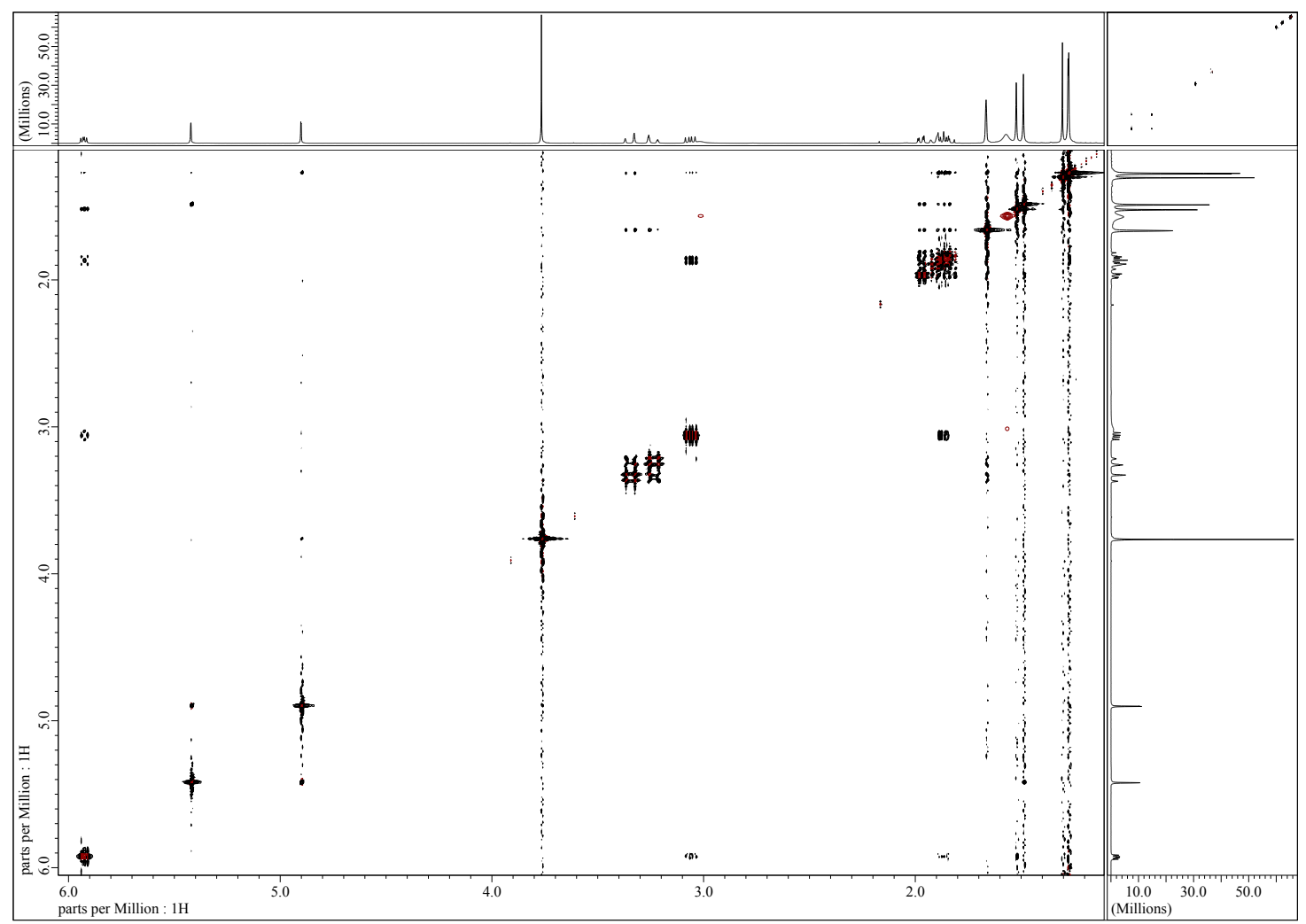

Figure S37. NOESY spectrum of berkeleydione (2). 


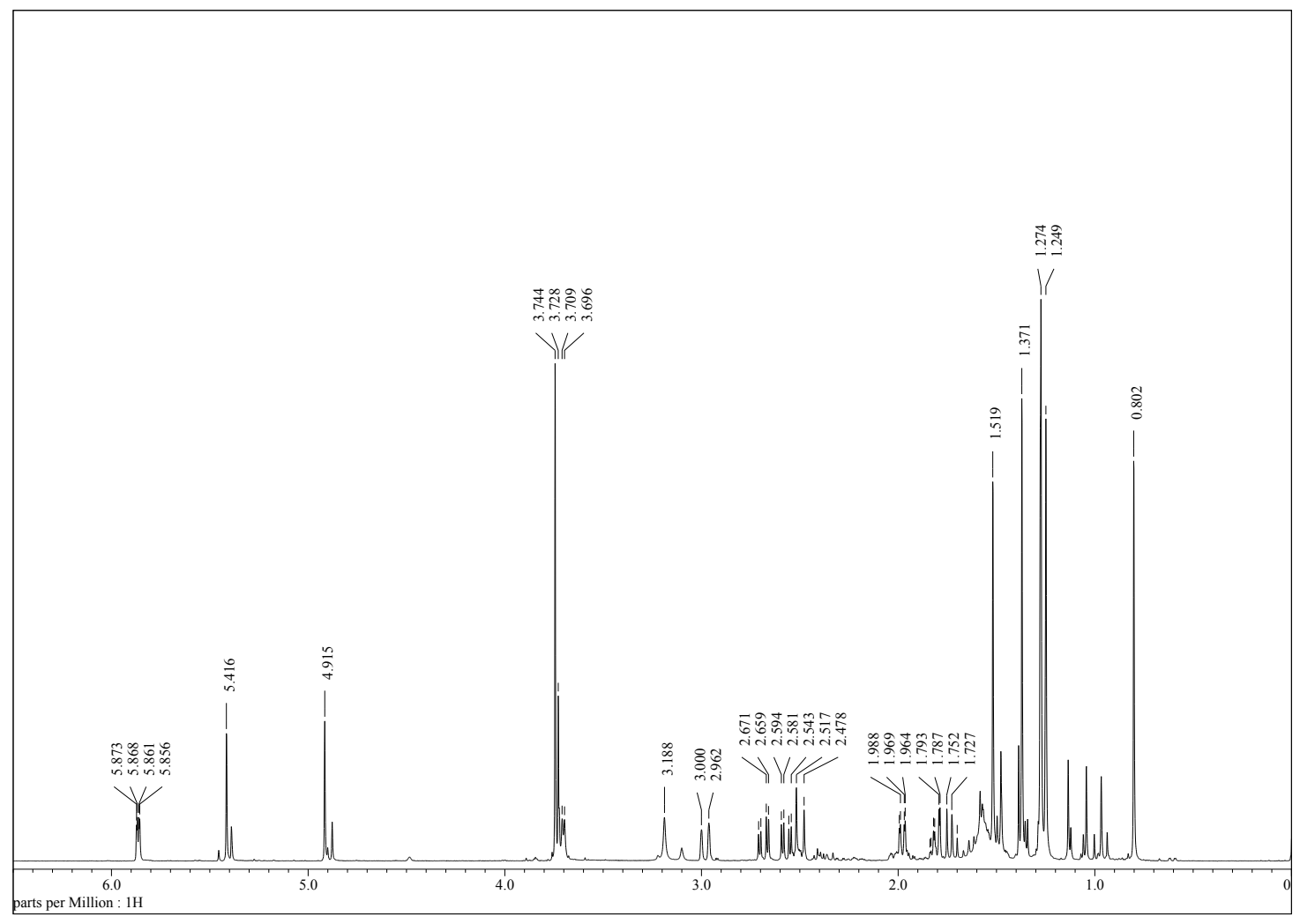

Figure S38. ${ }^{1} \mathrm{H}$ NMR spectrum of berkeleytrione (8).

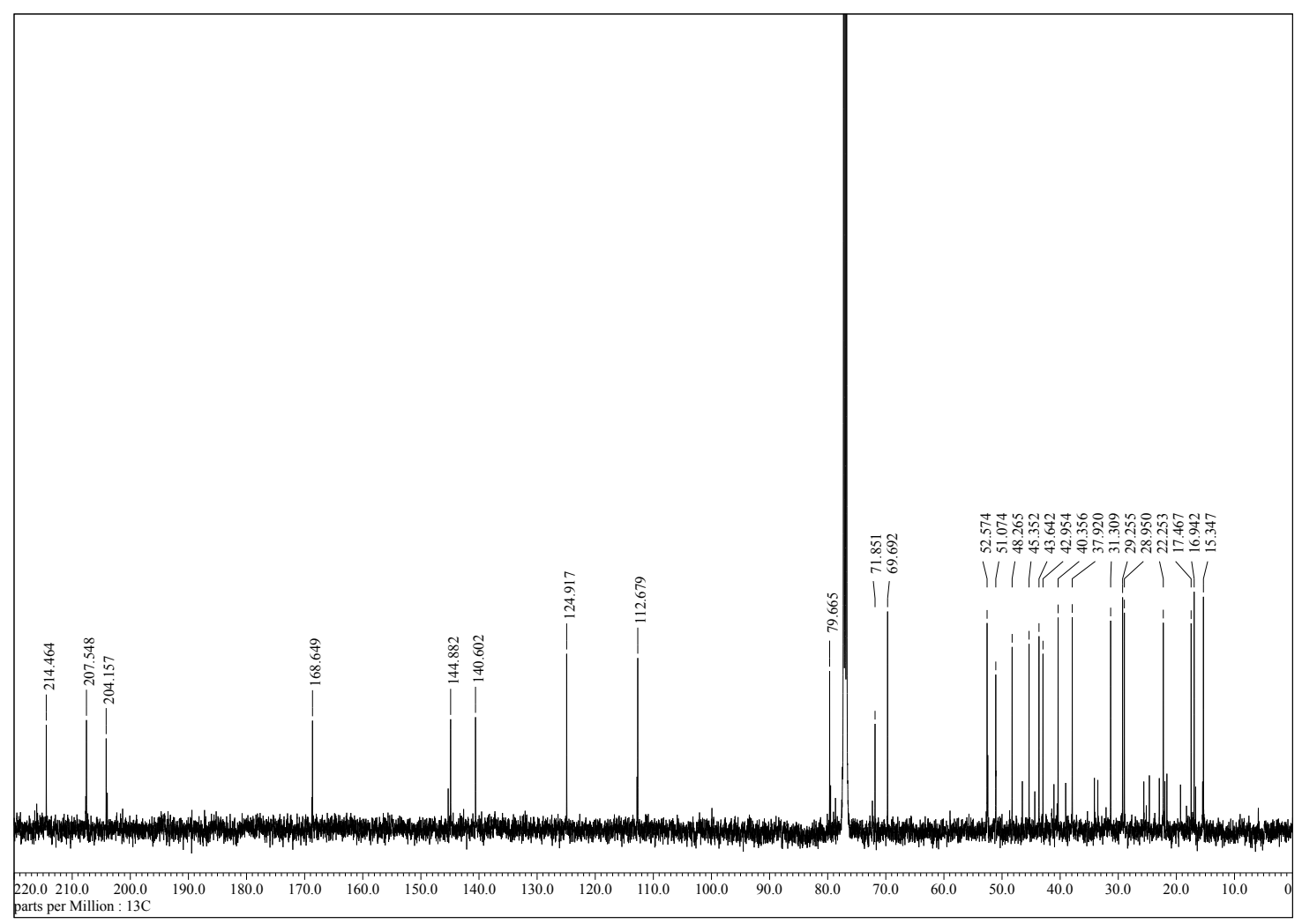

Figure S39. ${ }^{13} \mathrm{C}$ NMR spectrum of berkeleytrione $(\mathbf{8})$. 


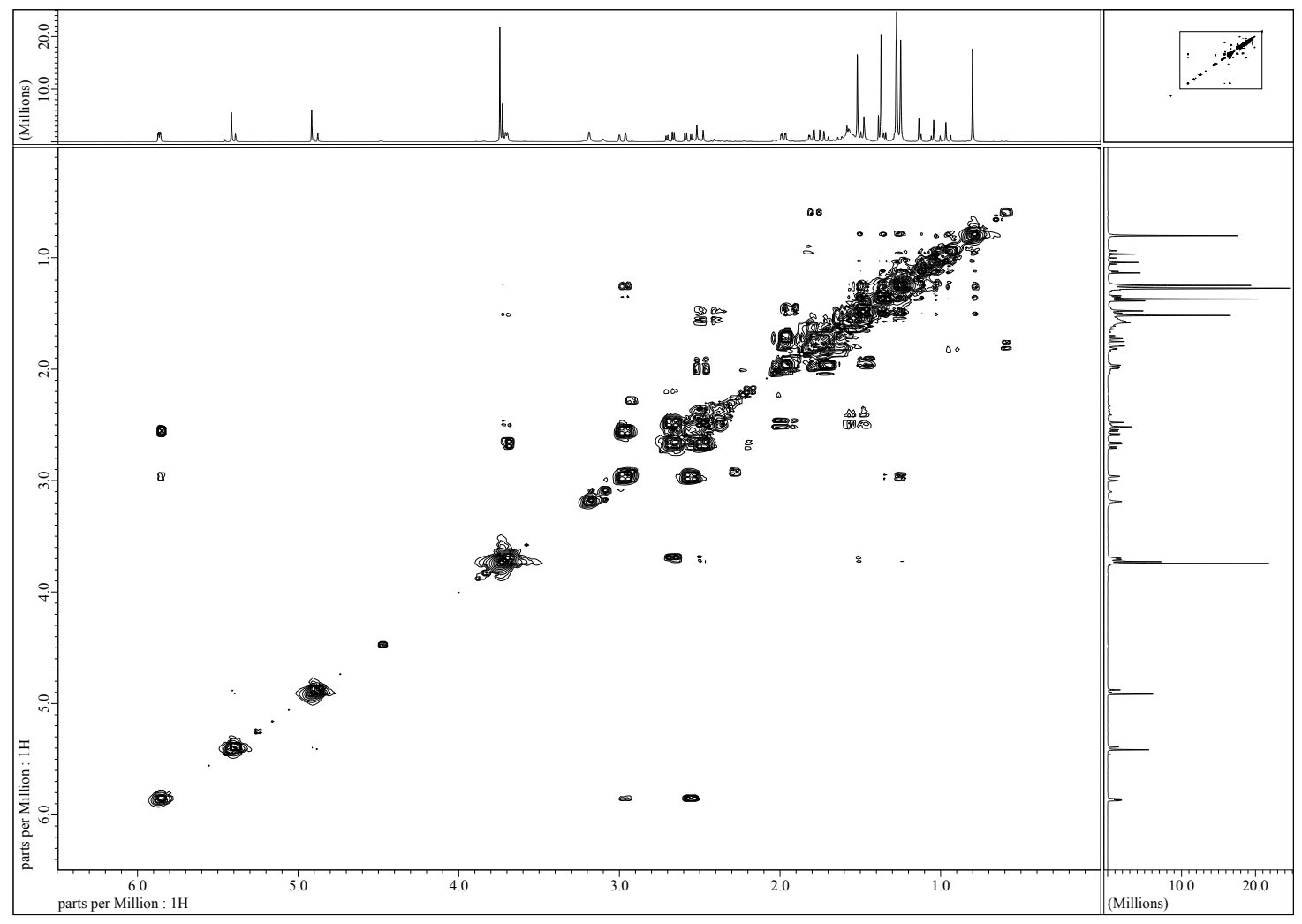

Figure $\mathrm{S} 40 .{ }^{1} \mathrm{H}-{ }^{1} \mathrm{H}$ COSY spectrum of berkeleytrione (8).

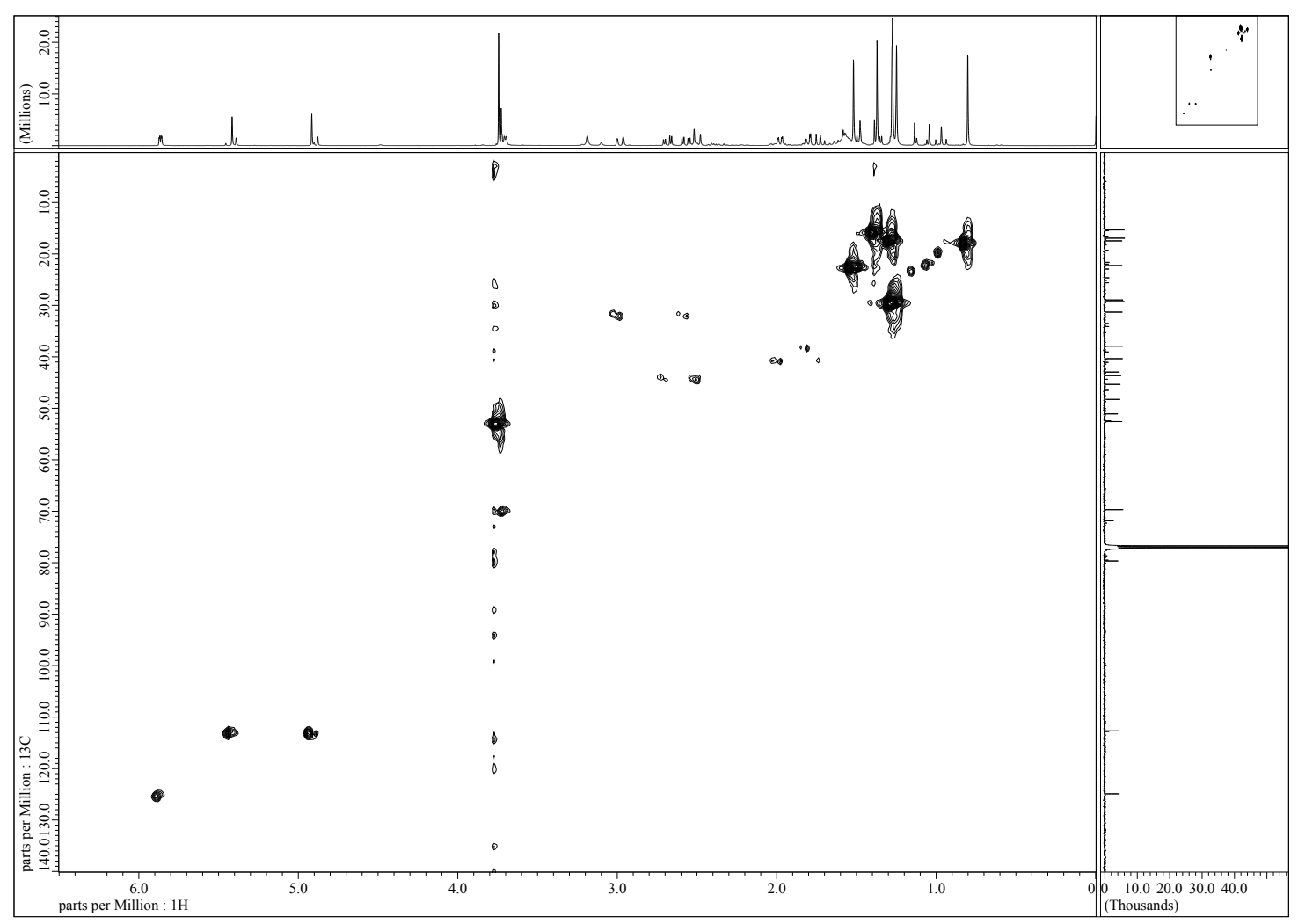

Figure S41. HMQC spectrum of berkeleytrione (8). 


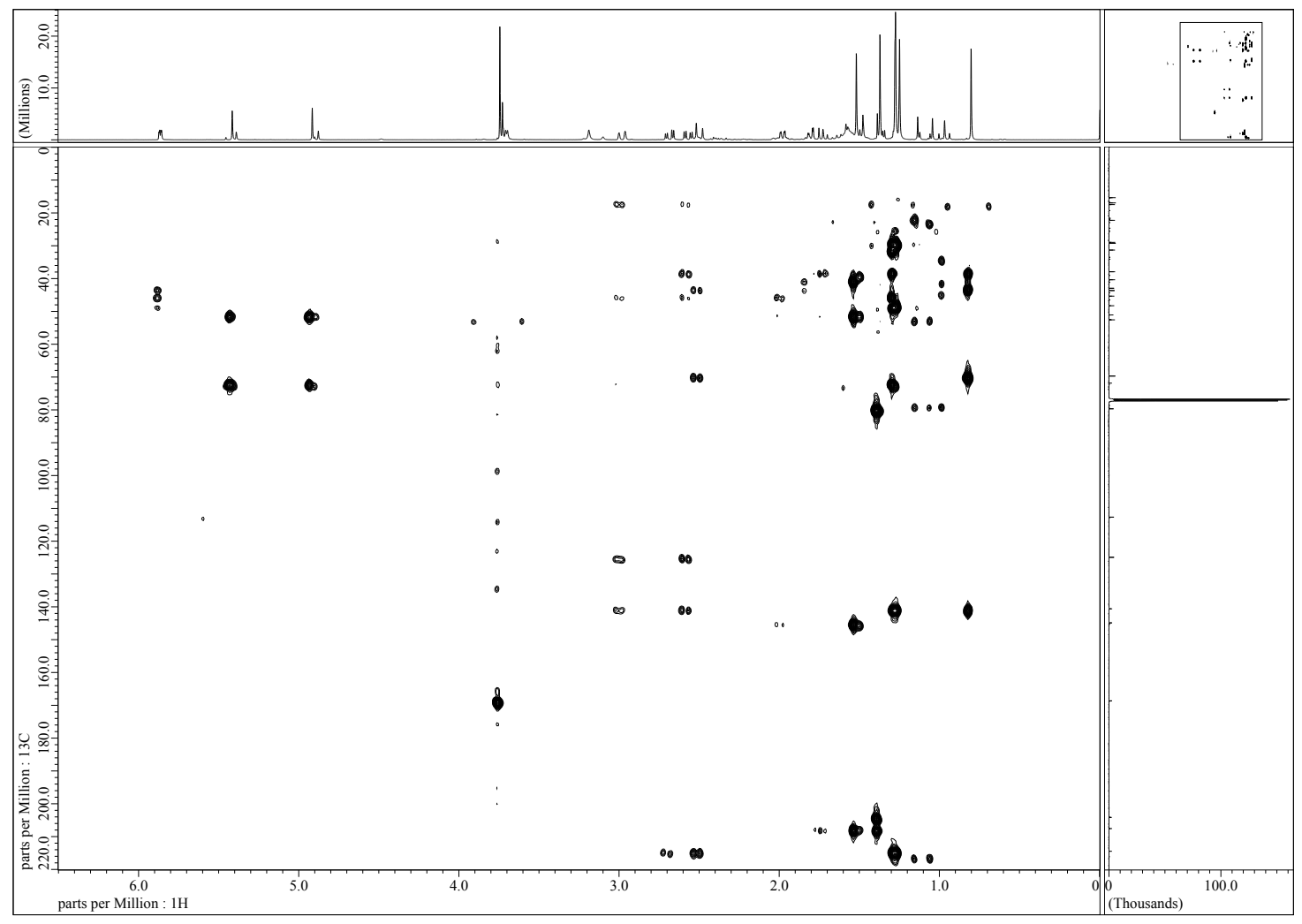

Figure S42. HMBC spectrum of berkeleytrione (8).

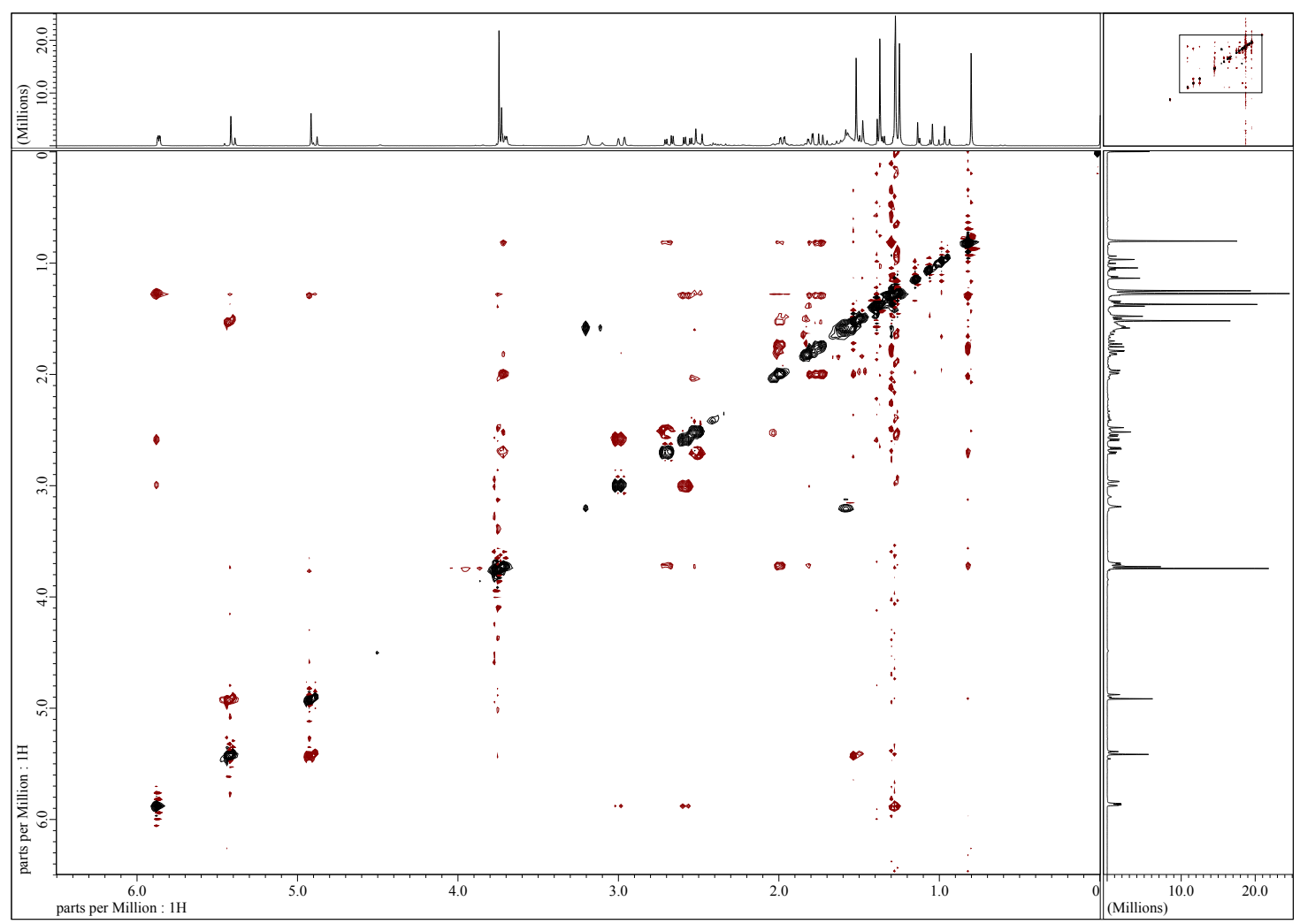

Figure S43. NOESY spectrum of berkeleytrione (8). 


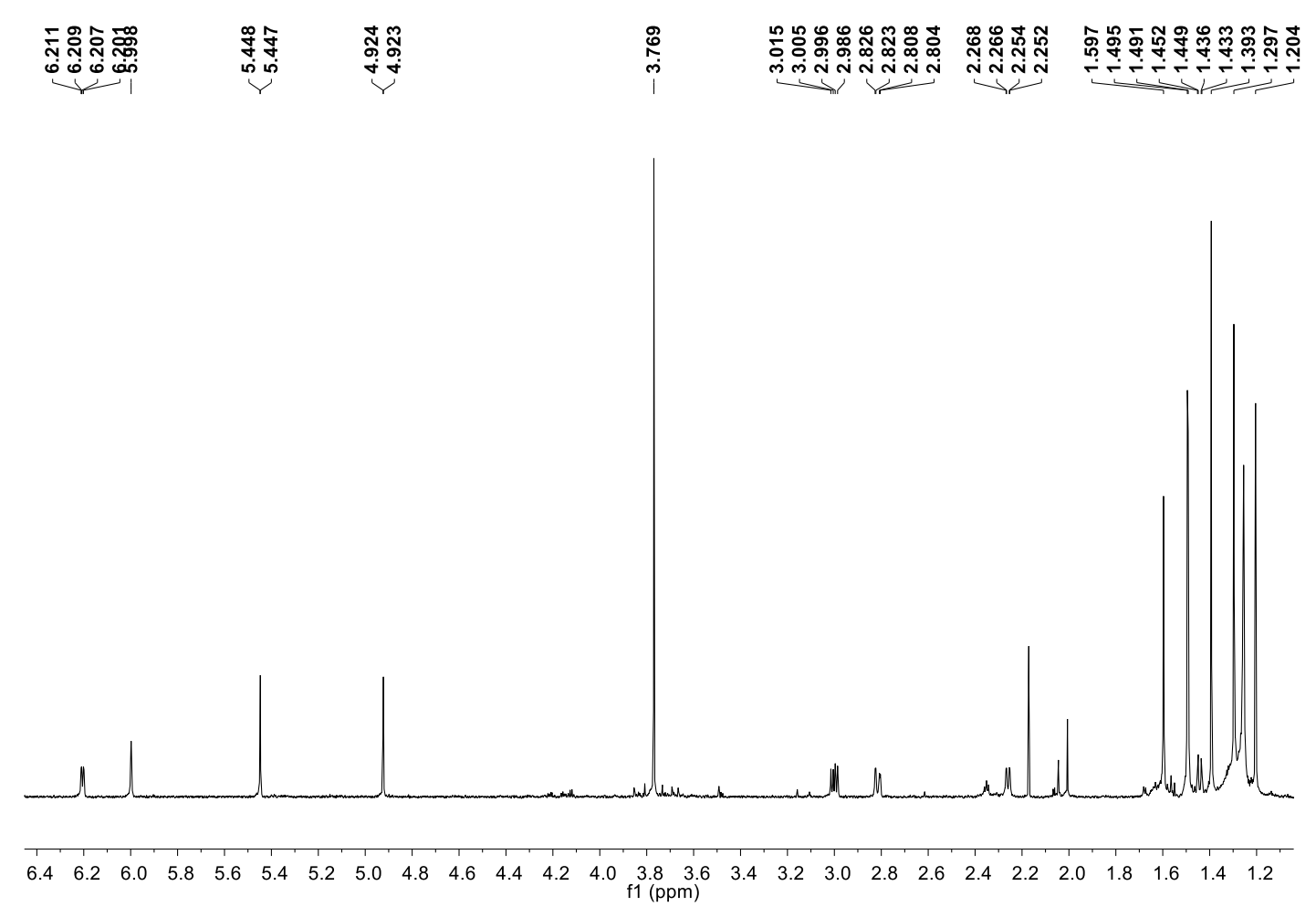

Figure S44. ${ }^{1}$ H NMR spectrum of paraheroid A (10).

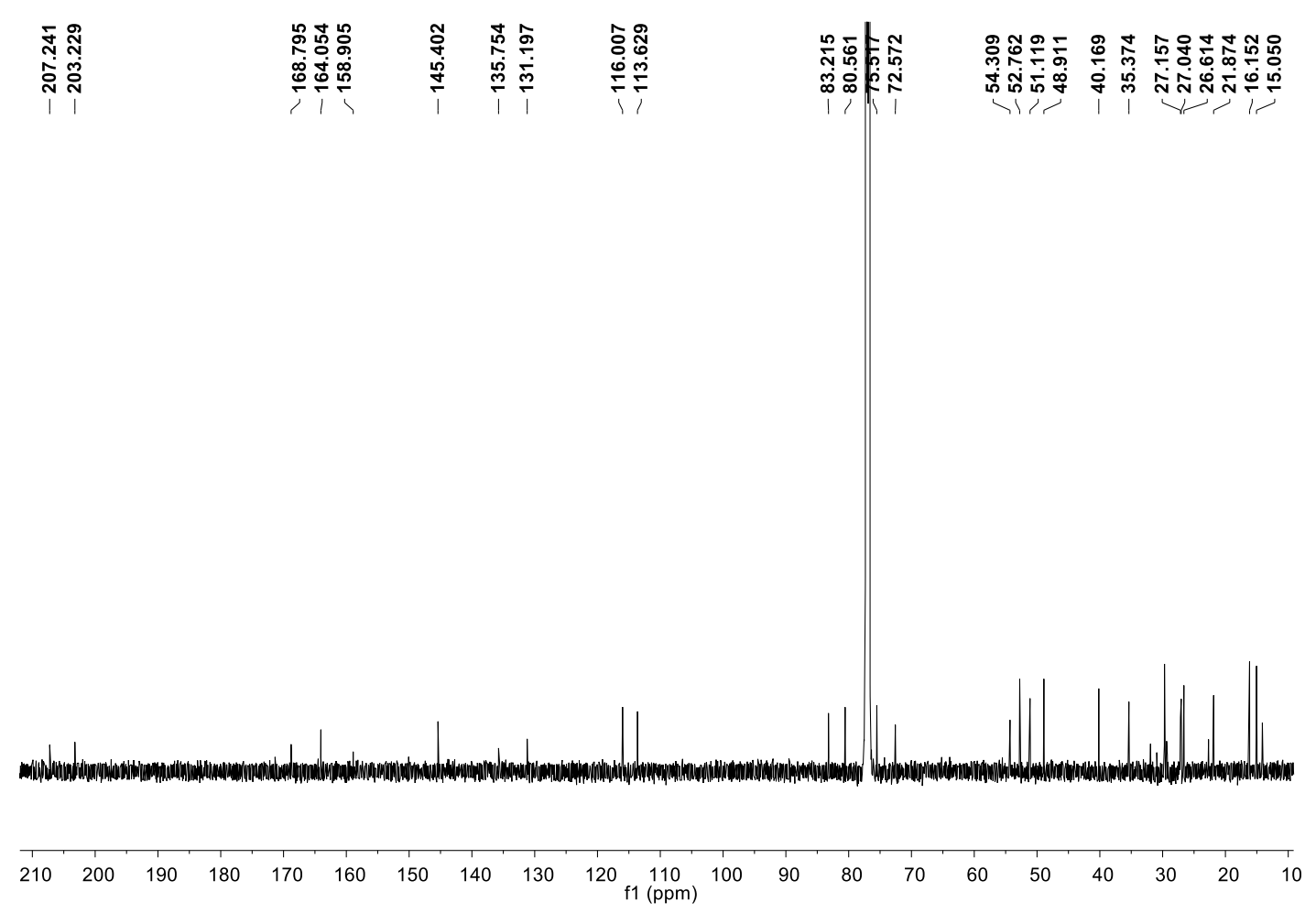

Figure S45. ${ }^{13} \mathrm{C}$ NMR spectrum of paraheroid A (10). 


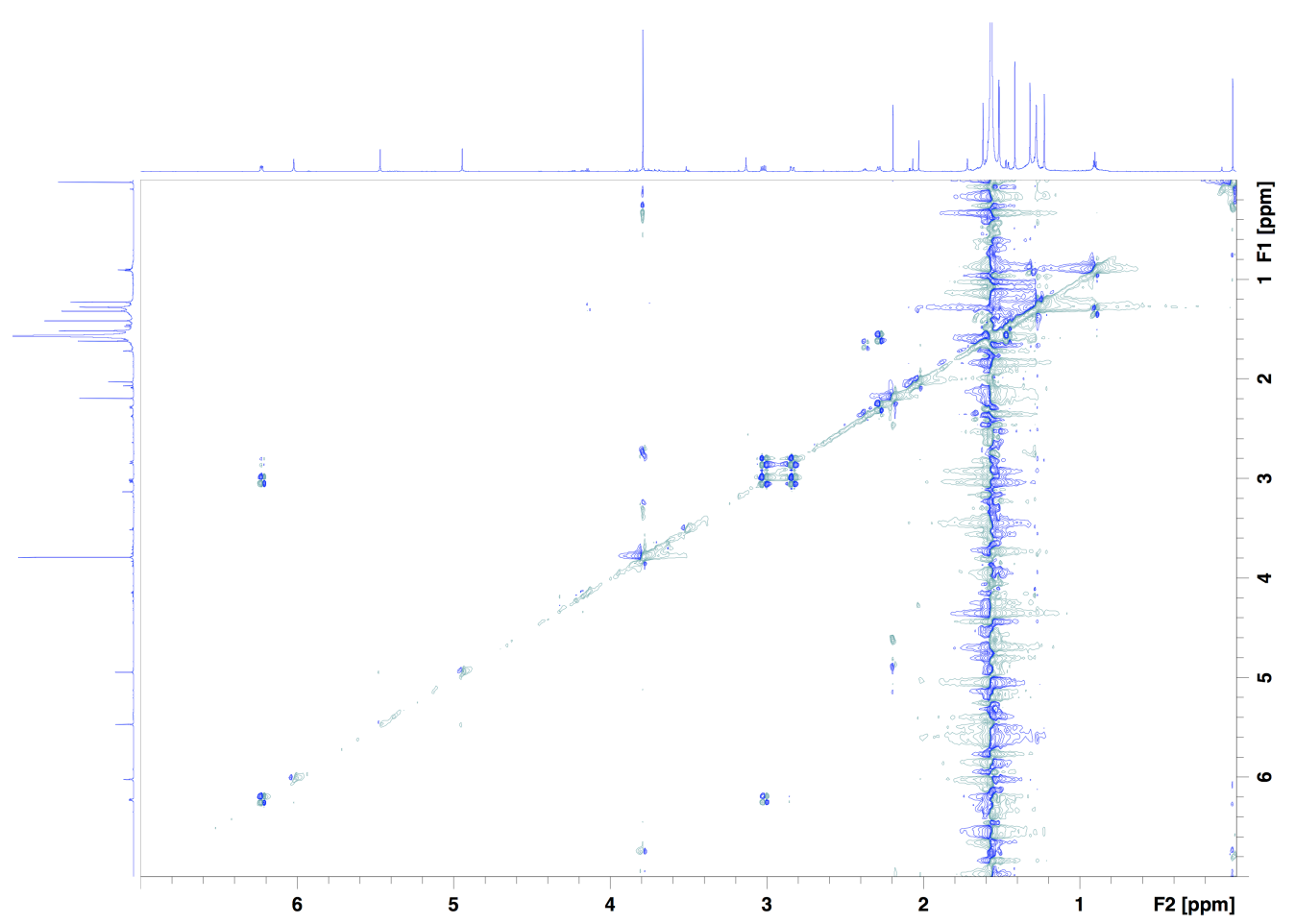

Figure S46. ${ }^{1} \mathrm{H}-{ }^{1} \mathrm{H}$ COSY spectrum of paraheroid A (10).

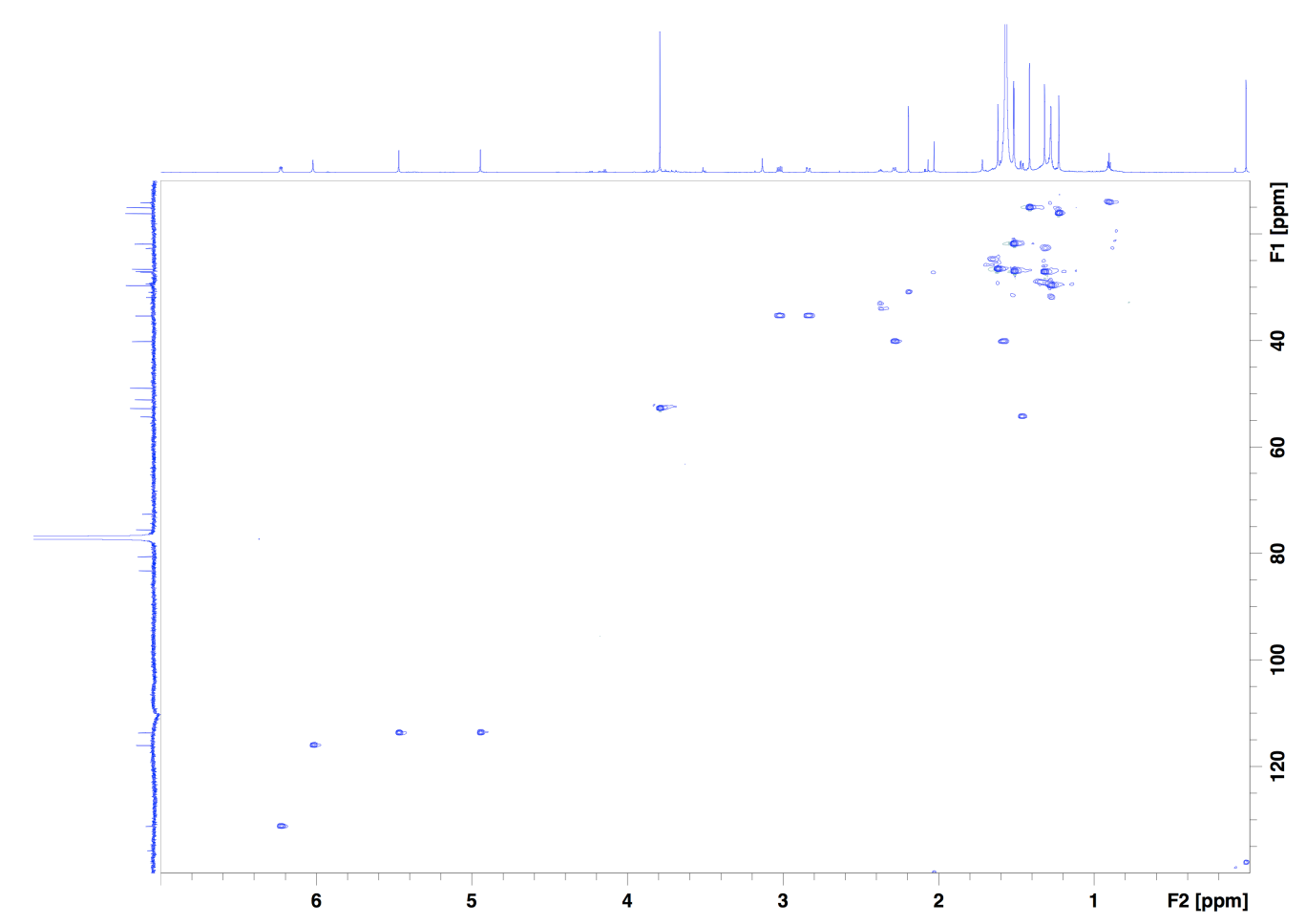

Figure S47. HMQC spectrum of paraheroid A (10). 


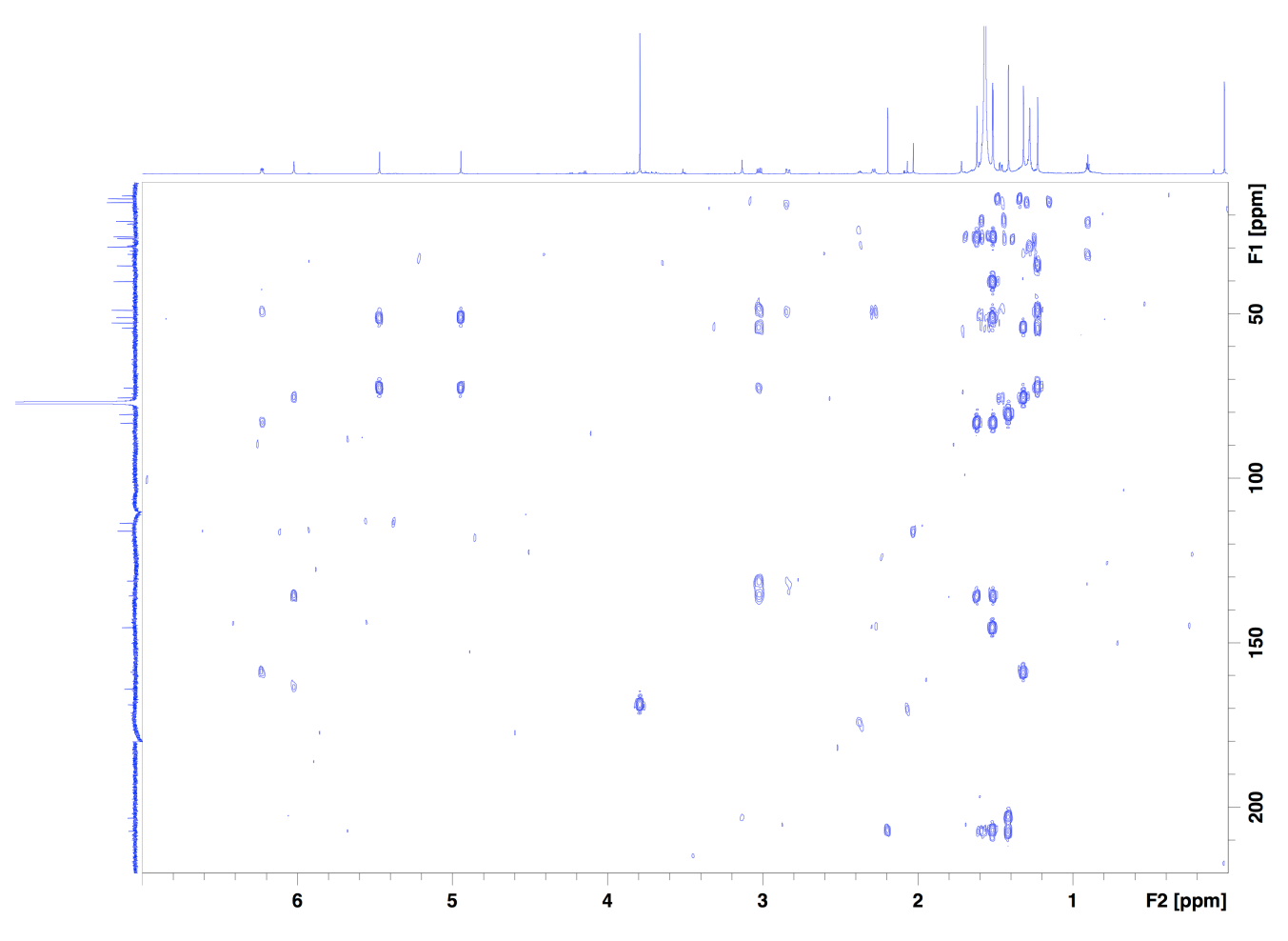

Figure S48. HMBC spectrum of paraheroid A (10).

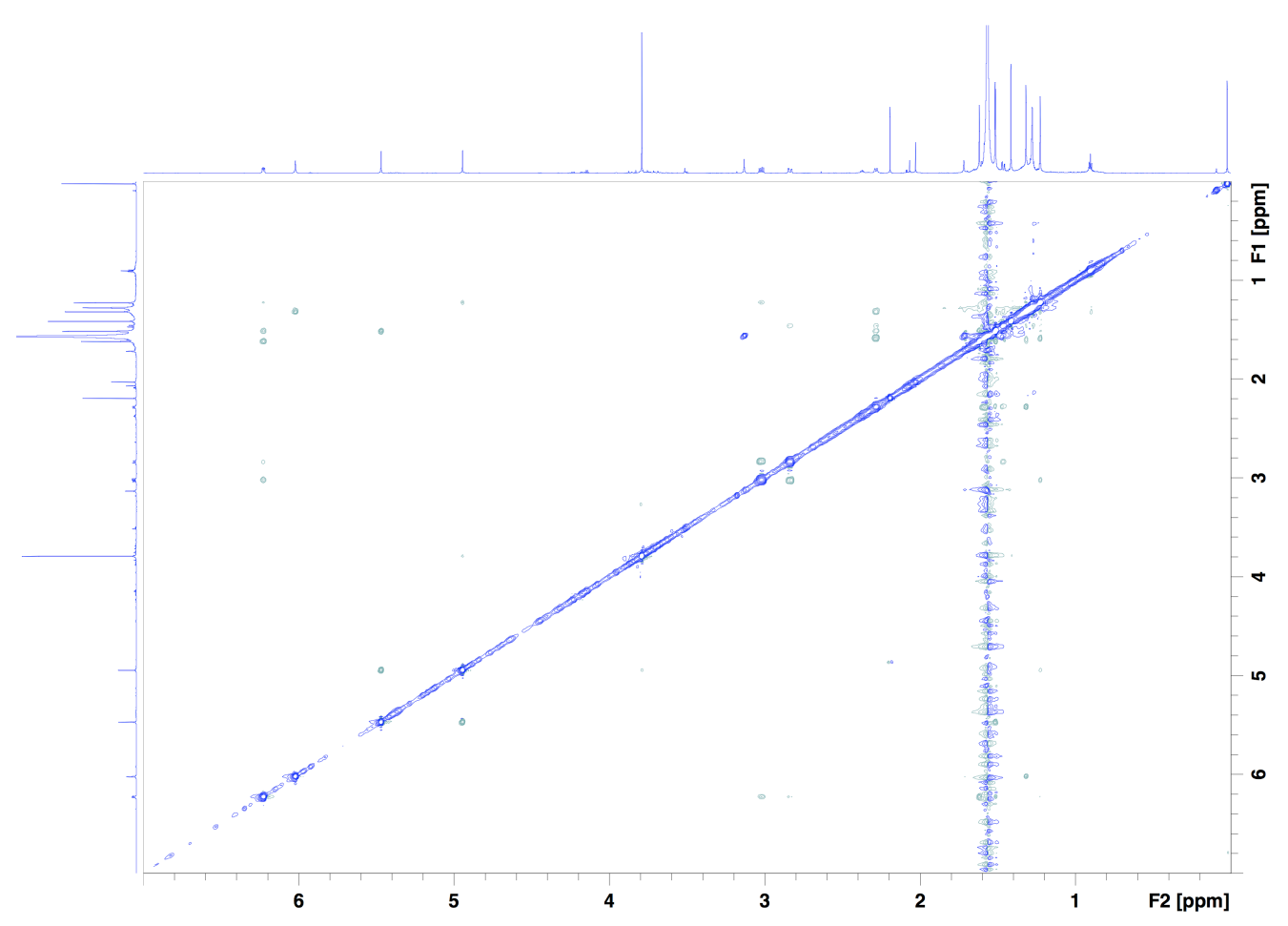

Figure S49. NOESY spectrum of paraheroid A (10). 